\title{
EXPLORING TEACHERS' PERCEPTIONS OF THE IMPLEMENTATION OF INCLUSIVE EDUCATION IN A REGULAR PRIMARY SCHOOL: A PAPUA NEW GUINEA STUDY \\ by
}

JENNY APUREL MAMBO

\begin{abstract}
A thesis
submitted to the Victoria University of Wellington

in partial fulfilment of the requirements for the degree of

Master of Education
\end{abstract}

Victoria University of Wellington

2011 


\begin{abstract}
The purpose of this study was to investigate teachers' perceptions of the implementation of inclusive education in one regular primary school in the Southern Highlands Province of Papua New Guinea. The school was made up of twenty-five teachers and an estimate of 350 students. However only twenty teachers participated in the study. The twenty teachers were composed of one head teacher, one deputy head teacher, two senior subject teachers, five senior teachers and eleven classroom teachers. It was a qualitative study using a case study approach. The data were gathered through questionnaires, individual interviews, focus group interviews, and document analysis. The results of this study showed that (i) teachers were not fully aware of inclusive education policy and practice, (ii) poor implementation of inclusive education policy was due to lack of appropriate training and professional development, (iii) inclusive education needs to be funded separately by all levels of government.
\end{abstract}




\section{Acknowledgements}

During the course of this study, many people have generously assisted me with their advice, and I would like to show my appreciation for this guidance and encouragement.

I wish to thank my supervisors, Dr Liz Jones and Dr Lex McDonald of Victoria University of Wellington. Their continuous encouragement and support are gratefully acknowledged. Thank you for having the trust that I would complete this work successfully.

I would like to thank NZAID for funding my studies. If it was not for NZAID, I could not have achieved a Masters Degree at Victoria University of Wellington.

Thanks to Travis Lealand for his assistance in proofing this work and to Irene Sattar for her assistance with formatting the final document.

My appreciation goes to Ema Sanga from the Student Learning Support Services for her positive academic writing advice.

To the head teacher, deputy head teacher, senior teachers and other teachers who participated in this study, your commitments were appreciated. Your involvement provided essential data to this study.

To Aunty Janet thanks for your support in the very last crucial moment when I felt like giving up. Your short stay with us here in Aotearoa was so helpful. 
Finally, my deepest thanks go to these people who meant so much to me. To Ps. Jerry Koyaiye and Ps. Alex Koyaiye, your generous support will always be remembered. To my husband Jacob Mambo, I would not have reached this far without your support. I owe you a lot. Thank you for always challenging me to complete this study. To my children, Jeremy, Jelintha, Jerolyn and Jacoberth, I would like to thank all of you for being patient with me and being there for me while I completed this study. I had to achieve a balance between the five of you and the demands of study. I will always remember your tolerance of this juggling act. 


\section{Table of Contents}

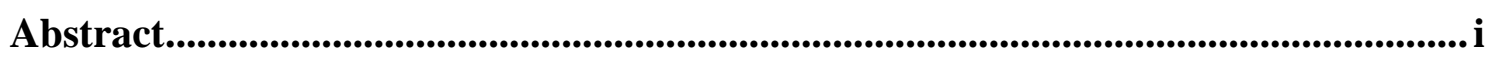

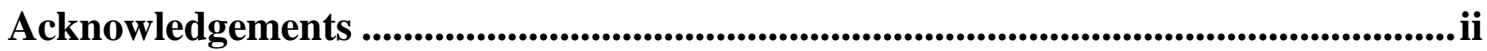

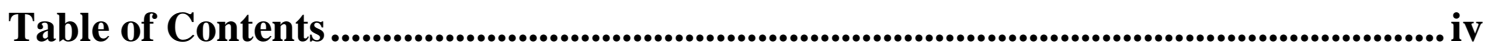

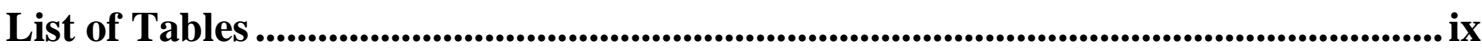

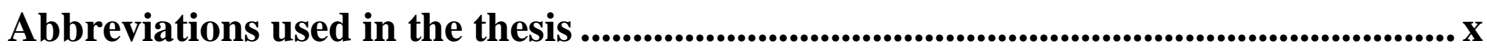

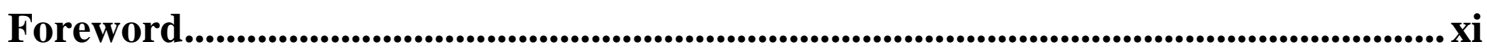

Chapter One: Introduction and Research Context ..................................................... 1

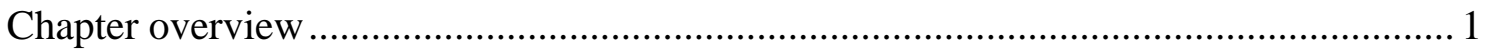

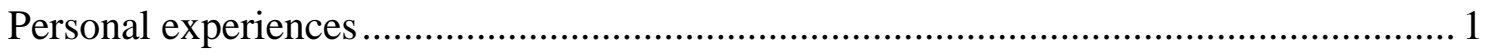

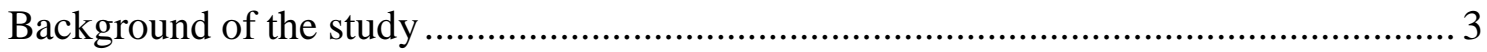

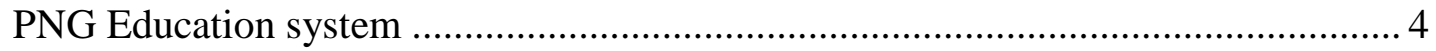

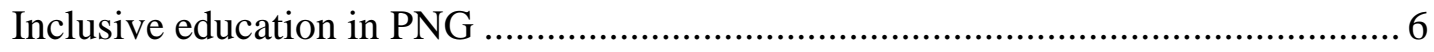

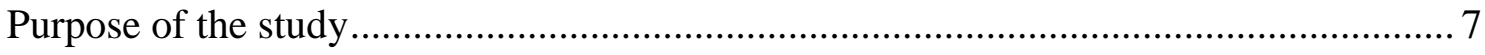

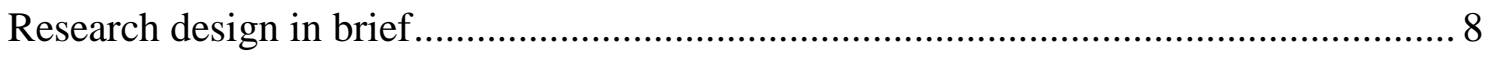

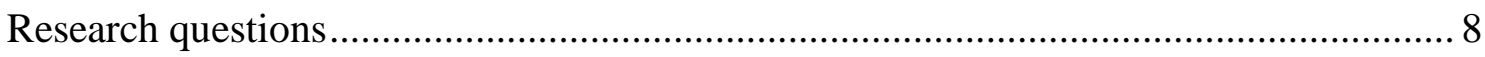

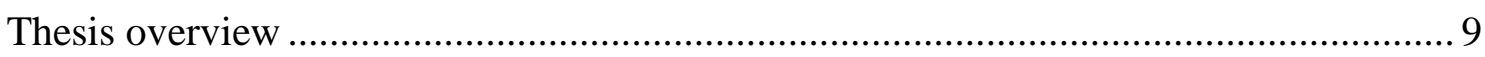

Chapter Two: Literature Review ...................................................................................... 10

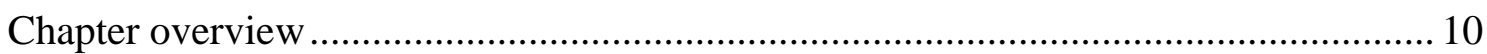

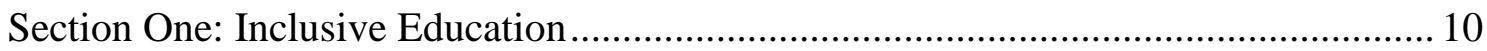

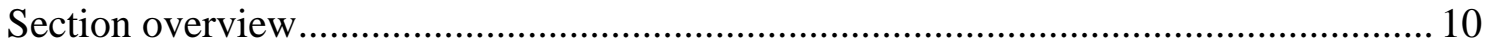

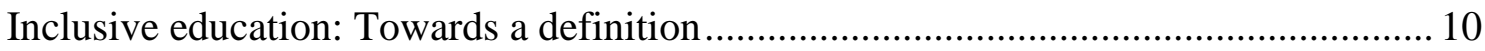

Historical background of special education and the move towards Inclusive

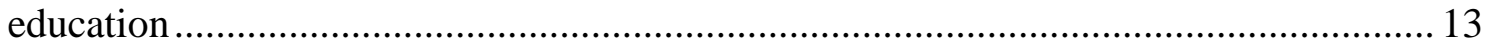

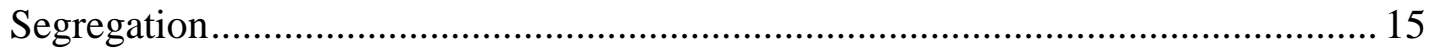

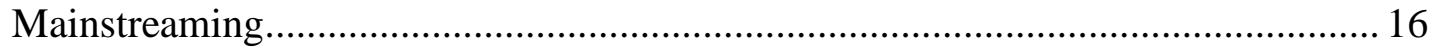

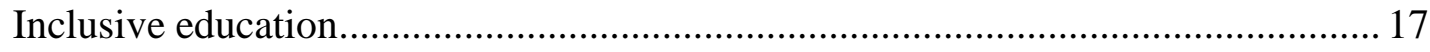




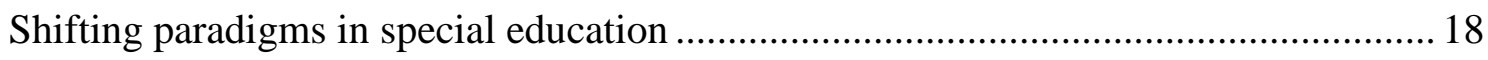

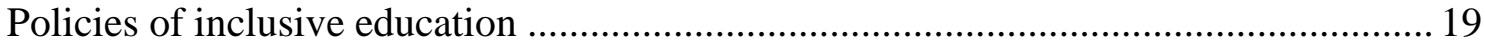

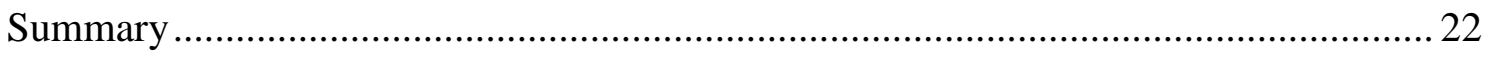

Section Two: Implementation of Inclusive Education Policy …..................................22

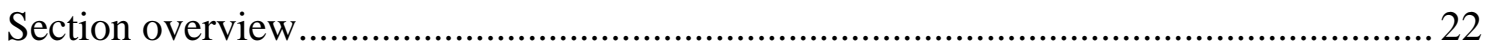

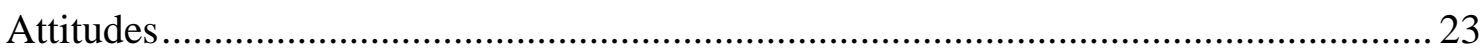

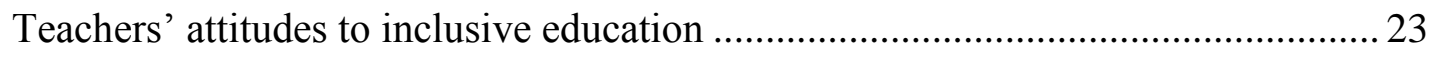

Parents' attitudes to inclusive education .............................................................. 25

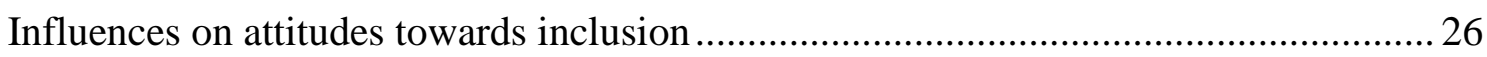

Training, teaching experiences and knowledge ................................................. 26

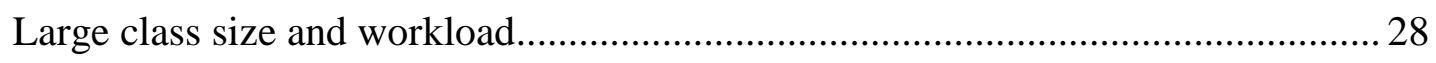

Teacher preparation for inclusive education policy implementation............................ 29

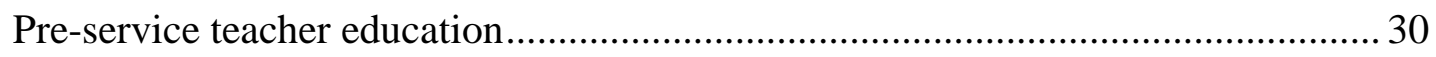

Teacher in-service or professional development.................................................... 31

Effective strategies involved when implementing inclusive education policy ............... 31

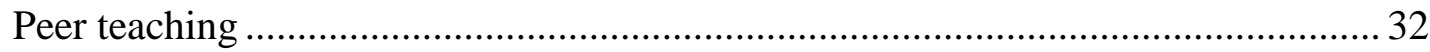

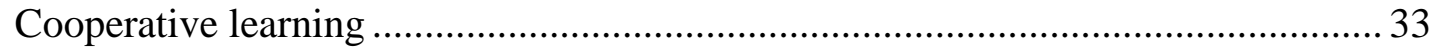

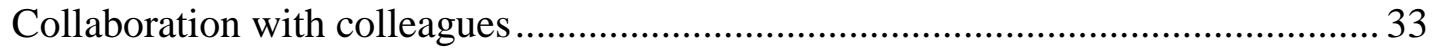

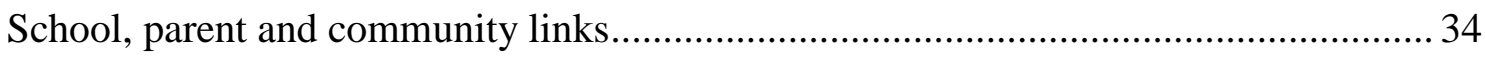

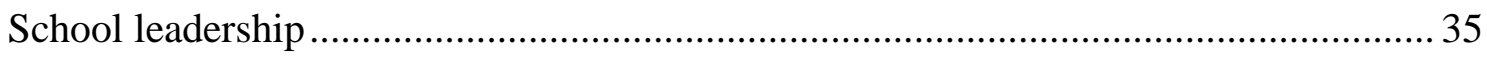

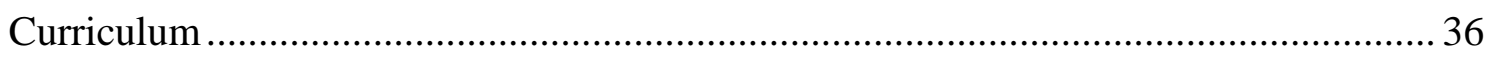

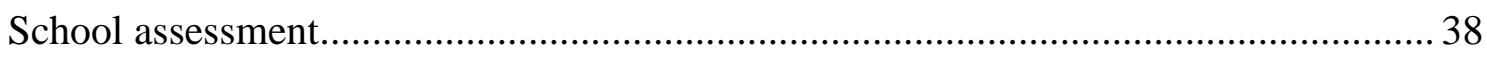

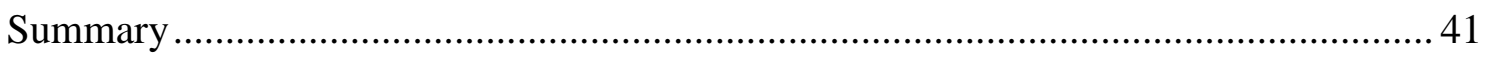

Chapter Three: Research Methodology .........................................................................4 43

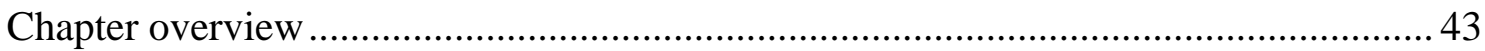

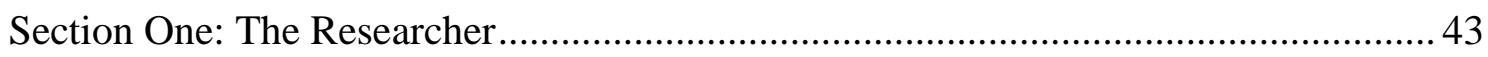

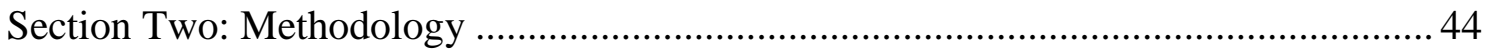

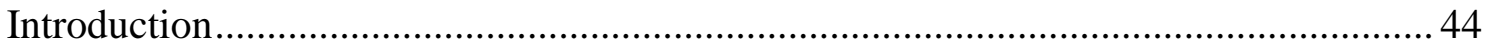

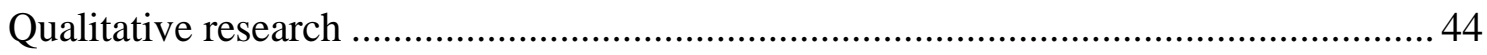

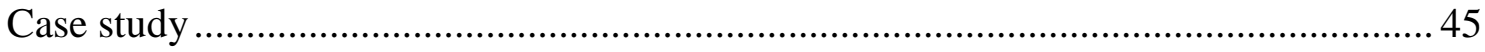




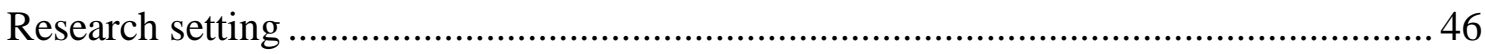

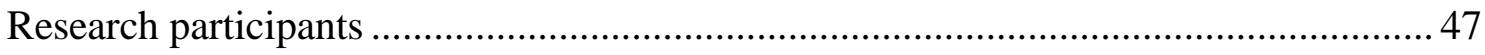

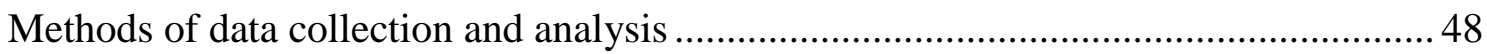

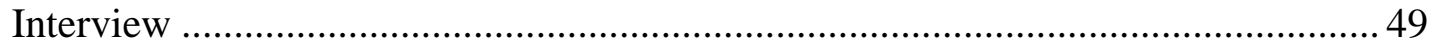

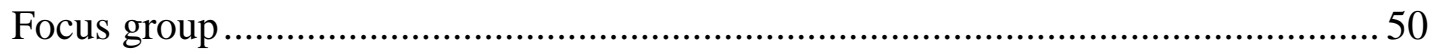

Data analysis of interview and focus group ….................................................. 50

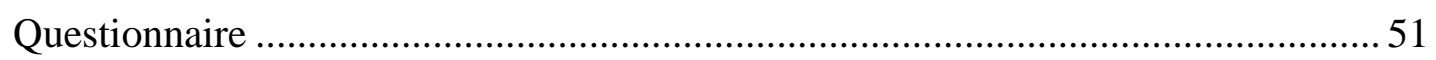

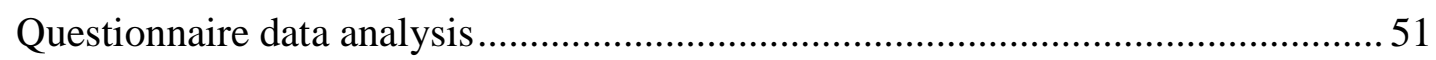

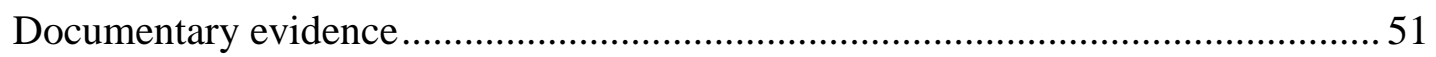

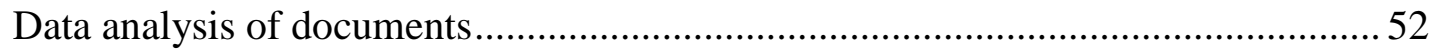

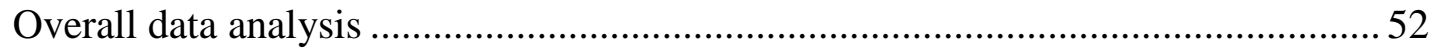

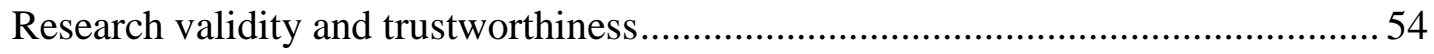

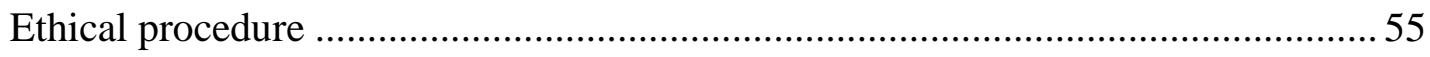

Problems encountered while collecting the data .................................................. 57

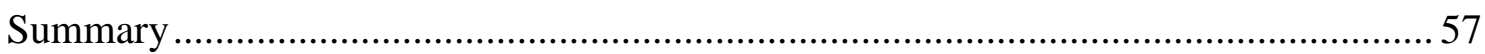

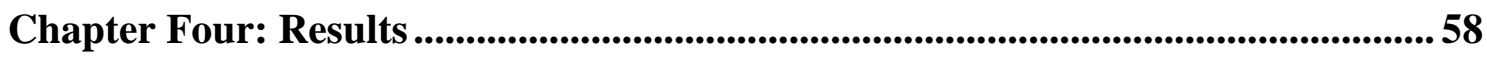

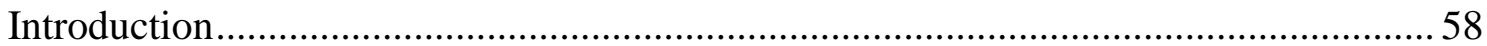

Theme 1: Teachers' attitudes, knowledge and understanding of inclusive education

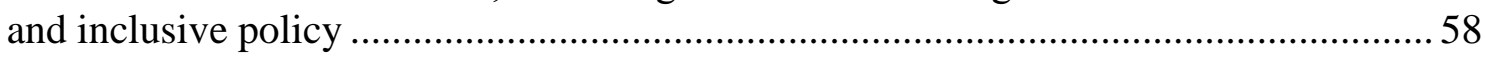

Theme 2: Teachers knowledge and understanding of strategies involved in

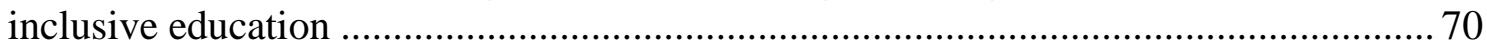

Theme 3: Important issues pertaining to effective inclusion ......................................... 79

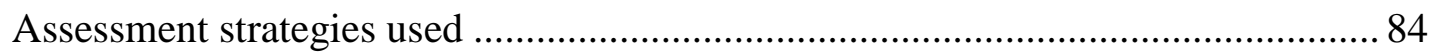

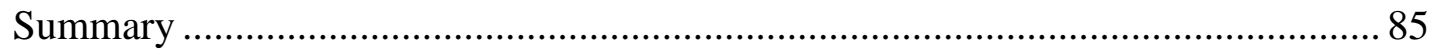

Chapter Five: Discussion...................................................................................................................... 87

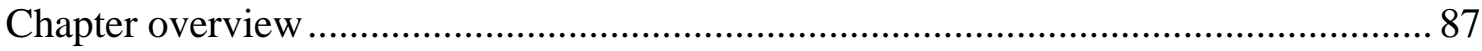

Teachers' attitudes, knowledge and understanding of the inclusive education

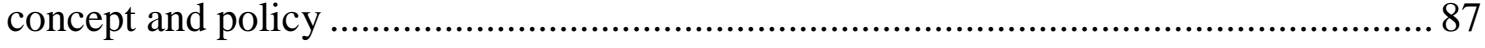

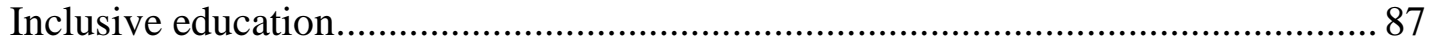

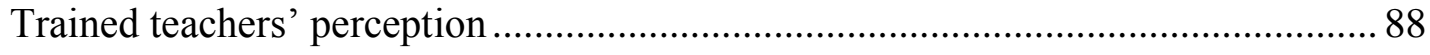

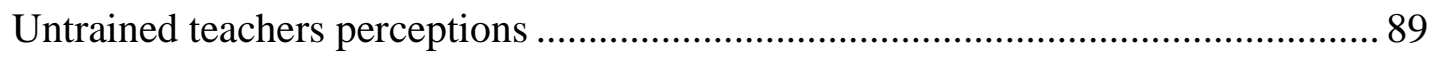

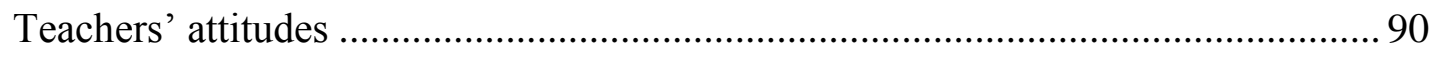

Teachers' views and experiences on the implementation of inclusive education policy 
Teachers' experiences and views on workload and time allocation 92

Teachers' experience and views on the issue of separate curricula ..........................93

Teachers' experiences and views on teaching strategies used ................................ 94

Other attributes for effective implementation of inclusive education policy ................. 96

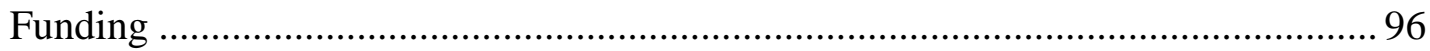

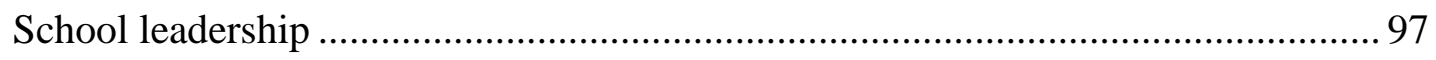

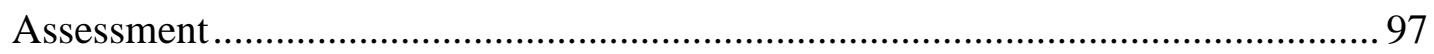

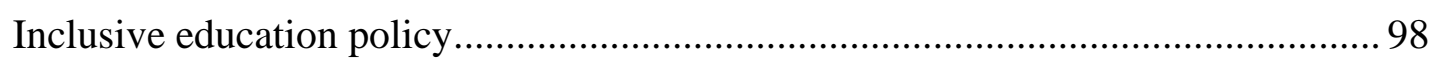

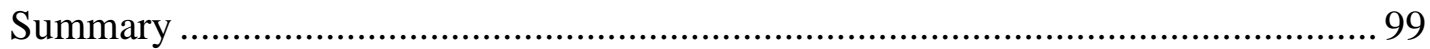

Chapter Six: Limitations, Implication for Practice and Implication for Further

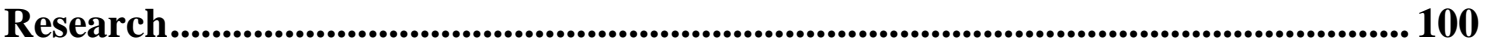

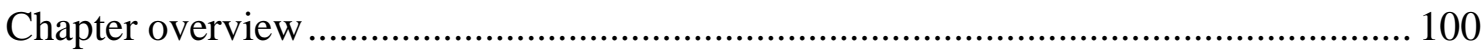

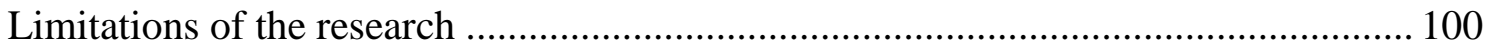

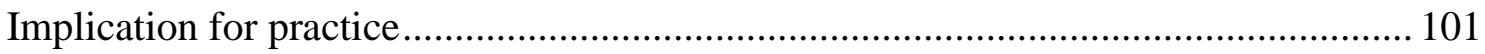

Knowledge, understanding and attitudes ........................................................... 101

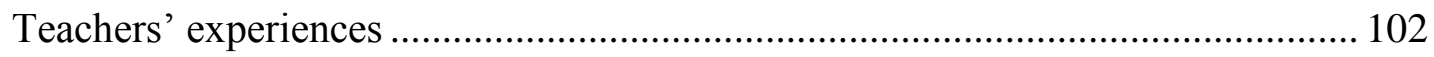

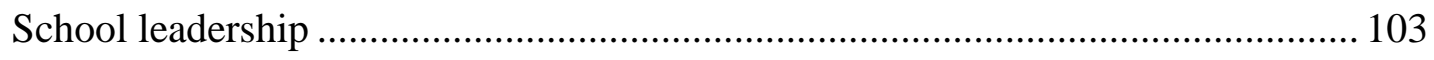

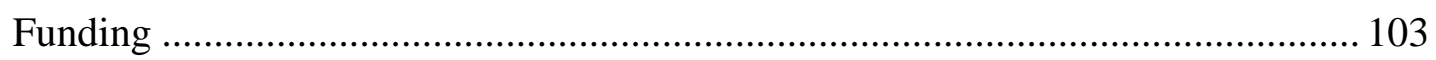

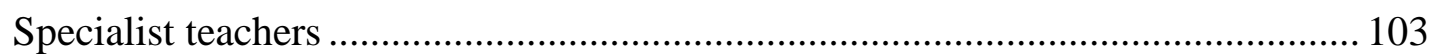

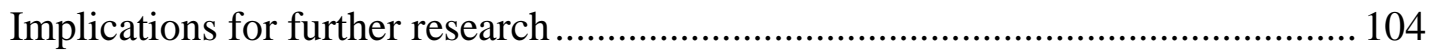

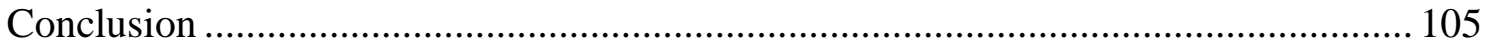

References................................................................................................................................. 107

Appendices................................................................................................................................................. 120

Appendix A: Table 1: Demographic information for the study................................ 120

Appendix B: Summary of research questionnaire results..................................... 121

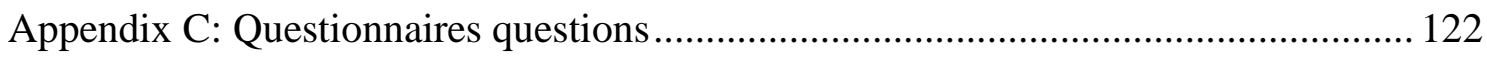

Appendix D: Interview questions for Head teacher, deputy and senior teachers ......... 124

Appendix E: Focus group interview questions for teachers .................................. 126

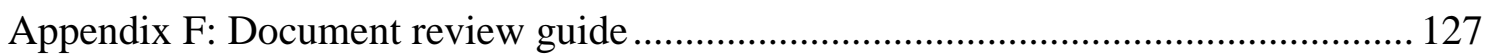

Appendix H: Ethics approval letter - PNG National Research Committee ................. 129

Appendix I: Ethics approval letter - PEB Southern Highlands Province .................... 131 
Appendix J: Ethical approval letter - School Head Teacher

Appendix K: Participants' letter

Appendix L: Consent Form

Appendix M: Questionnaire Consent Form (all teachers) 140

Appendix N: Focus Group Interview Consent Form (Selected teachers)

Appendix O: Individual Interview Consent Form (Head, Deputy and Senior Teachers)

Appendix P: Document Analysis Consent Form (Head teacher, Deputy Head teacher, senior subject master-curriculum) 


\section{List of Tables}

Table 1: Demographic information for the study (see appendix A) 48

Table 2: Q1: Inclusive education means all children learning together in one classroom/school.

Table 3: Q2: Every child regardless of the disability has the right to a formal education at a regular school.

Table 4: Q3: All regular schools in PNG enrol children with disabilities.

Table 5: Q4: All regular teachers in PNG are fully trained to teach children with disabilities.

Table 6: Q5: All regular schools should have policies that support children with disabilities.

Table 7: Q6: Children with disabilities require extra time from the regular teacher. 70

Table 8: Q7: The inclusion of children with disabilities in regular schools is moving at a slow pace.

Table 9: Q8: Regular school teachers need to be fully trained before enrolling children with disabilities.

Table 10: Q9: Children with disabilities disrupt other students' learning.

Table 11: Q10: Teachers have to use a separate curriculum to cater for children with disabilities.

Table 12: Q11: Children with disabilities enjoy learning in a regular school if their individual needs are fully met.

Table 13: Q12: Teachers' workload is increased in an inclusive classroom.

Table 14: Q13: Professional development is important for regular teachers before teaching children with disabilities.

Table 15: Q14: The government should train more specialist teachers to assist teachers in the implementation of the inclusive education programmes. .... 81

Table 16: Q15: The National Government and the local level Government have to provide sufficient funds to the school for improving the school facilities (e.g., disability toilets, walkways) so that inclusive education policy can be successfully implemented. 


\section{Abbreviations used in the thesis}

CBM: Christian Blind Mission

Children with disabilities: is used in replacement of the words children with special educational needs

DOE: Department of Education

D/HT: Deputy head Teacher

EFA: Education for All

F: Female teacher

H/T: Head teacher

IDEA: Individuals with Disabilities Education Act

IE: Inclusive Education

IEP: Inclusive Education Policy

M: Male teacher

NGO: Non-Government Organisation

OBE: Outcome-Based Education

PEB: Provincial Education Board

PNG: Papua New Guinea

SHP: Southern Highlands Province

SEN: Special Educational Needs

S/ST-1: Senior Subject Teacher -1

S/ST-2: Senior Subject Teacher -2

S/T: Senior Teacher

UNESCO: United Nations Educational, Scientific and Cultural Organisation.

T-1: Classroom teacher 


\section{Foreword}

An author who was inspired by the aspirations of inclusive teachers once wrote...

I see children as kites

You spend a lifetime trying to get them off the ground.

You run with them until you are both breathless.

They crash, they hit the rooftop.

You patch and you comfort.

You adjust and you teach.

You watch them lifted by the wind and assure them that someday they'll fly.

Finally they are airborne, and they need more string and you keep letting it out, but with each twist of the ball of twine there is a sadness that goes with the joy. The kite becomes more distance and you know that it won't be long before that.

String will snap and the lifeline that holds you together will no longer be the same.

Children as kites must be prepared to soar as they are meant to soar.

Free and alone to the greatest extent possible, and only then we collectively say that we have done our job.

(Tilton Linda, 1996, p. 11.) 


\section{Chapter One: Introduction and Research Context}

\section{Chapter overview}

This thesis begins with a poem on inclusion as a foreword (see page xi). This first chapter describes the researcher's personal experiences that led to her studying inclusive education. This is followed by a description of the study's background, which includes descriptions of the Papua New Guinea (PNG) education system and inclusive education in PNG. Then the purpose of the study is presented. A brief explanation of the research design is also presented in this chapter. Next, the research questions that guided this study are provided. The chapter concludes with the thesis overview and summary.

\section{Personal experiences}

My interest in inclusive education developed from my teaching experiences. I graduated with a diploma in primary school teaching in 1996 and began teaching in one of the biggest schools in the Southern Highlands Province of Papua New Guinea. This school normally hosts most of the school-based in-service courses for teachers' professional development, and in one of the in-service courses, my head teacher asked me to present a topic on inclusive education. I was nervous because I had insufficient knowledge of inclusive education. In my teacher training, I learnt nothing about inclusive education; special education was introduced to us at that time, but as it was an optional course I ignored it. Therefore, for the presentation for the workshop, I went to a special education resource centre in the main town in my province and requested some information about inclusive education. The resource centre teachers gave me some handouts and information. From these, I developed notes for the presentation. I presented some basic concepts of inclusive education, but my presentation was not really convincing because I did not really understand the concepts myself. I noticed that most teachers had little or no knowledge of inclusive education and teachers were 
taking inclusive education as a synonym of special education. They were aware that children with disabilities were given formal education in special schools with specially trained personnel. My interest in gaining more knowledge in inclusive education grew after this workshop. I decided that I should take up further studies in special education to build my knowledge in special and inclusive education. In 2004 I applied to study at University of Goroka in Papua New Guinea with special education as my major subject. It took me two years to complete this study and I graduated with a degree in special education in 2005. After graduating from this university I was involved in organising teacher professional development programmes for teachers in my district. Teachers were strongly influenced by the idea of having children with special needs in segregated schools. They knew that special education was for children with disabilities and specially trained teachers teach them. The inclusive education policy was not clearly defined for teachers and the idea of inclusion was a contentious issue for most teachers.

The papers that I took for my qualification covered only general issues in special education so I could not do much to help the teachers understand what inclusive education was all about. I thought that I could further my studies in inclusive education in a well resourced country like New Zealand or Australia where I could gain more indepth knowledge about inclusive education. I applied to do a Masters degree in special education in several universities in New Zealand and Australia. In 2007 I was accepted to study at Victoria University. However, I had no money to fund my studies, so I applied for a New Zealand Aid Scholarship in the following year (2008), and I was given a scholarship that fully funded my studies. I proposed to do research in inclusive education so that I could learn more from resources from the library, lecturers, reviewers and supervisors. 
Inclusive education is a broad subject and the knowledge gained here will be taken back to Papua New Guinea and be utilised in the areas that I will be involved in. For example, district and school based in-service courses will be conducted to inform head teachers and teachers about the national inclusive education policy as well as international policies. Community awareness will be carried out during community gatherings, especially on Sundays when everybody meets.

\section{Background of the study}

Inclusive education refers to the notion of educating all children regardless of their disabilities, age, gender, socio-economic background, language or ethnicity in one school environment (Stainback \& Stainback, 1996).

Inclusive education also requires parents and communities to support schools in providing effective inclusive education services to children vulnerable to exclusion (Fraser, 2005). Inclusive education has been adopted in policy by a number of countries since gaining recognition by the United Nations in 1994. The United Nation member countries recognised the importance of providing equal and quality education to children with disabilities.

Papua New Guinea is a member to the United Nations and has incorporated the inclusive education policy into its National Education Policy. The Papua New Guinea government developed its own national inclusive education policy and endorsed its implementation in all schools starting at the primary school level. However, the implementation of the inclusive education policy in Papua New Guinea is impeded by certain factors. One of the leading factors is teachers' lack of knowledge of inclusive education. Teachers are the key implementers of the inclusive education programmes in those schools in which children with special needs can be accommodated and provided 
equal learning opportunities and support to meet their potential. From my experience, many teachers are not aware of inclusive education. Some of the teachers pointed out that inclusive education is a new and unfamiliar concept, particularly those that graduated from teacher training before the introduction of inclusive education courses in teachers colleges. They think that children with special needs, especially with disabilities, have no place in regular schools. They also think that educating a child with a disability is the sole responsibility of teachers and they make no use of parents and other support personnel. The teachers who have graduated after the introduction of the inclusive education policy and courses are also uncertain whether to implement or to ignore the policy when the majority of their fellow staff are not supportive of the idea. Therefore, this research intends to investigate the teachers' perception of the progress of inclusive practices in a regular schooling environment.

\section{PNG Education system}

Papua New Guinea, like most other developing countries, inherited its colonizer's (British and Australia) education system (Waiko, 1997). Public and private schools were built, and children were enrolled and were taught using the Australian curriculum. Churches also established schools using both Christian and the Australian curriculum (Mapea, 2006). This form of education continued until PNG received its independence.

After considering options for a considerable time, a ministerial committee suggested specific policies for educating the whole human being and proposed a holistic approach to education (Matane Report, 1986). The committee recommended that the curriculum should be designed to fulfil the spiritual, mental, social, economical and political needs of every individual Papua New Guinean. Therefore, the country undertook educational reform and introduced the Outcome-Based Education (OBE) system (Maha, 2009). The Matane Report was seen as the birth of education reform, in particular the national 
curriculum (Kale \& Marimyas, 2003). This education reformation stage in PNG was

initiated with the primary purpose of establishing relevant education for all Papua New Guineans based on the five goals of the Philosophy of Education for Papua New Guinea (Matane Report, 1986). These are:

"Integral human development,

Equality and participation,

National sovereignty and self-reliance,

Natural resources and environment, [and]

Papua New Guinea ways" (p. 7).

The goal of integral human development is important for the education of all children in PNG and it acts as the basis for achieving the other goals (Matane Report, 1986). The PNG National constitution also advocates the education of children with disabilities where the goal of integral human development is defined in the following words:

"We declare our first goal to be for every person to be dynamically involved in the process of freeing him/herself from every form of domination or oppression so that each man and woman will have the opportunity to develop as a whole person in relationship with others" (Matane, 1986, p. 7).

Therefore, the Government of PNG developed its own national curriculum. It started with the development of a primary school curriculum followed by high school and secondary school curricula (Government of PNG, 2002). The guidelines in the new curriculum directed teachers to implement the curriculum in ways that are inclusive by “planning more children centred learning activities, carrying out continuous assessment, 
involving parents and communities and creating non threatening school environment" (p. 24).

\section{Inclusive education in PNG}

In the past, school age children with disabilities were institutionalised in schools such as the Mt Sion School for the Blind in Goroka in the Eastern Highlands Province, Chesire Homes in Port Moresby and in major hospital wards (Ahai, 1993; Rombo, 2006). The move towards inclusive education gained recognition in the national education system with the introduction of the 'National Special Education Plan and Policy and Guidelines for Special Education' in 1995. This was implemented after the Papua New Guinea Government became a signatory to the United Nations Convention on the Rights of the Children and 1994 UNESCO Salamanca Statement and Framework for Action. With a special education policy already in existence in PNG, the Department of Education expects all children to be educated in regular schools with allowances being given for some children to continue their education in other institutions, particularly children with severe developmental disabilities (Government of PNG, 2002).

However, having a policy is not the same as all schools actually having implemented quality inclusive education in a country like PNG. Papua New Guinea has more than 800 languages, diverse cultural groups and complicated geographical factors which make most changes in schools very complicated (Kale \& Marimyas, 2003). There is no continuous support from the government and as a result most schools are rundown, with inadequate facilities to provide quality education as proposed in the policy. The teachers' and communities' beliefs and negative attitudes towards children with disabilities also have some dampening effect on the progress of inclusive education. Two studies undertaken in PNG have indicated that schools ignored the policy or that their implementation of it was progressing slowing. Mapea (2006) carried out research 
on teachers' views on providing for children with special needs in inclusive schools. He identified that inclusive education was not clearly defined to teachers; indeed, some of the teachers did not know that there was an inclusive education policy. Another study undertaken by Rombo (2007) on cultural features within schools that influence inclusive education has identified similar limiting factors as in the previous studies. Some of the major barriers to effective implementation of inclusive education identified in both studies were: negative teacher attitudes; poor infrastructure and inadequate facilities in schools; diverse cultural beliefs; and unqualified personnel and poor funding. Furthermore, research undertaken in other developing countries has identified similar factors to the PNG studies. For example, Bosi (2004) studied inclusion in Malaysia and found teachers had limited understanding of inclusive education policies. However, the government has recently put considerable effort into improving the quality of inclusive education in PNG. For example, the government directed the Department of Education to allow existing teachers to upgrade qualifications while still on pay, as well as funding provincial and school-based workshops for professional development. This was done to enhance the teachers' knowledge and skills in inclusive education so that the implementation of the inclusive education policy can be improved.

\section{Purpose of the study}

In Papua New Guinea, the implementation of inclusive education policies in regular school settings seems to be challenging, especially at the primary level where resources and teachers are scarce. Therefore, this study investigated the implementation of inclusive education policy in a regular primary school to see the effectiveness of the implementation. The results would be useful for the future planning of successful and effective implementation of the inclusive education policy. The study firstly looked at teachers' attitudes, knowledge and understanding of inclusive education concepts and 
policy. It then investigated teachers' views and experiences of the implementation of inclusive education policy. Finally teachers' perceptions of important issues pertain to effective implementation of inclusive education policy were explored.

\section{Research design in brief}

This is a qualitative research using a case study approach. Qualitative research is defined by Creswell (2003) as an enquiry useful for exploring and understanding a central phenomenon. The phenomenon in this study is the progress of the implementation of inclusive education policy. Best and Kahn (1998) emphasised that qualitative data are useful within a research setting because participants will more freely express their thoughts, perceptions and experiences concerning the research topic in greater detail. Hence, to know more about the phenomenon, the researcher asked both broad and specific questions that allowed participants to express their thoughts, perceptions and experiences relating to the topic. Data were collected in several ways. Firstly, all participants were invited to complete a questionnaire. This was followed by an individual interview with head teachers, a deputy head teacher and two other senior teachers and a focus group interview with six classroom teachers. Some official documents such as teaching programme books and teachers' guides were also reviewed.

\section{Research questions}

\section{Main Question}

What are the teachers' perceptions of the implementation of inclusive education policy in the regular school under study? 


\section{Sub Questions}

The following sub questions are formulated to guide this study.

1. How is inclusive education defined and conceptualised by teachers?

2. What are the attitudes of teachers towards children with disabilities?

3. What are the teachers' perceptions of the inclusive practices used in the school?

4. What are some of the important issues pertaining to inclusive education?

\section{Thesis overview}

This thesis is organised into six chapters. Chapter One introduces the background of the study with a brief introduction of inclusive education. Chapter Two presents the literature related to inclusive education and defines the key terms of the study. The third chapter discusses the methodology used by the study and the researchers' views. It includes a discussion of the design and purpose of the study. It also discusses methodological procedures used in the study. These include a brief explanation of the two types of interviews, the questionnaire and the documents analysis. Chapter Four presents the research findings. It presents the information gathered from the questionnaire and interviews with support from the reviewed documents. From the findings, conclusions on teachers' perceptions of the implementation of inclusive education policy at the regular school under study are made. The final chapter contains the discussion of the main aspects of the research findings, which are linked with selected items from the literature review. 


\section{Chapter Two: Literature Review}

\section{Chapter overview}

This chapter has two sections. Section one discusses the concept of inclusive education. This includes the definition of inclusive education and a brief description of the history of inclusive education. This is followed by the definition of disability and a description of the perceptions people have about individuals with disabilities. A description of the paradigm shift in special education and the policies that were developed to recognise the importance of inclusive education are then discussed. The second section discusses the implementation of inclusive education policy. It describes some of the important elements involved in effective inclusive practices. This includes the description of teacher attitudes; teacher preparation and teaching strategies; school, parent and community links; leadership; curriculum; assessment; and policy and funding.

\section{Section One: Inclusive Education}

\section{Section overview}

Firstly, the definition of inclusive education is provided. This includes a brief description of special education and the move towards inclusive education. Secondly, a description of the shifting paradigms in special education is provided. Finally, some of the more important policies of inclusive education are provided.

\section{Inclusive education: Towards a definition}

Inclusive education is a global phenomenon that has been extensively advocated for in recent history. It is a philosophy and a principle that has its roots in the civil rights movements and educational reform (Kauffman \& Hallahan, 1995; Rombo, 2007). However, the implementation of inclusive education has been difficult because of the conflicts that exist between those who support it and those who do not. Mitchell (2005) 
suggests that inclusive education is seen as a complex and problematic notion that lacks a common definition. He states that:

Although there is no universally accepted definition of inclusive education, there is a growing international consensus as to the principle features of this multidimensional concept. With regard to students with disabilities, these include the following: entitlement to full membership in regular, age appropriate classes in their neighbourhood school; access to appropriate aids and support services, individualised programmes, with appropriately differentiated curriculum and assessment practices (p. 4).

Brown (2005) also maintained that the term is interpreted and applied in many different and sometimes contradicting ways in different cultures. Artiles and Dyson (2005) also stated "inclusive education is a multi-dimensional phenomenon where different countries, schools and classrooms define and develop in different directions as it suits their needs" (p. 37).

While the approaches to inclusive education have a common understanding of the concept as the recognition and valuing of student diversity in educational institutions, the scope of this in the literature varies. Some writers limit it to the education of students with disabilities and consequently focus on the intersection between regular and special education (Mitchell, 2005). For example, Mastropieri and Scruggs (2004) defined inclusive education as the education provided for students with disabilities in a regular school, where instruction is provided by a regular teacher. Others take an "education for all" perspective, arguing that all disadvantaged students such as those from poor backgrounds, ethnic minorities, the disabled, gifted or talented students, and girls in some cultures (Ainscow, 2007; Booth, et al., 2000; Cheminais, 2001; Moore et al., 1999 \& Stainback \& Stainback, 1996). For example, in South Africa inclusive 
education is focused on all vulnerable students, including over age learners who experience language barriers, children in prison, and children in poverty, in addition to students with disabilities (Naiker, 2005).

Researchers further argue that inclusive education does not involve itself in norming, labelling or pathologising learners (O’Neil, Bourke \& Kearney, 2009; Prochnow, Kearney \& Caroll-Lind, 2000). It is considered to be a philosophy and pedagogy that requires considerable thought around learning, assessment and social interactions. Therefore, the educational organisation should be restructured, adapted and improved to fit, foster and support the diverse needs of every student (Chemicals, 2001; Moore et, al. 1999). According to Ryba and Annan (2000), inclusive schooling allows more interactive and interdependence-forcing teaching methods in which students help each other and maximise participation This means that inclusive education is seen as an approach that seeks to address the learning needs of all learners with and without disabilities and allow them to be able to learn together in educational settings with an appropriate network and support system (Mitchell, 2005).

Tilton (1996) states that inclusive education involves a system-wide change in which every student is accepted, belongs and is a valued member of the learning community" (p. 16). This is possible only in a flexible education system that can assimilate the needs of a diverse range of learners and adapts itself to meet these needs (Parasuram, 2006). Parasuram further stated that all stakeholders in the system (learners, parents, teachers, the community as well as administrators and policy makers) need to be comfortable with diversity, and see it as a challenge rather than a problem. This is because a wide range of factors, including the home and school environment, the skills and methods of teachers, and cultural perceptions of what types of learning are valued and given status, affect children's learning. Therefore, the aim of inclusive education is to ensure that all 
children have access to appropriate, relevant, affordable and effective education within their community. It starts at home with the family and includes formal, non-formal and all types of community-based education initiatives.

Inclusive education is also considered to be a human right, where all learners are accepted and taught together in a regular classroom (Thomas \& Vaughn, cited in Florian, 2007; Mitchell, 2005; Ryba, 1995).The Salamanca Framework of 1994 emphasised the rights of people with disabilities. It has pointed out that the establishment of inclusive schools will help to combat discrimination and negative attitudes, develop children's social confidence and help build an inclusive society for them to live in. The framework gives children with disabilities the right to be recognised as a person who can contribute meaningfully to the building of a nation along with the rest of the population (UNESCO, 1994).

\section{Historical background of special education and the move towards inclusive education}

There were many myths about children who were born deformed, handicapped or in some way abnormal. Some believed that they were non-humans who came from fairies or demons (Sutherland, 1981) while others believed that they were cursed for breaking cultural beliefs and taboos (Frost, 2002). However, Neilson (2005) argues that people with disabilities have always existed, across all cultures and all ethnic groups. Hence, the changes in thinking about disability has been sequential from a "sociological critique of labelling and segregation; to physiological and medical child-deficit models of integration; and to the social model of disability which is inclusion; placing the responsibility on institutions to remove barriers which limits participation" (Corbett, 2001, p. 33). According to Farrell (2008) special education is the education of children 
with special needs in a way that addresses their individual needs and involves individually planned and systematically monitored arrangements of teaching procedures, adapted equipment and materials, accessible settings, and other interventions designed to help learners with special needs achieve a higher level of personal self-sufficiency and success in school and the community. Special education was associated with the provision of education to children with special needs in special facilities. Children with special needs included learners with disabilities, learning difficulties, communication or behaviour difficulties, and sensory or physical impairment (Mitchell, 2005). This means that special education was constructed on an "ideology of individual pathology that created separation between normal and abnormal' '(O'Neil et al., 2009, ...p. 589).

As early as the seventeenth century, institutions were established in some parts of the western world to cater for children with special needs (Center, 1989, Sutherland, 1981). For example, educational programmes for individuals with special educational needs were developed as early as the 1700s in Europe. The New England Asylum for the Education of the Blind was established in 1784 and was followed by the experimental school for teaching and training of idiotic children in 1846 (Stainback \& Stainback, 1996). Several other schools were developed in the next 20 years (Bosi, 2004). In the USA, the American Asylum for the Education and Instruction of the Deaf and Dumb was established in 1817. Later the American Congress passed legislation that supported people with disabilities.

In Australia, one of the first institutions to provide education for children with disabilities was the Royal Institute for Deaf and Blind Children. It was established in Sydney in 1860 as a school for children who were deaf; the institute welcomed its first blind pupils in 1869. Similar schools were established in Victoria (1860), Queensland (1883), South Australia (1874) and Western Australia (late 1890s). 
In New Zealand, students with special educational needs were educated by churches and voluntary organisations as early as 1877 . By 1917, however, special classes were introduced for less successful learners whilst children with sensory and physical disabilities were more likely to remain in separate establishments, often under the control of hospitals (Mitchell, 1989, Moore et al., 1999).

In Papua New Guinea children with special needs were rarely provided with formal education. Some were educated in NGO organised schools such as the Mt Sion centre for the visually and hearing impaired (Government of PNG, 2002) while the majority were kept in villages under their parents' care (Rombo, 2007).

\section{Segregation}

Segregated care or education was organised to care for children with disabilities, for their protection, and also as a way of enforcing social control (Vlachou, 1997). Children were enrolled in a separate school or sometimes in a dedicated self-contained room in a general school (Kauffman \& Hallahan, 1995). A child with disabilities was categorised as someone who had a physical, mental or sensory impairment which had a substantial and long term effect on their ability to carry out day-to-day activities (Farrell, 2005). This practice was closely associated with the "medical discourse and charity discourse where children with disabilities were seen as dependent, childlike, helpless, passive and needy and require some form of care and support from the society." (Neilson, 2005, p. 21). They were considered as fundamentally handicapped and unable to contribute fully to the well-being of society (Mapea, 2006). On the basis of this view, people with disabilities were kept in one place so that care and medical attention could be provided for them. The type of education offered in the segregated schools was limited to an emphasis upon a special philosophy and practice. They were not introduced to the

curriculum that the other students in non-segregated settings received (Hoskins, 1996). 
Therefore, it was later argued that this segregation was a violation of the basic human rights of disabled people (Vlachou, 1997). Criticism of these practices raised queries about the basis of the type of education offered to children with disabilities and its efficacy. For instance, Kauffman and Hallahan (1995) stated that children with disabilities were physically separated and labelled, stigmatised and discriminated against, and unequal educational opportunities were made available to them. Therefore, there was a gradual increase in the demand for the mainstreaming of people with disabilities into regular classrooms (Zionts, 1997).

\section{Mainstreaming}

Mainstreaming or integration refers to the inclusion of children with disabilities into the regular school environment for a specific period of time based on their skills. In a mainstream school, children with disabilities attend a special class for most of the day and have little interaction with their non-disabled peers (Kauffman \& Hallahan, 1995). One of the purposes of mainstreaming was to break the barrier of children with disabilities being segregated and gave them more freedom and equal opportunities to interact with their peers without disabilities (Smith et al., 2005). According to Vlachou (1997) integration was perceived as a mechanism for promoting socialisation between disabled and non-disabled children. Others like Corbett (2001) think that integration was all about children with disabilities having physical access to mainstream schools and specialist resources.

However, advocates of children with disabilities argue that children with disabilities still receive an inferior education to everyone else. The problem was that the regular school system with its fixed curriculum was not sufficiently accommodating for students with disabilities. It was assumed that students were to fit straight into the regular classroom, which would proceed with its pre-set curriculum and fixed standard 
(Hoskins, 1996). It was also argued that mainstreaming had not realised its intention as students were placed in regular classrooms but were not included in the classroom programme, and some classrooms had no special education programme at all.

Segregation and mainstreaming education was associated with the medical model of disability, in which an individual with a disability was seen as having needs that required fixing by therapy, medicine or special treatment (Peters, 2007). Criticism of this approach brought about another change, and this was the move towards a unified educational system.

\section{Inclusive education}

The concept of inclusive education is considerably different from a mainstreaming school (Andrew \& Lupart, 1993). In mainstreaming, students with disabilities started out in a separate system and were integrated into the regular school to fit into the existing curriculum and practices. However in inclusive education, the education of the child with a disability starts at the regular school together with their other non-disabled peers. The child is not expected to fit into the existing curriculum and practice, instead the curricula and teaching style, practices and environment are adapted to suit the range of diversity that is found among children in the class (UNESCO, 2001). The main emphasis is that all children, regardless of disabilities and other factors that could prevent them from schooling, should be educated together with their non-disabled peers in a regular school, unlike the integration approach, which involved limited inclusion (Andrews \& Lupart, 1993). An inclusive practice allows more interactive teaching methods that increase interdependence, in which students help each other and maximise

participation (Ryba \& Annan, 2000). It requires teachers to 
provide equal learning opportunities with appropriate support and assistance to meet their students' potential. It implies shared responsibility from all stakeholders and joint concern in the process (Corbett, 2001).

Inclusive education is associated with the rights discourse, where children with disabilities are considered to be the equal of any other citizen, and who can participate in the social and economic system of the society that they live in (Neilson, 2005).

\section{Shifting paradigms in special education}

A paradigm shift is a shift in our fundamental assumptions about how things work (Hahn cited in Hoskins, 1995). Hence, the change process in education is often referred to as a paradigm shift (Hoskins, 1995). For instance, there are two competing conceptual paradigms (i.e., a functional limitation paradigm and an ecological paradigm) that are competing for consideration in special education (Moore et al., 1999; Stainback \& Stainback, 1996). The functional limitation paradigm is based on a medical or a biological model in which the cause for failure is conceptualised as coming from within the individual (Moore et al., 1999). Moore et al. further stated, “

"from that perspective, the role of the educator is to find out what was wrong with the individual (clinical diagnosis) and remediate the individual's functional deficits where possible by providing them with skills to be able to succeed in a regular educational environment and school set-ups" (p. 8).

In short, the functional limitation approach proposed that children with special needs are expected to fit into the existing educational environment (Moore, et al., 1999). Those students who do not fit into the existing programmes are referred to separate settings (Stainback \& Stainback, 1996). 
However, this paradigm is slowly being challenged by a new paradigm. The emerging paradigm, based on ecological theory, is known as the ecological paradigm (Moore, et al., 1999). It calls on educational organisations and environments to be adapted, improved, and made ready to meet the needs of all students. They further noted that one of the aims of the ecological paradigm is to develop educational environments that will reduce exclusion and to promote educational environments that permit inclusion. The educational environment refers to classrooms, curricula, students and teachers' skills, knowledge and attitudes.

Farrell (2000) argued that an ecological approach is careful to recognise the influences of "contextual factors" such as the teachers, family and school and that it avoids placing too much emphasis on the factors within the child. Therefore, the task of educators working within this paradigm is to alter, adapt and improve educational organisations and environments to meet the needs of all students. Udvari-Solnar (1995) pointed out that such adaptation is a necessary precondition for successful inclusion of all students in regular education. To strengthen the idea, policies of inclusive education were developed.

\section{Policies of inclusive education}

The development of inclusive education policies and practices is a step towards advocating for the education of children with disabilities in an inclusive education system (Mentis, Quinn \& Ryba, 2005). In some parts of the western world, education for children with disabilities was underpinned by legislation. According to UNESCO's Salamanca Statement (1994), some of the important legislation and policies that are considered to promote the approaches of inclusive education include: 
- The United Nation Convention on the Rights of the Child (1989) which sets out children's rights in respect of freedom from discrimination and in respect of their representation of their wishes and views.

- $\quad$ The United Nations Education Scientific and Cultural Organisation, Salamanca Statement (1994) which calls on all governments to give the highest priority to inclusive education.

- The United Nations Convention on the Rights of Person with Disabilities (2006) which calls on all States Parties to ensure an inclusive education system at all levels of education.

- World Declaration on Education for All (1990) which calls on equal access to education for every category of disabled person as an integral part of the educational system.

The Salamanca Statement proclaims that:

The fundamental principle of the inclusive school is that all children should learn together, regardless of any difficulties or differences they may have. Inclusive schools must recognise and respond to the diverse needs of their students, accommodating both different styles and rates of learning and ensuring quality education to all through appropriate curricular, organisational arrangements, teaching strategies, resources use and partnerships with communities. There should be a continuum of support and services to match the continuum of special needs encountered in every school.

(UNESCO, 1994, p. 19)

This framework strongly emphasised that the establishment of inclusive schools actually helps to fight against discrimination and negative attitudes, develops children's social confidence and builds an inclusive society for them to live in. It gives them the 
right to be recognised as a person who can contribute meaningfully to their country along with the rest of the population. Therefore, every country should take into consideration the importance of this policy so that they can implement it effectively for the benefit of all its citizens (Ainscow, 1999)

These international policies are being adopted and reflected in the legislation and policy of many countries in the world. Each country has developed its own policy in order to suit the needs of all citizens (Mitchell, 1999). For instance, in the United States, the Public Law 94-142 (the Education for All Handicapped Children Act of 1975), later renamed the Individuals with Disabilities Education Act of 1990 (IDEA), was seen as the basis of inclusive education. It called for free and appropriate education to be provided to all students at public schools regardless of disabilities (Stainback \& Stainback, 1996).

In the United Kingdom, the Warnock Report of 1978 and the Education Act of 1981 had recommended replacing the categories of disabilities then used with an umbrella term 'special educational needs'. This was to assist in moving away from an individualised medical model of need to a more responsive or social model (Florian, 2007). In New Zealand, the amendment to the Education Act 1989 was seen as the basis for inclusive education. It authorised all children with special needs to be entitled to free enrolment and free education at a state school (O’Brien \& Ryba, 2005).

In the case of PNG, a policy was developed in 1995 and named as National Special Education Policy, as the term "inclusive education" was not used at the time (Rombo, 2007). 


\section{Summary}

The first section in the literature review examined the definition of inclusive education, presented a brief history of inclusive education, and explored the shifting paradigms and policies that underpin inclusive education. According to the literature, inclusive education has been defined and interpreted in various ways as it suited particular needs. Most defined inclusive education as the inclusion of children with disabilities in regular schools. Inclusive education is a recent development, spearheaded by advocates of children with disabilities who felt that segregated education limited some of the children's learning opportunities. Inclusive education has progressed from a segregated approach to a mainstreaming or integration approach to the inclusive approach. To strengthen the notion of inclusive education, different international policies concerning human rights and equal participation of children with disabilities were developed. The international inclusive education policies were adopted by many countries around the world with the intention of implementing them in their schools. The progress of the implementation of inclusive education policies is examined in the next section

\section{Section Two: Implementation of Inclusive Education Policy}

\section{Section overview}

This section examines the issues involved when implementing inclusive education policies in regular schools. Attitudes play a major role in effective implementation of inclusive policy, so the section begins by defining attitude. This includes a description of teachers' and parents' attitudes. Some of the factors that influence attitudes are also discussed. Secondly, the other elements that are seen as important for the effective implementation of inclusive education are presented. These include teacher preparation and other strategies that are deemed to be important for the effective implementation of an inclusive education policy. 


\section{Attitudes}

Attitudes are defined as basic aspects of human life, helping human beings to be able to analyse and react to events, make decisions, and make sense of their relationships with other people (Vaughan \& Hogg, 2002). Simi (2008) also pointed out that attitudes are thoughts, feelings and actions that human beings have about other people and things they encounter in their daily lives, and can guide them in deciding whether or not they like or dislike someone or something. It can be a positive or negative evaluation of something that can influence us to act in a certain way towards that particular thing. With regard to inclusive education, teachers' attitudes play a significant role on whether inclusive education policies can be fully implemented in regular schools or not (Frost, 2002).

\section{Teachers' attitudes to inclusive education}

Over the years, research had been conducted on general and special educators regarding their attitudes towards inclusive education because this can determine the failure or success of inclusion (Kitchen, 2007). Researchers pointed out that teacher attitudes are an important factor in the education of children with special needs (Frost, 2002; Moore et al., 1999). According to Pearce (2008), attitudes are even more important than knowledge and skills and claimed that a positive attitude is the most crucial factor in becoming an inclusive teacher. Wang (2008) also suggested that attitude is one of the most important factors of successful inclusion and further states that in order for inclusion to be successful, "regular teachers need to have positive attitudes towards children with disabilities as their beliefs and attitudes will influence their classroom behaviours, students' behaviours as well as students learning outcomes and teacher performance" (p. 76). 
Kitchen's (2007) literature review shows that teachers who were positive towards inclusive education had a positive effect on students' learning while those with negative attitudes limited the opportunities of students with disabilities in a regular class. According to Mentis et al., (2005), "teachers who have positive attitudes about inclusive education accept students with special needs into their classroom" (p.56). Tilton (1996) also states that a teacher in an inclusive classroom needs a positive attitude in order to move beyond initial fear and incomprehension to discover the benefits of the inclusive classroom.

Two researchers (Scruggs \& Mastropieri, 1996) reviewed 28 investigations spanning from 1958 to 1995 that were conducted in the United States, Canada and parts of Australia. The review focused on identifying regular teachers' perceptions towards inclusive education. From the studies reviewed, they found that two-thirds of regular teachers supported the concept of inclusion and they were willing to teach children with special needs in their class. Another study (Mapea, 2006) undertaken in PNG investigating regular teachers' views on providing for children with special needs in inclusive schools also revealed that the majority (76\%) of the teachers supported inclusive education. The researcher therefore concluded that most of the teachers had positive attitudes towards inclusive education.

Despite such positive attitudes, some teachers also have negative attitudes. However, researchers pointed out that the attitudes teachers express on paper do not necessarily agree with the actual behaviours they showed in their daily interactions with children with special needs (Mitchell, 1989). For example, a New Zealand study investigated primary school teachers' perceptions towards children with special needs in regular school. They surveyed 763 regular teachers and the responses revealed that teachers did not want children with special needs to be placed in their own classes, even though they 
expressed positive attitudes towards the principles of placing children with special needs in regular classes (Mitchell, 1989). A similar result was found by Jimenez and Graf (2008), who observed in their study that the majority of the teachers were in favour of inclusive education in concept, but not really in practice. Most teachers felt they did not have adequate time, training, and expertise to meet the needs of exceptional learners. The Papua New Guinea study (Mapea, 2006) mentioned earlier also identified teachers with similar attitudes. In his study, teachers with teaching certificate were supportive of the idea of inclusion; however, they did not necessarily favour the placement of such children in their own classrooms. They believed that they had insufficient training in inclusive education.

\section{Parents' attitudes to inclusive education}

Parents' attitudes and behaviour play a major role in the education of children with special needs. Their involvement is also associated with improvement in students' achievements, attendance, sense of well-being, readiness to complete homework and behaviour (Sileo \& Prater, 2001). According to Boer, Pijl and Minnaert (2010), parents of students with a disability had mixed views on inclusive education. Some were supportive of inclusive education practices while some did not like the idea. Those parents who were supportive seem to hold predominantly positive attitudes towards inclusive education (Miller \& Phillips cited in Mapea, 2006). They have also found that their children had improved in many areas of learning such as developing social values.

However, some parents were not supportive of inclusive education. They had concerns about the social impact on their child (Bailey \& Winton, 1987; Leyser \& Kirk, 2004; Salisbury \& McGregor, 2002). They thought that the other children in the class could isolate, reject and bully them. There were several other negative perceptions communicated by parents. For example, parents of children with educational issues and 
needs who opposed inclusion were concerned that children with special needs may not be receiving adequate attention in the way that they would in special education settings. Moreover, parents were worried that many general education teachers lacked the skills and adequate training to teach and work with their children (Fox \& Ysseldyke, 1997).

\section{Influences on attitudes towards inclusion}

Numerous studies have been undertaken to identify the factors that influence the teachers' attitudes towards inclusion (e.g., Forlin \& Sin, 2010; Putman, 1998). The influence can be either negative or positive and some of the factors that influence such attitudes are discussed further.

\section{Training, teaching experiences and knowledge}

It was identified that teachers' training, knowledge and experiences of teaching children with disabilities influenced their attitudes towards inclusion. The quality of knowledge about children with disabilities and inclusion that teachers gain through pre- and inservice teacher training is paramount because this can improve their attitude (Jupp cited in Forlin, 2008). Authors like Kitchen (2007) and Forlin (2008) also assert that teachers' attitudes are certainly shaped in part during initial training. Therefore, Jimenez and Graf (2008), recommended that appropriate training and support would increase the confidence of teachers in their ability to teach students of all abilities and would ensure

positive attitudes. One study (Mapea 2006) undertaken in PNG, investigating teachers' views on providing for children with special needs in inclusive classrooms, found that teachers who had some training in inclusive education had positive attitudes towards inclusion.

Research also shows that a teacher's experiences of teaching a child with special needs or having a family member with a disability also influenced their attitudes. According to 
Kitchen (2007), people who experience high levels of interaction with individuals who have disabilities hold more positive attitudes towards people with disabilities. For instance, the Mapea (2006) study noted variables like having a family member with a disability influenced teachers to seek further training in specific areas of inclusion (e.g., sign language) to help in their relative's learning.

A similar study (Parasuram, 2006) was undertaken in India to identify the variables that affects teachers' attitudes towards disability and inclusive education. The study investigated possible variables such as age, gender, length of teaching experience, teacher qualifications, and extent of association with a person with a disability, income level and teaching position. The analyses revealed that while some of the variables of interest did affect teachers' attitudes towards disabilities and inclusion, the only variable that affected most of the teachers' attitudes towards inclusion was prior association with a person with a disability. Teachers who had a child with a disability in their stock of previous teaching experiences were positive while those who did not were negative. Consequently, this study also concluded that prior association with a person with a disability had a positive impact on the teachers' attitudes.

However, despite these positive influences, teachers' negative perception of inclusion has become an obstacle to general educators, hindering their ability to include students with disability into their classroom (Sharma, 2001). For instance, the Parasuram (2006) study also noticed that some teachers who had previous experiences of teaching students with disabilities did not want to take any more students with disabilities into their class. They expressed that having a student with a disability in their class sometimes created problems such as slowing the pace at which they covered lessons. 


\section{Large class size and workload}

Teaching students with special needs in a regular classroom requires a lot of commitment, preparation and planning. According to studies, the pressure of a heavy workload is the main concern for the majority of teachers at all levels of schooling. Researchers (e.g., Mclaughlin et al., 1998; Sharma, 2001) have reported that large class sizes are challenges to the implementation of inclusive education. It has been noted that there was a decline in academic gain for students when class sizes increased and gain when class sizes were reduced (Schmidt \& Harriman, 1998). Large class size can impede some of the useful strategies used to assist children's individualised education programmes (IEPs). A study (Irma cited in Jemenez \& Graf, 2008) conducted in South Africa found that teachers were not giving attention to slow learners. The teachers expressed concern that they had a higher number (40-50) of students to teach in the inclusive classroom.

Furthermore, some researchers have pointed out that having children with special needs in a regular classroom meant additional work for the teachers, which added to their existing workload (Forlin, 1995). This is because teachers are also required to do other professional and administrative tasks as well as extracurricular activities in addition to teaching. However, researchers also stated that there are other ways of overcoming pressures of workload and large class sizes that influences teachers' attitudes. Some of the possible ways that could be used to minimise such pressure would be through "cooperative teaching" (Farrell, 2005; Forlin \& Lian, 2008) or "collaboration" (Putman, 1998) with co-teachers and other support personnel to share responsibilities. When responsibilities are shared with other teachers or support personnel, the pressure is also shared. 
It is also mentioned that not all children with disabilities require additional help from teachers; it depends on the severity and type of disabilities (Stainback \& Stainback, 1996). Thus, different disability levels mean different levels of demand on teachers trying to meet children's needs. This means some children with mild disabilities and fewer characteristics problems would be less demanding than children with moderate to severe learning difficulties and physical challenges.

\section{Teacher preparation for inclusive education policy implementation}

The importance of teachers having support and training in order to contribute to the effective implementation of inclusive practices in schools is considered in this section. Pre-service training and professional development in inclusive education are very important if inclusive practices are to be implemented successfully in schools (Mastropieri \& Scruggs, 2004). Bosi (2004) stated that teachers should be adequately equipped to meet the diverse needs of their students, as students with special needs are increasingly being included in classrooms to learn with other students. Choate (1997) also stated that pre-service and in-service teachers need to be trained in special education and inclusive practices which will enable them to provide assessment and teach academic and social skills to all students. Some researchers (e.g., Al-Zyoudi, 2006; Haider, 2008) found that general teachers' lack of training, knowledge and skill in inclusive education resulted in teachers developing negative attitudes. Therefore, the need for teachers to be adequately trained is a concern for many advocates of inclusive education. For example, Dickens-Smith (1995) studied the perception of teachers towards inclusive education. She surveyed their attitudes towards inclusive education before and after the training programme. The respondents revealed more favourable attitudes to inclusive education after the training than they did before. Dickens-Smith then concluded that staff development through training and other support opportunities 
is key to the success of inclusive education practices. As a consequence, descriptions of pre-service teacher education and in-service teacher education need to be discussed in the next two sections.

\section{Pre-service teacher education}

According to O'Neill et al., (2009), special education ideology is still very dominant in thought, policy and practices, so special education is at present deeply rooted in most teacher education programmes. For example, a recent study done in New Zealand (Morton \& Gordon, 2006) examining the nature and extent of initial teacher education and ongoing professional learning around inclusive education identified that teacher educators uphold the theory of inclusion but not its practice. There were contradictory definitions and contrasting policies and practice of inclusion in teacher education. Therefore they concluded that the up-and-coming teacher might not always have a clear view of what inclusion means in New Zealand. This shows that inclusive education has to be clearly defined and understood by all policy makers and educators and that they need to ensure that they make provisions for inclusive practices in their training programmes.

Therefore, teacher education programmes must be geared towards preparing teachers in order to help them meet the challenges of inclusion when they begin teaching in regular classrooms (Smith et al., 2005). Hodkinson (2005) conducted a study in England, examining final year pre-service teachers' knowledge and understanding of inclusion, and found that while the majority of pre-service teachers do understand that inclusive education is a complex and multi-faceted concept, their understanding of the implementation of inclusionary practices within an applied education setting was limited. Therefore, Hodkinson suggests that effective implementation of inclusive education depends very much on how individual teachers define it and whether they 
have received the necessary training to inspire a belief that they can deliver inclusive practices in their classroom.

A similar study was undertaken in the Solomon Islands, studying both teacher educators and pre-service teachers' knowledge and attitudes towards inclusive education. Semi (2008) interviewed student teachers and lecturers and found that they appeared to have a limited knowledge and understanding on what constitutes inclusive practices. The idea of teaching children with special needs in an inclusive classroom and environment was never introduced to pre-service teachers in the course of their teacher training. Semi consequently concluded that teaching children with special needs in inclusive classrooms should be introduced into the curriculum of pre-service training for beginning teachers. This shows that institutions offering pre-service teacher training programmes need to ensure that they make provision for special education and inclusive practices in their programmes.

\section{Teacher in-service or professional development}

On-going professional development for teachers who are already teaching in schools is also very important. According to Fraser et al., (2005) and Tilton (1996), on-going inservice training equips teachers with new skills and knowledge that are used in their teaching to enable them to increase their students' achievements. Lipsky and Gartner (1997) supported the above idea and argue that inclusion does not mean "dumping" children in a classroom; it requires a continuation of support and promotes on-going staff development.

\section{Effective strategies involved when implementing inclusive education policy}

For the success of effective implementation of inclusive education policy, some effective strategies are required. According to Stainback and Stainback (1996), effective 
teaching approaches enable all students to learn and engage with the curriculum in the classroom. However, it is argued that teaching strategies alone do not guarantee effective implementation of inclusive education. The teaching strategies need to be matched with other factors that promote inclusion (Bosi, 2004). Therefore, some specific approaches recommended as effective for the implementation of inclusive education policy are presented below.

\section{Peer teaching}

Researchers (Gartledge, Gardner and Ford, 2009) pointed out that peer teaching emphasises active teaching and learning approaches. Students have the opportunity to learn from their classmates through peer teaching. This practice is often highly effective, as some students are more likely to listen to their peers than a teacher, and the act of teaching the information helps cement understanding in the student's mind. There are many ways teachers can integrate peer teaching into their curriculum. For example, they can do so by arranging interactive activities such as mini and large group activities, shared presentations and other activities that involve peer interaction.

The above authors further stated that one other way that peer teaching/learning can be effective is through arranging buddy systems. In buddy systems, students with disabilities are assisted by their non-disabled peers. The peer buddy ensures that the student with the disability has the opportunity to participate and provides him or her supportive feedback. Buddy systems have proven to be an effective tool in assisting children with disability. However, the peer buddy needs to be carefully trained on how to work with the student. 


\section{Cooperative learning}

Cooperative learning is defined as students working together to "attain group goals that cannot be obtained by working alone or competitively" (Johnson, Johnson, \& Holubec, 1994). It is a strategy that allows students to work together in small groups with individuals of varying talents, abilities and backgrounds to accomplish a common goal (Putman, 1998). Each individual team member is responsible for learning the material and also for helping the other members of the team; research shows that this cooperative learning creates an atmosphere of achievement (Tilton, 1996). For example, students could work together until each group member successfully understands and completes the assignment. This process results in a deeper understanding of the material and greater potential that the material will be retained.

Communication skills can also be developed through cooperative learning. When students work in mixed ability groups, they are free to communicate with their peers and develop confidence in their spoken language skills (Cross, 2002). Cooperative learning also requires teacher observation and feedback (Johnson, Johnson \& Holubec, 1994).

However, cooperative learning is a complex process and many factors determine its success. It is argued that the processes that make up cooperative learning cannot be mastered quickly within a two to three hour workshop (Putman, 1998).

\section{Collaboration with colleagues}

Collaboration is the process of a team of individuals working together to create opportunities for students to learn. According to researchers (Putnam, 1998; Villa \& Thousand, 2005) it is the process of working together as equals to help students experience success in the classroom. This can include approaches such as co-teaching 
(Baker \& Zigmond, 1990) in which a general teacher and support personnel teach together to support children with special needs. Collaboration involves a partnership among many people to facilitate the implementation of inclusion. For instance, the collaboration of teachers, school administrators, parents, special education teachers, teacher aids, health workers, school board members, vocational teachers, and community resources is important. When they work together as a team, they share a common goal of providing learning opportunities for their students (Tilton, 1996) and can develop an appropriate policy as well as promote a culture that facilitates inclusive education (Naidu, 2008)

However, learning to work together and to respect differences is a challenge. Heiman (2002) argues that, "communication process and relationship among team members determine success or failure in effective planning for students" (p. 128).

\section{School, parent and community links}

Effective inclusive practices do not solely include teachers and schools; they also involve the parents and the wider community that the child belongs to. Parents and the community (which includes family members and neighbours) play an important role in the education of a child. They are the key people in supplying the school with any information concerning the child. According to Tilton (1996) parents know their children better than anyone else; they provide information about how their children function in a variety of settings. Ware (1999) maintains that parents know their children in the everyday context of life, and not simply against a context of standardised test scores. There is a reciprocal need for mutual exchange of information and support between home and school (Tilton, 1996). This means schools and teachers need to establish a system where they can spend time with parents to talk about the child's weaknesses as well as strengths and plan effective ways of helping the child. Parents 
can be asked to support school programmes at home, by practices like reading to children and reinforcing skills and practices learnt at school at home.

Parents cannot only support at home, they also must be involved in the school programme. Schmidt and Harriman (1998) pointed out that parents could participate in monitoring the child's progress, supporting the teacher and child in setting goals and working towards achieving them. When parents and teachers work together "sharing a common bond and common goal of developing the child's strength, the opportunities for success rise dramatically" (Tilton, 1996 p. 174). The importance of establishing a 'sense of community' in the school, in which teachers accept parents and welcome their contribution to school activities, is also another important factor that could enhance the development of inclusive practices in schools. Parents and child develop positive attitudes and feel that they belong to something and are valued. Furthermore, parents' skills and knowledge can be utilised to support school activities that would promote inclusion (Macfarlane, 2005).

\section{School leadership}

The introduction of inclusive education also has implications for school leaders. Inclusive schools require leaders who are democratic, transformative (Sharma \& Desai, 2008), collaborative with other staff (Villa \& Thousand, 2005), and who act as facilitators (Hoskins, 1996). Effective inclusive leaders:

Develop and sell a vision of inclusion, seek and support active involvement of parents and family members, obtain and provide resources, modify school policies to support inclusion, develop and plan for professional development, monitor the progress of inclusive efforts and support staff in their effects to implement inclusive practices... (Hoskins, 1996, p. 156) 
Armstrong (2006) states that when school leaders facilitate an initiative to include students with disabilities, teachers develop positive attitudes and demonstrate a motivation to perform beyond expectation.

However, Sergiovanni (2001) argues that leaders can be major obstacles for school change and improvement. He states that school leaders who have no sense of purpose and value achieve capacity building and commitment from the staff members within a school community. They work in isolation and try to enforce rules and policies according to their own will without much consultation of other teachers. The influence of this kind of school leader is generally limited (Ryan, 2006).

\section{Curriculum}

Curriculum can be defined in many ways. Rose (2008) defines curriculum as all the "formal and informal learning opportunities provided by the school" (p. 195). Hoskins (1996) thinks that the curriculum required for inclusion is not confined to paper and pencil. It involves a wide diversity of forms. Therefore advocates of inclusion view curriculum in a comprehensive way. This could include the subjects taught as well as the teaching they receive, the school environment and other activities that take place outside of the classroom (UNESCO, 2001).

It was formerly believed that there had to be a common set of educational experiences provided for all students through a common curriculum (Rose, 2008). Therefore many countries in the world adapt inclusive curriculum to be used in their educational institutions. The purpose of adapting inclusive curriculum was to provide equal learning opportunities to all students in any educational institution. For example, in New Zealand the curriculum is based on the premise that the individual student is at the centre of all teaching and learning programmes, and schools must ensure that this principle is 
embodied in their programmes (Mitchell, 1999). Likewise in PNG, there is only one official curriculum for all students to use in schools (Department of Education, 2002). This means children with special educational needs do not have a different curriculum. They should follow the same curriculum that is used in regular schools. The curriculum is still the same, although modification can be made to teaching and learning resources to meet the diverse needs of all students (Forlin, 2008). Modification and adaptation to the curriculum should be made to fit the student's learning needs (Tilton, 1996, Working Forum on Inclusive Schools, 1994). For example, a child with learning difficulties can be given alternative assignments rather than long written instructions.

According to Santangelo, Knotts, Clemmer and Mitchell, (2008), "differentiating" the curriculum, using teaching strategies and planning can also help ensure equal opportunities for all learners. This means teachers have to be inventive and creative to appropriately differentiate their teaching instructions and strategies in order to help all learners have meaningful and enriched learning opportunities (Pearce, 2008). For example, a visually impaired student's instructional materials can be translated into Braille or into large print, while others can use the normal text.

Inclusive teachers find out how their students learn best, assess their learning style and plan according to their needs (Forlin, 2008). An inclusive teacher understands that students learn at different times and different students may use different pathways of learning to reach the same outcome (Pearce, 2008). This means that teachers need to know their students personally because some students require quite different learning goals. This can be done by observing students in various contexts, asking parents and previous teachers, or reviewing previous academic records. 


\section{School assessment}

Assessment is a process of gathering, analysing, interpreting and summarising information that reflects an individual's behaviour, performance or functions (Dent cited in Ballard, 1999). According to Ballard (1999 assessment is an "evaluative and interpretive appraisal of performance on a variety of tasks in a variety of setting" ( $p$. 177). The above author further states that the purpose of educational assessment is to obtain a description of a child's learning and developments in terms of cognitive, social, emotional academic or other variables. According to Hoskins (1996), assessment is designed to determine students' strengths and weakness to assist people in planning. Therefore, appropriate assessments should be provided to focus the learning process and achievements of the student (Mentis et al., 2005). In the past, standardised testing was exclusively used to measure students' level of ability (Peterson, LeRoy, Field \& Wood, 1992). However, more recently teachers have discovered the challenges posed by the assessment strategies involved in inclusion. Teachers or educators in inclusive classroom are required to know "what each student has learnt, what he or she is capable of learning next and how to best help that learning occur" (Schmidt \& Harriman, 1998, p. 134). An inclusive teacher understands that students learn at different times and different students may use many different pathways of learning to reach the same outcome (Pearce, 2008).

Teachers are required to gather a variety of information from multiple sources (observation, tests) to create a comprehensive report on an individual (Shmidt \& Harriman, 1998). This can be done by observing students in various contexts, interviewing their parents and previous teachers, reviewing previous academic records or even administering quick tests. 
Furthermore, in inclusive classrooms the ecological assessment model is used more frequently (Moore et al., 1999). Smith et al. (2005) also emphasised that through the application of an ecological assessment, emphasis is placed on the child's interaction with his or her surrounding environment. This is because a student's performance in school is a function of an interaction between the student and the instructional environment (Moore et al., 1999). This includes time allocation for instructions, the appropriateness of the curriculum, and the level of tasks presented to the students. Therefore, all these have to be assessed in addition to assessing the learner.

\section{Policy and funding}

Policy and funding also determines the progress of inclusive education. According to Laure (2002), a policy is typically described as a principle or rule put in place to guide decisions and measure outcomes. In the case of inclusive education, there has to be strong policy in place at the governmental level as well as in schools and at any educational institutions that will guide the implementation of inclusive education (Fraser et al., 2005). For example, in New Zealand, the government's aim is to achieve a world-class inclusive education system that provides equal and quality learning opportunities to all students (Ministry of Education, 2008). To achieve this goal, specific goals on inclusive education were formulated and put in place. For example, the Special Education 2000 Policy was formulated and put in place to govern all special education programmes in New Zealand (Davies \& Pragnell, 1999). From this national policy, schools are also expected to develop their own school policy that will affirm the expectations of the goals of the Education Act of 1989 and the Special Education 2000 Framework on inclusive education.

Likewise in Papua New Guinea, the National Department of Education formulated a national Special Education Policy in 1993. There were three major goals formulated 
which supported the education of children with special educational needs. They are as follows:

i. Children with disabilities should have the same rights of access to education as other regular children.

ii. The Government of Papua New Guinea and the National Department of Education should allocate an equitable proportion of resources, provide special education teacher training and provide specialist teachers to support the education of students with special needs.

iii. Students with disabilities should attend a regular school along with regular students in all cases where that is feasible (Department of Education cited in Mapea, 2006).

To enforce the policy, the National Department of Education has developed several directives. These contain a significant amount of detailed, practical information and objectives, which serve as guidelines. For example, all teachers colleges were directed to include special education courses in their training programmes, all schools were directed to enrol children with special educational needs and Boards of Management and teachers were instructed to accept children with special needs who were able to be accommodated at the school (Department of Education, 1993; Frost, 2002).

Apart from effective policies, funding is also very important in implementing any policy. Goals cannot be achieved if there is no funding to support the implementation of the policies. Fraser et al. (2005) emphasised the importance of funding inclusion and stated that the goals of inclusive practices in schools can be achieved if there is adequate funding from the government. The funding should help secure resources, facilities, teacher aides and other necessities that will support and enhance inclusive education. 
According to O'Brien and Ryba (2005), there has to be unconditional and ongoing resourcing for inclusive education. This means that policy makers also have to focus on finding ways to continually support inclusive education.

In Papua New Guinea, funding is a major issue that needs more consideration. There have been some funds allocated for teachers training in special education. However, there were no funds made available specifically for children with special needs in regular schools. The government only provides a subsidy for each primary school. It is at the discretion of the Board of Management of each school to provide support for children with special needs in the school (Mapea, 2006; Rombo, 2007).

\section{Summary}

The literature reviewed included two mains sections. The first section included a definition of inclusive education, a brief history of inclusive education, the shifting paradigms in special education and the policies that underpin inclusive education. The second section presented the issues pertaining to implementation of inclusive education policy. This includes attitudes, and the factors that influence attitudes, teacher preparation, effective teaching and learning strategies involved in effective implementation of inclusive education policy, leadership, policy and funding, and use of assessment and curriculum when implementing inclusive education policy.

According to the literature, inclusive education has been defined and interpreted by various reviewers differently because these issues are complex in both theory and practice. Inclusive education has been influenced by history, time and place together with disability discourses. The literature further suggests that different school and teacher related practices such as policy, curriculum, assessment, knowledge and experience combine to influence the implementation of inclusive policy. In PNG, 
inclusive education is supported by the United Nations and its associated policy frameworks. Given a detailed description of what the literature states about the implementation of inclusive education, this study attempted to achieve one primary aim. It was to investigate how effective the implementation of the inclusive education policy was in a school in Southern Highlands Province of Papua New Guinea. Having in mind this research aim, the next chapter describes the research methodology used in the study. 


\section{Chapter Three: Research Methodology}

\section{Chapter overview}

This chapter presents the research methodology used in this study. Firstly, a brief description of the researcher's views on the effective implementation of inclusive education policy is presented. Secondly, the research methodology that guided the study is presented. It includes the description of the qualitative research method and the case study approach. This is followed by a description of the questionnaire, interview process and document review method. An explanation of the selection of the research participants, setting and plan of the data analysis is also presented in this section. The chapter concludes with an explanation of the research's validity and trust-worthiness, and the ethical considerations that guided this study.

\section{Section One: The Researcher}

This is a qualitative study and it is important to establish the researchers' views towards inclusion. My position is as follows. The inclusive education policy has been adopted into the education policy of many countries. Inclusive education brings together children of 'all' abilities, ethnic groups, gender, age and social status to be educated in regular classrooms/school environments. It is a learning environment that provides access, accommodation and support to all learners. I support this approach as I believe it to be morally right for all children to be given the recognition that they all can learn and achieve their potential abilities regardless of their disabilities.

However, the effectiveness of the inclusive education policy implementation differs from country to country, school to school or teacher to teacher. For effective implementation, we need to develop positive attitudes towards children with disabilities and inclusive education approaches. This is because difficulties in learning and 
participation that the children experience should be seen as external rather than internal (Moore, et al., 1999). Positive attitudes make other requirements possible. This means that when we are positive towards inclusion, we will pursue further training in order to be equipped with the necessary skills and knowledge, seek funds to upgrade facilities in the school, carry out awareness in inclusion and children with disabilities, and create an appropriate learning environment that accommodates the learning needs of all students. Thus, the next section presents the methodology that the study employed to gather the data that revealed how inclusive education policy was implemented.

\section{Section Two: Methodology}

\section{Introduction}

This study was a qualitative study using a case study approach. The qualitative methodology was used in order to gain in-depth information from the single case (one school). The data was gathered through individual and focus group interviews and document analysis. The sample size of the study was 20 teachers in one primary school in the SHP of PNG.

\section{Qualitative research}

Creswell (2003) defines qualitative research as an enquiry useful for exploring and understanding a central phenomenon. The phenomenon in this study is the inclusive education practice within the target school. To know more about this phenomenon, the researcher asked the teachers both broad and specific questions in order to understand their personal views and experiences. From the data, the researcher interpreted the meaning of the information by drawing on personal reflection and past research. 
Furthermore, Best and Kahn (1998) emphasised that qualitative data are useful within the research setting because participants will freely express their thoughts, perceptions and experiences in more detail in relation to the research topic. For instance, since the study's primary focus is on teachers' perceptions on inclusive education practices, research participants (teachers) have expressed their personal reflections in relation to how they experience or view the said topic. Thus, in order to obtain in-depth information on the research topic, the study incorporated some of the basic characteristics of a qualitative research paradigm. These include conducting fieldwork, where the researcher has to physically visit the selected site and research participants in order to conduct the interviews in the interviewees' natural setting (Johnson \& Christensen, 2008). In this study, the researcher visited the selected primary school to conduct the fieldwork. Secondly, data collected are made in-depth by placing emphasis on the researcher's understanding of the subjects' point of view and his or her interaction with the studied group (Bogdan \& Biklen (2007). One way that is possible to obtain in-depth data is using a case study approach. Hence, the researcher had investigated the teachers' perceptions on inclusive education via a case study approach. Essentially, it was a study with a phenomenological orientation, because much of the data were descriptions of the participants' perceptions.

\section{Case study}

A case study is an empirical inquiry that investigates in depth a contemporary phenomenon within its real life context, especially when the boundaries between phenomenon and context are not evident (Yin, 2003). It is a detailed examination of one setting, a single subject, a single depository of documents, or one particular event (Bodgan \& Biklen, 2007). The phenomenon under study here is teachers' perception on inclusive education in a regular school. I have chosen to use a form of case study known 
as single-case study (Yin, 2003). Its intent is to understand a single case by describing in-depth the particulars of the case (in this case, one school) (Johnson \& Christensen, 2008). This type of case study assists the researcher to learn more about a little-known phenomenon because all of the researchers' time and resources are put into gaining an in-depth understanding of the case. Furthermore, the above authors claim that a case study is defined as a bounded system so it is better to study how the system operates. A bounded system is made up of components. This study had carefully examined some of the parts of the bounded system (i.e., the school) such as attitudes, policies, training, funding and school organisation. Therefore, some of the important information that I might not be able to access during other times was obtained in this study from the indepth interviews.

However, a case study is not easy to undertake, as one can imagine (Johnson \& Christensen, 2008, Anderson, 1990). It involves good listening, questioning and observation skills with an unbiased mind. Furthermore, some information can be missed in a single case, so generalising can be very risky.

\section{Research setting}

This study was undertaken in one urban primary school in the Southern Highlands Province (SHP) of Papua New Guinea. This school was selected because it was one of the biggest schools in the province and also was located in the major town of the region. The school had children from all over the country. The student enrolment was an estimated 350 students. This figure includes those students who were currently in the school and those that had left schooling during the year as well. About $75 \%$ of the students were boys and 25\% girls. Children aged between 6 and 13 years attend the school. The school had four classes of each school grade (24 classes altogether) and each class role size was about $20-25$ children. There were twenty-five teachers (12 
female and 13 male) at the school. There was one head teacher, who was a non-teaching staff member, one deputy head teacher, two senior subject coordinators, five senior teachers and sixteen classroom teachers. English was used as the official language for teaching and communication.

\section{Research participants}

All teachers in the selected school were invited to participate in the study. These teachers either had a certificate or diploma in teaching primary and only a few had a Bachelor's in Education. The rational for this choice was to involve as many teachers as possible, which would allow comparisons between their views and experiences to be made in order to identify similarities and differences. However, five teachers decided not to participate. Therefore, only twenty teachers participated in the study. The composition of the participants were: one head teacher, one deputy head teacher and two senior subject teachers participated in the individual interview; eight selected classroom teachers participated in the focus group interview; and all twenty teachers completed the questionnaire. The focus group members were selected based on their experiences of teaching children with disabilities, training received in inclusive education, and their interest in inclusive education and children with disabilities. This group was purposely selected because they had positive views towards inclusive education policy and practice.

The demographic information below in Table 1 presents details about the teachers who participated in the study. 
Table 1: Demographic information for the study (see appendix A)

\begin{tabular}{|c|c|c|c|c|c|}
\hline Teachers & Gender & Qualification & $\begin{array}{c}\text { Yrs } \\
\text { teaching }\end{array}$ & $\begin{array}{c}\text { Grade } \\
\text { Teaching }\end{array}$ & $\begin{array}{c}\text { Training } \\
\text { in } \\
\text { Inclusion }\end{array}$ \\
\hline $\mathrm{H} / \mathrm{T}$ & $M$ & T/Certificate & 28 & $4 \mathrm{~A}(9$ yrs olds $)$ & Yes \\
\hline $\mathrm{D} / \mathrm{HT}$ & M & T/Certificate & 32 & $5 \mathrm{~A}(10 \mathrm{yrs}$ old $)$ & No \\
\hline S/ST-1 & $\mathrm{F}$ & T/Certificate & 28 & $3 \mathrm{~A}(8 \mathrm{yrs}$ old $)$ & No \\
\hline S/ST-2 & $\mathrm{M}$ & T/Diploma & 26 & $6 \mathrm{C}(11 \mathrm{yrs}$ old $)$ & Yes \\
\hline $\mathrm{S} / \mathrm{T}-1$ & $\mathrm{M}$ & BE/Degree & 22 & $8 \mathrm{~A}(13 \mathrm{yrs}$ old $)$ & Yes \\
\hline $\mathrm{S} / \mathrm{T}-2$ & $\mathrm{~F}$ & T/Certificate & 19 & 7D(12yrs olds & No \\
\hline $\mathrm{S} / \mathrm{T}-3$ & $M$ & T/Certificate & 26 & 7A(12 yr old $)$ & No \\
\hline $\mathrm{S} / \mathrm{T}-4$ & $\mathrm{M}$ & T/Certificate & 22 & $3 \mathrm{C}(8 \mathrm{yrs}$ old $)$ & No \\
\hline $\mathrm{S} / \mathrm{T}-5$ & $\mathrm{M}$ & T/Certificate & 18 & $5 \mathrm{D}(10 \mathrm{yrs}$ old $)$ & Yes \\
\hline $\mathrm{T}-1$ & M & T/Diploma & 10 & $7 \mathrm{C}(12 \mathrm{yrs}$ old $)$ & No \\
\hline $\mathrm{T}-2$ & $\mathrm{~F}$ & T/Certificate & 18 & 8B(13yrs old $)$ & No \\
\hline $\mathrm{T}-3$ & $\mathrm{M}$ & T/Certificate & 29 & $6 \mathrm{~B}(11 \mathrm{yrs}$ old $)$ & No \\
\hline $\mathrm{T}-4$ & $\mathrm{M}$ & T/Diploma & 4 & $8 \mathrm{D}(9$ yrs old $)$ & Yes \\
\hline $\mathrm{T}-5$ & $\mathrm{~F}$ & T/Certificate & 31 & $5 \mathrm{~B}(10 \mathrm{yrs}$ old $)$ & No \\
\hline $\mathrm{T}-6$ & $\mathrm{~F}$ & T/Certificate & 29 & 4D(9 yrs old $)$ & No \\
\hline $\mathrm{T}-7$ & $M$ & T/Certificate & 23 & $4 \mathrm{C}(9$ yrs old $)$ & No \\
\hline $\mathrm{T}-8$ & $\mathrm{~F}$ & T/Diploma & 3 & $7 \mathrm{~B}(12 \mathrm{yrs}$ old $)$ & Yes \\
\hline $\mathrm{T}-9$ & $\mathrm{M}$ & T/Certificate & 20 & $5 \mathrm{C}(10 \mathrm{yrs}$ old $)$ & No \\
\hline $\mathrm{T}-10$ & $\mathrm{~F}$ & T/Certificate & 26 & 4B(9 yrs old $)$ & No \\
\hline $\mathrm{T}-11$ & $\mathrm{M}$ & T/Certificate & 17 & 6D(11yrs old) & No \\
\hline
\end{tabular}

\section{Methods of data collection and analysis}

Methods of data collection are techniques for physically obtaining data to be analysed in a research study (Johnson \& Christensen, 2008). Bouma (1996) asserts that it is better to use several data gathering methods to answer a research question because this increases the depth and quality of information. Thus, this research employed a questionnaire, interviews and document analysis in order to gather the data. 


\section{Interview}

Interviewing is a specified form of communication between people for a specific purpose associated with some agreed subject matter. Therefore, the interview is a highly purposeful task that goes beyond ordinary conversation and involves several approaches (Anderson \& Aresnault, 1998).

This study used a type of interview called the interview guide approach or semistructured open-ended interview. In an interview guide approach, topics and issues to be covered are specified in advance in outline form, and the interviewer decides sequence and wordings (Johnson \& Christensen, 2008). It is flexible (can be asked in any sequence) and situational (wordings can be changed to suit the situation). However, it is argued that interview flexibility in sequencing and wording questions can result in different responses, therefore reducing the comparability of responses (Fraenkel \& Wallen, 2006).

The interviewees were asked the pre-established questions and more follow up questions were then asked to solicit more information on what they were saying. The head teacher and deputy were interviewed about administrative issues while the senior teachers were interviewed on supervisory issues. All the interviews (60 minutes each) were undertaken individually and face-to-face in an office setting. They were released from teaching responsibilities to take part in the interview. The interview questions were written in English because the participants' official language of communication used in the workplace is English. However, further clarification and explanations were done in PNG Tok Pisin and were audio taped. Brief notes were also taken and all information provided is kept confidential. 


\section{Focus group}

A focus group is a type of group interview in which a moderator leads discussion with a small group of individuals to examine in detail how the group members feel and think about a topic (Johnson \& Christensen, 2008). A focus group usually involves 8 to 12 individuals who discuss a particular topic under the direction of a moderator, who promotes interaction and ensures that the discussion remains on the topic of interest and creates a non-threatening and non-evaluative environment (Stewart \& Shamdasani, 1990). As the moderator, I used the beginning part of the discussion to provide information about the topic and the rules that would guide us to create a comfortable atmosphere. For example, they were informed earlier that information provided by the focus group members would not be disclosed to anyone, real names would not be mentioned in the report and all information would be kept confidential. There were six participants in the focus group and it took about 80 minutes. I asked the school administration to release these teachers from teaching responsibilities for the 80 -minute interview. All discussions that came out of the focus group were audio recorded and were transcribed by the researcher after the discussion. The focus group members had agreed to be audio recorded. The language of communication used was a mixture of English and PNG Tok Pisin. The collective views from all the focus group members were summarised and put into points on the blackboard in the room, which are then used as 'views from the focus group' in the findings.

\section{Data analysis of interview and focus group}

Interviews were transcribed, read through and printed copies were delivered to the participants for their feedback. The feedback transcripts were then collected and the Tok Pisin transcripts were translated into English. The priori coding system is used here for 
coding. Segment of data that fitted the codes were identified and new codes were generated if some did not fit. The coded items were then categorised and put into themes, which are used in the final analysis.

\section{Questionnaire}

A questionnaire is qualitative in nature. It is a self-reporting data collection instrument filled out by research participants. Johnson and Christensen (2008) pointed out that questionnaires obtain detailed information about the participants. There were three parts to the questionnaire (see appendix A). In the first part there are ten open-ended questions. The information gathered from these items was used to select the focus group members. The next section of the questionnaire was a Likert scale with a choice of five options for each of the ten items. The final section had three open-ended items. After two days the researcher collected the questionnaires and all information provided was kept confidential.

\section{Questionnaire data analysis}

The responses from the first section of the questionnaires were used to select the focus group members. The qualitative responses from the section were analysed using descriptive statistics and the third section reported by narrating teachers' views.

\section{Documentary evidence}

The most important use of documents in a case study is to confirm and supplement evidence from other sources (Yin, 2003). The strengths of documentary evidence are that they can be reviewed repeatedly, are not generated by the case study and are exact. The above author further states that, their weaknesses are that they can be difficult to find, can be bias reporting and access to them may be intentionally withheld. The researcher intended to review copies of two daily teaching day books (one lower and 
one upper) from two teachers, four curriculum documents (math \& personal development), and overall school assessment reports and policies. These documents were obtained from the head teachers' office and from relevant individuals. The daily programme books were reviewed to see how the lessons were planned to provide equal opportunities for children with special needs and curriculum documents were reviewed to see if the teaching topics, aims, objectives and lessons were inclusive. The overall school assessment reports and policies were reviewed to see how they organise them to cater for children with special needs. This was done during the two weeks on site.

\section{Data analysis of documents}

Document analysis are not systematically analysed but are drawn upon to add rich description to the analysed findings. For instance, the programme books of the class teacher were utilised to check upon the validity of the report. Pseudonyms were used for the document owners.

\section{Overall data analysis}

Data analysis is a process of systematically searching, arranging and creating meaning from raw data (Johnson \& Christensen, 2008). It requires coding and searching for relationships and patterns until a holistic picture emerges (Biklen \& Bogdan, 2007). A coding system referred as priori codes were used here, which were developed before actually examining the data (Johnson \& Christensen, 2008). These codes were associated to the research objectives for the study. It was a deductive analysis based on the research questions, key themes from the data and the experiences of the researcher. The steps that were followed were borrowed from the model of Creswell (2003). 
Step 1:

Organisation and preparation of raw data. The raw data were transcribed, typed and sorted into different groups depending on the source of information. For example, transcribing of interviews. Some of the respondent's feedbacks were in PNG Tok Pisin so they were translated into English by the researcher.

Step 2:

Read through all the data in order to gain a general sense of the ideas that the participants were expressing.

Step 3:

Begin a detailed analysis with a coding process. In this study, priori codes were used and these were developed in line with the research questions and key issues on inclusive education. When data segments did not fit new codes were generated. Different sources of data were written and coded separately before coding across all data. Then the codes were sorted to fit in the priori codes.

Step 4:

Provide a detailed description of the setting using the coding process. Here detailed information on what the participants said in relation to the codes were described. The codes were then put into categories or themes that appear as major headings in the findings.

Step 5:

Interpretation of the data. This is the final step, which involves interpreting the raw data and makes it meaningful. This involved using my own experience and comparing the findings with available literature, previous research and suggestions for further inquiry 


\section{Research validity and trustworthiness}

With regard to issues relating to trustworthiness, Guba's model for evaluating research was used (Krefting, 1991).

Credibility: the degree to which a researcher is justified in making certain claims. This study addressed this by data triangulation (used multiple data sources and data collection methods), member checking (gave transcripts to participants to confirm), and reflexivity (awareness and critical self-reflection on my own potential biases).

Transferability: generalising from a set of research finding to other people, settings, times, treatment and outcomes. This research's findings may not be applicable to making generalisations because of the single case study. However, its findings may inform the practices in similar setting because dense information was gathered through data triangulation (used multiple data) and also rich descriptions were provided for the research setting and participants.

Dependability: refers to the consistency of the measurement and the extent to which the results are similar over different forms of the same instrument or occasions. This study addressed this by data triangulation (used multiple data) and peer examination (discussed interpretation with other people, e.g., supervisor).

Confirmability; refers to how neutral the researcher is to avoid bias. I have encountered this by reflexivity (ruled-out all my prejudices and employed critical self-reflection on my own potential bias), and triangulation of data (used multiple data collection methods and data source). 


\section{Ethical procedure}

This study involved humans and therefore ethical approvals were sought through the organisation and individuals involved in the study. Firstly, ethical approval for the research was sought through the Human Ethics Committee of the Faculty of Education at Victoria University in order to comply with Victoria University's ethical guidelines. The Human Ethics Committee of the Faculty of Education at Victoria University approved the application. Secondly, a similar ethical application was submitted to the National Research Committee based in Port Moresby in PNG to conduct research in the country. The application was approved and signed by the director of research committee.

This study involved humans and therefore ethical approvals were sought through the organisation and individuals involved in the study. Firstly, ethical approval for the research was sought through the Human Ethics Committee of the Faculty of Education at Victoria University in order to comply with Victoria University's ethical guidelines. The Human Ethics Committee of the Faculty of Education at Victoria University approved the application (see appendix E)

Secondly, a similar ethical application was submitted to the National Research Committee based in Port Moresby in PNG to conduct research in the country. The application was approved and signed by the director of research committee (see appendix, F). Thirdly, another ethical application form was given in to the Chairperson of Provincial Education Board in Mendi, SHP to undertake the study in the schools in the province. The letter was approved and signed by the Chairperson of the Provincial Education Board in Mendi. He authorised me to enter schools in the province and invite teachers to participate in the research. Once, these approvals were granted, a letter of invitation was sent to a Head teacher of a school to seek permission to undertake the study in his school. This head teacher accepted the invitation to involve his school in the 
study. After the head teacher's permission was gained, all teachers in the school were invited to participate in the study. The school had 25 teaching staff so all teachers were given an invitation letter (see appendix I) to participate in the study. All teachers agreed to participate in the study so they were informed that their participation was voluntary. The consent forms (see appendix $\mathrm{J}$ ) were signed to confirm their agreement to participate in the study.

After all permissions were granted, the data collection began. The first visit at the school was to meet with the head teacher and other teachers to discuss about the research project in general. These included discussions about the purpose, participants' roles, ethical issues and methods of data collection.

Freedom to withdraw: participants were informed that they could withdraw before the third week of the data collection.

Confidentiality: participants were assured that all information they provided would remain confidential and will not be disclosed to any one in any manner except for in this study. All data collected will be stored in a secure place and destroyed after the study is completed.

Anonymity: maintaining anonymity for the participants was challenging here because the rest of the school community knew the participants. However, every step was taken to ensure that their identities were not publicly revealed and pseudonyms were used instead of real names.

Participants' safety: as much as possible, I ensured that the participants were not subjected to any physical, mental or emotional harm. 


\section{Problems encountered while collecting the data}

During the research fieldwork, I encountered a number of problems. Firstly, the Chairperson of the National Research Committee in Port Moresby was not in his office to endorse the application. Therefore I extended my stay in Port Moresby for several days while waiting for the application to be approved. Secondly, the participating school was closed for the first few days that were scheduled for delivering the questionnaires. However, I managed to get to the teachers as soon as they resumed duties. The questionnaires were delivered and collected. Thirdly, some teachers did not return the questionnaires to the researcher as scheduled. Two teachers handed their responses in late while five others teachers did not hand one in at all. I was told that these teachers were attending training in the provincial headquarters. Despite these obstacles, I managed to collect most of the data as scheduled.

\section{Summary}

The approaches used for this research were outlined in this chapter. This was a qualitative study, which involved the use of questionnaires, interviews and document reviews. There were twenty five (25) participants from one school in the Southern Highlands Province. Ethical approvals were sought from the relevant research participants and organisations before the actual research was undertaken. The confidentiality of the participants was maintained throughout the research process and problems encountered during the research were also noted. 


\section{Chapter Four: Results}

\section{Introduction}

In this chapter the results of the study are presented. There were 25 teachers invited to participate in the study. However, five (5) participants did not return the questionnaire, so only responses from twenty (20) participants are analysed. Of the twenty respondents, four senior teachers were interviewed individually, six classroom teachers took part in a focus group interview, and the rest completed a questionnaire. Hence, data were gathered through questionnaires, interviews and document review, although the information gathered from the document review was not formally analysed. The results are reported by major themes and sub-themes that emerged from the pre-established codes in data analysis. These are used as headings. Firstly, the teachers' knowledge and understanding of inclusive education and inclusive policy are provided. Secondly, the teachers' knowledge and understanding of the strategies involved when implementing inclusive education policy are presented. Finally, teachers' knowledge and understanding of some important issues pertaining to effective inclusion are provided.

\section{Theme 1: Teachers' attitudes, knowledge and understanding of inclusive education and inclusive policy}

The teachers' attitudes, knowledge and understanding of inclusive education were investigated to see how they perceived inclusive education. It was important for the researcher to know how they understood inclusive education and the inclusive education policy because their understanding determined the nurturing of inclusive education practices in their school.

Whilst the understanding of inclusive education definition, policy and practice was quite varied, many teachers had heard about inclusive education, either through professional development, further studies or from their own teaching experiences. 
There was no direct question about the definition of inclusive education in the questionnaire. However, responses from the questionnaire items which were related to teachers' knowledge and understanding of inclusive education and the inclusive policy were categorised under this theme and are summarised in the following tables.

Table 2: Q1: Inclusive education means all children learning together in one classroom/school.

\begin{tabular}{|c|c|c|c|c|c|c|c|c|c|}
\hline $\begin{array}{c}\text { Strongly } \\
\text { Disagree }\end{array}$ & $\%$ & Disagree & $\%$ & Neutral & $\%$ & Agree & $\%$ & $\begin{array}{c}\text { Strongly } \\
\text { Agree }\end{array}$ & $\%$ \\
\hline & & 5 & 25 & & & & & 15 & 75 \\
\hline
\end{tabular}

The majority (75\%) of teachers believed inclusive education was all children learning together in one school while some $(25 \%)$ of the teachers did not. According to the interview data, the teachers' understanding of inclusive education also varied. Some teachers who have received some form of training in inclusive education responded more positively. When they were asked to define inclusive education, they expressed clearly what constitutes inclusive education. Here are two examples of respondents' views:

I agree that inclusive education is the practice of including every children, whether they have some disabilities or not, together in one school or classroom. The teachers' responsibility is to plan and prepare learning activities that benefit every child. Inclusive education also requires schools and teachers to be nondiscriminative and non-biased in enrolling new children and treat all as equal. (Interview)

To my understanding and from what I have heard from the school primary inspector and from some training that I got, inclusive education is something to do with children with special educational needs. This includes those who are 
handicapped and those that do not learn properly in class. It is about including all those children in the normal school/classrooms and teachers providing assistance for them to learn effectively in the classroom/school. (Interview)

However, the teachers who did not receive any training in inclusive education responded less positively. They suggested that education for children with disabilities should be provided in a separate school. Their lacking of essential skills and knowledge in implementing inclusive education programmes at the school was one of the reasons they provided for this judgement. One of the interviewees stated:

I have heard about inclusive education but to be honest I think I will not implement it because I did not receive any training in inclusive education. (Interview)

Another teacher thought that 'inclusive education' was same as 'special education'. He mentioned:

I am still confused with inclusive education and special education. I was introduced to special education when I went to in-service college in 1999. It was about the education provided to handicapped children in the special education centres. Nowadays I hear teachers talking about inclusive education but I know nothing about inclusive education. (Interview)

The focus group members were made up of teachers who were familiar with children with disabilities and inclusive education, so they responded more positively and recommend inclusive education as best practice. When the group was asked to define inclusive education, they explained the same basic concept in many ways. The following statement summarises the views they expressed: 
Inclusive education talks about the education provided to children with disabilities and other disadvantaged students in a normal school. They are taught together with the other students by one teacher using the same curriculum; however, modifications are made according to the individual needs of the students. (Focus group)

The teachers were further asked to explain their understanding of the term 'children with disabilities' and their responses were also diverse. The teachers who had received some training in inclusive education viewed children with disabilities as children with some form of barrier to learning and participation in the school/classroom. Here are two examples of these responses:

'Children with disabilities' refer to any child in the class that does not perform well in school due to some problem. This includes handicapped children, slow learners, children from our warring tribes, and all other disadvantaged children. (Interview)

Children with disabilities does not refer to physically handicapped children only, it includes all the children in the school or classroom whose learning opportunities is minimised by certain situation. For example in our case we can include the girls because they are always shy and do not participate much in class, especially in open discussions. (Focus group)

However, the teachers who had not received any training in inclusive education stated:

Children with disabilities are the handicapped children who cannot talk, walk, see or do things by themselves. They are taught by specially trained teachers at special schools. (Interview)

In view of the above responses, teachers were asked to talk about their attitude towards inclusive education and children with disabilities. The data indicated that those teachers who had experiences of children with disabilities through teaching or had relatives with 
disabilities were more positive than those who had no experiences. Below is an example of a respondent's view:

To be honest, I did not like teaching children with disabilities, especially those with obvious physical disabilities. However, my attitude changed when my daughter became deaf after a long illness. I like the inclusive education policy because my daughter can get the same education as the other normal children. (Interview)

One of the focus group members stated:

I was confused about inclusive education, I thought that it was about including children with obvious physical disabilities only but it is not. It is also about recognising and providing appropriate and equal learning opportunities for those that are marginalised and ignored in class like the slow learners. I like the inclusive education policy because it is also about networking with parents and other teachers too. When I need to know something about a student, I consult the parents. (Focus group)

The teachers who had no experiences of inclusive education or children with disabilities stated:

I do not like having children with disabilities in my class and I do not think others like it too. (Interview)

The data indicated that teachers who received training in inclusive education and those who had experience interacting with someone with disabilities believed that all children are capable of learning together in one school. The others who received no training in inclusive education believed that children with disabilities should be educated in a separate school. 
However, the data from the document analysis revealed that the school as a whole were more positive towards inclusive education. The school had a draft policy in inclusive education that supported the children with special needs at the school.

Table 3: Q2: Every child regardless of the disability has the right to a formal education at a regular school.

\begin{tabular}{|l|l|l|l|l|l|l|l|l|l|}
\hline $\begin{array}{l}\text { Strongly } \\
\text { Disagree }\end{array}$ & $\%$ & Disagree & $\%$ & Neutral & $\boldsymbol{\%}$ & Agree & $\boldsymbol{\%}$ & $\begin{array}{l}\text { Strongly } \\
\text { Agree }\end{array}$ & $\%$ \\
\hline & & 6 & 30 & 2 & 10 & 10 & 50 & 2 & 10 \\
\hline
\end{tabular}

The questionnaire data show that more than half $(60 \%)$ of the teachers believed that every child has a right to formal education. However, some $(30 \%)$ of the teachers did not believe that children with disabilities had a right to formal education while some $(10 \%)$ of the teachers were undecided.

The data from the individual interviews was also diverse. Some teachers who were familiar with inclusive education policy mentioned that formal education was a right for all children. This is illustrated in the following words of the respondents:

The Philosophy of Education in Papua New Guinea strongly emphasises that every child has the right to formal education so we teachers should not be neglecting children whether they are disabled or not but accept them and teach them. (Interview)

Yes, I know that education is a right for every student whether disabled or not so I tell the teachers not to reject the children who are found to be having some form of disabilities or causing any problems at school. I also tell the parents that education is a right for all children so they have to encourage their children to come to school. (Interview) 
One of the interviewees responded that parents never recognised the children's right to education. He mentioned that:

I know that education is a right for every child; the parents also have to know this because I see most school-age children still hanging around in the villages (Interview)

The participants in the focus group also provided supportive comments. The following statement summarises the collective views:

Every child has a right to be educated therefore; children with disabilities, children from our warring tribes, or others that have migrated to our villages should be included and accepted by teachers (Focus group)

While the majority of the teachers supported the view that all children regardless of disabilities should have admission to formal education in a regular school setting, some did not like the idea. They argued that some students with disabilities presented many problems for teachers. For example, one of the focus group members stated:

The children with severe disabilities, especially physically handicapped children and children with behavioural disorders should be taught separately because they require specially trained teachers and specially designed resources. (Focus group)

It appears that teachers were aware of education as a right for every child; however, some argued that children with severe disabilities could be problematic for the teachers at the regular school.

The data from the document analysis revealed that education was seen as a right for all children. For example, a statement in the teachers guide pointed out that every child has the right to be taught the content of this document with respect and pride. 
Table 4: Q3: All regular schools in PNG enrol children with disabilities.

\begin{tabular}{|c|c|c|c|c|c|c|c|c|c|}
\hline $\begin{array}{c}\text { Strongly } \\
\text { Disagree }\end{array}$ & $\%$ & Disagree & $\boldsymbol{\%}$ & Neutral & $\boldsymbol{\%}$ & Agree & $\boldsymbol{\%}$ & $\begin{array}{c}\text { Strongly } \\
\text { Agree }\end{array}$ & $\%$ \\
\hline 15 & 75 & 3 & 15 & & & 2 & 10 & & \\
\hline
\end{tabular}

The responses to this item showed that most (90\%) of the teachers felt that all the regular schools in the country were not enrolling children with disabilities while some (10\%) agreed that all regular schools did enrol children with disabilities. From the interview data, it was seen that the teachers' responses varied. The teachers who viewed children with disabilities as being children with severe physical disabilities mentioned that regular schools were not enrolling children with disabilities. The following are some of the teachers' responses:

I think most schools do not enrol children with disabilities because the teachers do not have the specific knowledge and skills... especially to teach children who are blind. (Interview)

School facilities and resources should be upgraded and teachers should be trained to teach children with disabilities if regular schools are to enrol children with disabilities (Interview)

I think only a few schools in the towns and cities enrol children with disabilities where they have right facilities for them to use. We know that these children are to be accepted by teachers and schools; however, some of the schools do not enrol them because they do not have the facilities. (Interview)

The focus group members pointed out that schools enrol children with disabilities unintentionally, though children with obvious physical impairments are not considered. Their collective views are summarised as follows: 
From our point of view, we think that children with obvious physical disabilities may be not enrolled in most of the regular schools but children with unnoticed impairments are enrolled in regular schools. Teachers realised their disabilities once they are already part of the school community. This is actually what happens in our school. (Focus group)

The teachers who viewed children with disabilities as any student with special educational needs supported the statement. They mentioned that children with disabilities are already part of the school community. One of the teachers stated:

I think children with disabilities are already part of the school community because we have children who require inclusive education programmes at our school. (Interview)

The data from the document analysis indicated that the school was enrolling children with disabilities. This was evident in a report that the head teacher provided where he had list of children with disabilities in the school.

Table 5: Q4: All regular teachers in PNG are fully trained to teach children with disabilities.

\begin{tabular}{|c|c|c|c|c|c|c|c|c|c|}
\hline $\begin{array}{c}\text { Strongly } \\
\text { Disagree }\end{array}$ & $\%$ & Disagree & $\%$ & Neutral & $\%$ & Agree & $\%$ & $\begin{array}{c}\text { Strongly } \\
\text { Agree }\end{array}$ & $\%$ \\
\hline 15 & 75 & 5 & 25 & & & & & & \\
\hline
\end{tabular}

All $(100 \%)$ of the teachers felt that regular teachers were not fully trained to teach children with disabilities. This was also evident in the interview data. Most of the interviewees commented that the training they got in inclusive education was insufficient. Diploma and degree holders appeared to have some knowledge of inclusive education; however, this was not always the case. A teacher with a bachelor's degree made the following comments when interviewed: 
I got two papers in inclusive education when I was doing my studies at University of Goroka. However, the lecturer who was taking the course did not know some of the things like sign language so he brought a community rehabilitation officer to teach us. This fellow he brought was not a teacher so he was struggling to teach us even though he had the content knowledge. Therefore, we were not taught properly some of the skills. When the head teacher asked me to in-service the teachers here, I told him that I learnt nothing at the University. (Interview)

The other interview data indicated that some teachers were trained in inclusive education; however, much of the emphasis was on theory. This was stressed in the comments of the following respondents:

We were in-serviced on some of the issues in inclusive education but we did not do any practical exercise so I forgot most of the things I learnt. Even I was telling the teachers here about some of the things we learnt but we were introduced to so many things one after the other so they took less interest in it. (Interview)

When this particular person was further asked to explain what he meant by 'some of the issues in inclusive education', this was his response:

I mean small things like changing of some words that we use in lesson plans and teaching programmes. For example, when writing objectives in teaching programmes and lesson plans we normally write, by the end of the lesson the children will be able to know/understand... However, when we were introduced to inclusive education, we were asked to use measurable words like, students will be able to 'name, say, write' instead of the commonly used words like 'know, understand'. (Interview)

The focus group discussion data also shows similar responses to the one above. One of the focus group members stated: 
The government should train the teachers properly before implementing so many policies. How are they expecting us to teach children with special needs, especially those with physical disabilities like deaf and blind children, when we are not trained properly? Maybe they are trying to get Foreign Aid and telling us to do so many things. (Focus group)

However, the data from the document analysis did not indicate any points about this issue.

Table 6: Q5: All regular schools should have policies that support children with disabilities.

\begin{tabular}{|c|c|c|c|c|c|c|c|c|c|}
\hline $\begin{array}{c}\text { Strongly } \\
\text { Disagree }\end{array}$ & $\%$ & Disagree & $\%$ & Neutral & $\%$ & Agree & $\%$ & $\begin{array}{c}\text { Strongly } \\
\text { Agree }\end{array}$ & $\%$ \\
\hline & & & & & & & & 20 & 100 \\
\hline
\end{tabular}

All the teachers strongly felt that regular schools should have polices to support inclusive education and children with disabilities. The interview data also showed that the majority of the teachers want schools to have policies supporting children with special needs. When they were asked if their school had written policies for inclusive education, two of the interviewees' answers were no while the other two mentioned that they were working on one. They pointed out that their school have some children with disabilities but they treat them as the other normal children. The following are some of the words of one such respondent:

I think by now all schools should have developed school policies in line with the National Special/Inclusive Education policy. In our school we have draft one towards the end of last year but this year I had plenty things to do so I left that aside but I see it is very important to have a policy. (Interview) 
When he was further asked when they would finalise the draft policy, he responded:

Sometime this year maybe in term three, I will just get a few teachers to help me finalise the draft policy. (Interview)

Another interviewee pointed out that there was a lack of communication between the policy makers and education officials on the one hand and the schools and teachers on the other. He stated:

The school inspectors always come here to judge us and tell us what to do. They do not even understand what they say. The national inclusive education policy is there but I do not think we got one established in our province and in the schools. They need to carry out awareness and show the teachers how to do it. To my understanding I think that, the education officials need to carry out more awareness and make it clear to every schools and teachers. When there is continuous awareness in all the schools will definitely develop inclusive policies. It is just like the elementary school system, they were talking about it over and over again and now it has happened. (Interview)

One other interviewee also agreed with schools having inclusive policies and further emphasised the importance of having an inclusive policy. He pointed out that having inclusive policy also helps them run the school well. He mentioned that:

It is very important to have an inclusive policy because when we make any decisions on issues concerning children with special needs, we have grounds to stand on. For example, in scenarios like parents of children without disabilities not wanting their children to be educated together with children with disabilities. They can be referred to the inclusive education policy in the school. It acts as a guide to make strong decisions concerning inclusive education practices. (Interview) 
The data from the focus group interview also revealed that teachers agreed for schools to have inclusive policies. A summary of their views:

The schools should have policies to support children with special needs because sometimes the special needs children's rights are not considered by the school. (Focus group)

When they were further asked to explain what made them to say that, one of the focus group members responded:

"The school never does some of the things we request. For example, repainting a blackboard in the classroom because some of the blackboard paints are worn out so children find difficulty reading from it." (Focus group)

The data from the document review revealed that the school had a draft inclusive policy that needed finalising.

\section{Theme 2: Teachers knowledge and understanding of strategies involved in inclusive education}

This section analyses the teachers' perceptions and experiences of the implementation of inclusive education policy in their regular school.

Table 7: Q6: Children with disabilities require extra time from the regular teacher.

\begin{tabular}{|c|c|c|c|c|c|c|c|c|c|}
\hline $\begin{array}{c}\text { Strongly } \\
\text { Disagree }\end{array}$ & $\%$ & Disagree & $\%$ & Neutral & $\boldsymbol{\%}$ & Agree & $\boldsymbol{\%}$ & $\begin{array}{c}\text { Strongly } \\
\text { Agree }\end{array}$ & $\%$ \\
\hline & & & & 2 & 10 & 10 & 50 & 8 & 40 \\
\hline
\end{tabular}

Of the twenty (20) teachers, the majority (90\%) felt that teaching children with disabilities required extra time for the teacher while some (10\%) were undecided. In the interviews the majority of the teachers pointed out that teaching a child with disabilities required a considerable amount of extra time because they do not learn at the same pace 
as their non-disabled peers. One of the interviewees mentioned that he spends nearly half of a lesson's time explaining and showing examples before he tells them to do the exercises that are prepared for them. Others mentioned that the teaching hours are not enough so they use their own time to work with children with disabilities. The following are the words of two respondents:

I use up all my official working hours in teaching and explaining over and over again and I see that I have no time to plan and prepare my teaching notes and activities so I normally do them in the night at home or after school when all the children are gone. (Interview)

I do not like to teach in a class where children with disabilities are found because I do not want to get annoyed for using my free time to work with such children. (Interview)

The focus group discussion data also indicated that children with disabilities require extra time from regular teachers. They mentioned that children with disabilities need extra time from the teacher because some children need one-to-one assistance from the teacher, while some others need modification to the learning materials in order to enhance their learning.

The data from the document review also revealed that teachers required extra time when implementing inclusive education policy. It was indicated that teachers were extending previous weeks' lessons to the current week to compensate. Some wrote comments like "not taught in the lesson evaluation section". 
Table 8: Q7: The inclusion of children with disabilities in regular schools is moving at a slow pace.

\begin{tabular}{|l|c|c|c|c|c|c|c|c|c|}
\hline $\begin{array}{l}\text { Strongly } \\
\text { Disagree }\end{array}$ & $\%$ & Disagree & $\%$ & Neutral & $\boldsymbol{\%}$ & Agree & $\boldsymbol{\%}$ & $\begin{array}{c}\text { Strongly } \\
\text { Agree }\end{array}$ & $\%$ \\
\hline & & & & & & 15 & 75 & 5 & 25 \\
\hline
\end{tabular}

The teachers strongly felt that the inclusion of children with disabilities in regular schools was not progressing as they thought it would be. This was made evident by $75 \%$ of teachers agreeing to the statement and the other $25 \%$ having strong agreement that the inclusion of children with disabilities in regular schools was slow. The interview data also showed that children with disabilities were considered minimally at the regular schools. One of the reasons teachers gave was that the schools were not fully equipped with resources that can accommodate the individual needs of children with disabilities. The others mentioned that the negative perceptions that people have about disability has also affected the enrolment of children with disabilities in regular schools. In the words of two respondents:

From my own view, I think regular schools were established to teach children who can learn and compete with the other children all over the country. The disabled children should have their own schools to compete like that with their own other disabled peers. (Interview)

Our school had a good number of children with disabilities but most left schooling because their parents did not like them to come to school and some teachers were not treating them properly too. (Interview)

The focus group members mentioned that there has to be more awareness among all stakeholders about the inclusive education policies. 
The data from the document review revealed that the enrolment rate of children with special needs was decreasing. This was evident by a drop in the enrolment figures of children with disabilities and other disadvantaged students.

Table 9: Q8: Regular school teachers need to be fully trained before enrolling children with disabilities.

\begin{tabular}{|l|c|l|l|l|l|l|l|c|c|}
\hline $\begin{array}{l}\text { Strongly } \\
\text { Disagree }\end{array}$ & $\%$ & Disagree & $\%$ & Neutral & $\%$ & Agree & $\boldsymbol{\%}$ & $\begin{array}{c}\text { Strongly } \\
\text { Agree }\end{array}$ & $\%$ \\
\hline & & & & & & 2 & 10 & 18 & 90 \\
\hline
\end{tabular}

The need for regular teachers to be fully trained was a concern for these teachers. All $(100 \%)$ the teachers who participated in the study believed that teachers needed to be fully trained before implementing inclusive education policy. The interviewees also supported this view. One of the interviewees responded that:

I think training our teachers about the importance of inclusive education and how to implement inclusive education should have been the first aim of the National Government or whoever is responsible because teachers are the key people. You policy makers will not come and teach in the classrooms. We have to know what to do before you tell us to do so many things. (Interview)

Another interviewee suggested that teacher-training institutions also have an important role to play in educating student teachers about inclusive education. He mentioned that:

Nowadays they say new teachers are coming out with some knowledge in inclusive education but I do not see any of the new teachers in our school implementing them. I am not really sure whether the teachers colleges are teaching inclusive education courses. (Interview) 
Another interviewee supported the statement and pointed out that training and funding for teachers for further training should be continuous. The focus group members emphasised that inclusive teaching requires teachers who are skilful and knowledgeable and mentioned that teachers need to widen their teaching knowledge and skills.

The data from the document reviewed also had implications for further training for teachers. One of the curriculum documents reviewed revealed that teachers need to widen their knowledge and skills because the content in that particular document was a set of instructions. The teachers were required to do a lot of research to gain more information on the content.

Table 10: Q9: Children with disabilities disrupt other students' learning.

\begin{tabular}{|c|c|c|c|c|c|c|c|c|c|}
\hline $\begin{array}{c}\text { Strongly } \\
\text { Disagree }\end{array}$ & $\%$ & Disagree & $\%$ & Neutral & $\%$ & Agree & $\%$ & $\begin{array}{c}\text { Strongly } \\
\text { Agree }\end{array}$ & $\%$ \\
\hline & & & & & & 14 & 70 & 6 & 30 \\
\hline
\end{tabular}

All $(100 \%)$ of the teachers agreed that children with disabilities disrupt other children's learning. The interview data also shows that teachers felt children with disabilities disrupt the pace of the lessons. One of the interviewees stated that:

I teach a topic or unit in a term and if the children with disabilities are not achieving to the goal than I re-teach the unit or topic again and this holds the flow of the lesson. (Interview)

When the teacher was further asked what he does with the upcoming unit or lesson, he mentioned that:

I ignore that and move to the new term's lessons or units, because I have to go by the school calendar. (Interview) 
The same view was shared by one of the senior teachers interviewed. She mentioned:

"children with disabilities drag the lessons especially the slow learners. They are slow in doing any exercises that are provided for them.” (Interview)

However, the focus group members came up with some ways of minimising the interruption caused by children with disabilities. They mentioned that activities and lessons could be modified according to the level of understanding of the children or enrichment and remedial work could be used.

The data from the document analysis revealed that some teachers indicated that some do lesson modification and remedial and enrichment work while some did none.

Table 11: Q10: Teachers have to use a separate curriculum to cater for children with disabilities.

\begin{tabular}{|c|c|c|c|c|c|c|c|c|c|}
\hline $\begin{array}{c}\text { Strongly } \\
\text { Disagree }\end{array}$ & $\boldsymbol{\%}$ & Disagree & $\boldsymbol{\%}$ & Neutral & $\boldsymbol{\%}$ & Agree & $\boldsymbol{\%}$ & $\begin{array}{c}\text { Strongly } \\
\text { Agree }\end{array}$ & \% \\
\hline 4 & 20 & 12 & 60 & & & 4 & 20 & & \\
\hline
\end{tabular}

The results from this item were mixed. When disagreed and strongly disagreed responses are compared with the agreed and strongly agreed responses, it shows that most $(80 \%)$ of teachers do not agree with using a separate curriculum for teaching children with disabilities. This was supported by the interview data. The teachers mentioned that lessons can be varied according to the needs and level of the children understanding but the curriculum has to be the same one. For example, a teacher pointed out that:

It's the same curriculum but I prepare extra work for those children who don't understand the topic I teach. For example, in a maths lesson I teach a topic like addition and if disabled children do not understand I prepare work according to their understanding. (Interview) 
The data from the focus group discussion indicated that teachers wanted only one curriculum for all students in the classroom. Their collective views are summarised:

We think there are not two curricula being used in any school. All the teachers use the official curriculum from the Department of Education to teach all children. Whether the child is clever or not clever, one curriculum is used to teach them all. (Focus group)

The researcher asked if those teachers using the one curriculum were preparing two different lessons for their children in the class. One teacher stated:

No I don't think the teachers are preparing two lessons. I teach everybody the same lesson together but when I see some children not doing well, I prepare remedial work for them. I also prepare enrichment work for children who do the work very quickly and disturb the others. (Interview)

The data from the document analysis revealed that teachers were using one curriculum. However, there was not much evidence of the lesson modification, enrichment and remedial work as mentioned verbally by teachers.

Table 12: Q11: Children with disabilities enjoy learning in a regular school if their individual needs are fully met.

\begin{tabular}{|c|c|c|c|c|c|c|c|c|c|}
\hline $\begin{array}{c}\text { Strongly } \\
\text { Disagree }\end{array}$ & $\%$ & Disagree & $\boldsymbol{\%}$ & Neutral & $\boldsymbol{\%}$ & Agree & $\boldsymbol{\%}$ & $\begin{array}{c}\text { Strongly } \\
\text { Agree }\end{array}$ & $\%$ \\
\hline & & 8 & 40 & 2 & 10 & 10 & 50 & & \\
\hline
\end{tabular}

Teachers had differing perceptions on children with disabilities learning in a regular school. Some (50\%) felt that children with disabilities enjoy learning in a regular school while others $(40 \%)$ felt that they do not enjoying learning in this environment. The 
interview data also indicated that teachers had differing viewpoints. The teachers who agreed with the statement felt that children with disabilities enjoy learning in a regular school. For example, a teacher pointed out that:

A child in my class always celebrated every attempted that he made to any activities that I have set for the all class to do. He thought that he can do the things that the non-disabled can do. I provided one-on-one assistance when he needed it. (Interview)

However, others felt that children with disabilities had negative self-worth and did not enjoy learning in a regular school because they see themselves as different from the others. One of the teachers mentioned that a visually impaired child in the school left schooling because he could not read and write.

The focus group members supported the statement and mentioned that children with disabilities grew academically and socially if their individual needs were met in the regular classroom.

The data from the document review indicated that enrolment figure of children with special needs has decreased. It was then identified that one of the reasons for these children leaving schooling was because they felt that their needs were not fully met.

Table 13: Q12: Teachers' workload is increased in an inclusive classroom.

\begin{tabular}{|c|c|c|c|c|c|c|c|c|c|}
\hline $\begin{array}{l}\text { Strongly } \\
\text { Disagree }\end{array}$ & $\%$ & Disagree & $\%$ & Neutral & $\%$ & Agree & $\%$ & $\begin{array}{c}\text { Strongly } \\
\text { Agree }\end{array}$ & $\%$ \\
\hline & & & & & & & & 20 & 100 \\
\hline
\end{tabular}

The questionnaire data shows that all $(100 \%)$ the teachers' believed that there was an increase in their workload. This was one of the major issues that most of the teachers talked about in the interviews. All the teachers in the study strongly felt that they were 
doing extra work and have seen an increase in their workload. About half of the interviewees had similar opinions. The following are some of the words of the respondents:

Yes, there is really a lot of workload. When I first did the course at the college, I was excited to implement it out in the schools but now I am teaching grade seven and eight students with 30 to 40 students and there is so much preparation, teaching and marking to be done. I quite honestly spend no time helping individual children with their academic problems. (Interview)

It's a lot of workload. I do admit that I sometimes give up and reject these children because there are more things to prepare in order to teach both the normal children and disabled children. Another thing is that we need some special teaching resources in order to help such children. (Interview)

When asked what types of special equipment he was referring to, he replied:

"equipment like photocopy machines, typewriters, and duplicating machines, where we can run remedial worksheets off for children. This will make our work easier in preparing work for disabled children."

The data from the focus group also showed that most of the teachers agreed with the statement. They mentioned that the existing teaching load and student-teacher ratio was too high for them. They suggested that the current teaching loads and student-teacher ratio should be reduced for teachers. However, from their experience, they identified some ways of minimising the burden of their workload. For example, below is a summary of the focus group members' views: 
Workload can be minimised by collaborating with teachers, school administrators, parents, special education teachers, teacher aids, health workers, school board members and other important resources in the community. We can also use cooperative teaching skills, where responsibility is shared with another teacher. (Focus group)

The data from the document analysis revealed that teachers had high work requirements. This was confirmed from the teachers guides reviewed, which indicated that teachers had to create their own specific teaching topics and lessons based on provided broad themes and units. This means teachers were required to develop their own teaching topic, lesson objectives, plan activities and prepare teaching aids/materials if any.

\section{Theme 3: Important issues pertaining to effective inclusion}

There were several important issues relating to effective inclusive practices raised by the teachers. The responses from the questionnaire items are summarised under each table. The data from the individual and focus group interviews and the document analysis that are similar to the responses from the questionnaire are also presented under each questionnaire response. The responses for other issues that do not fit to the questionnaire responses are presented separately.

Table 14: Q13: Professional development is important for regular teachers before teaching children with disabilities.

\begin{tabular}{|l|c|l|l|l|l|l|l|c|c|}
\hline $\begin{array}{c}\text { Strongly } \\
\text { Disagree }\end{array}$ & $\%$ & Disagree & $\%$ & Neutral & $\%$ & Agree & $\%$ & $\begin{array}{c}\text { Strongly } \\
\text { Agree }\end{array}$ & $\%$ \\
\hline & & & & & & & & 20 & 100 \\
\hline
\end{tabular}

All of the teachers strongly felt that regular teachers needed to get proper training in inclusive education before teaching children with disabilities. This was manifested by $100 \%$ of teachers strongly agreeing to the statement. This was also supported in comments offered by the majority of the teachers in the open-ended section of the 
questionnaire. The interview data also showed that teachers recognised the importance of professional development before teaching children with disabilities. They mentioned that they were influenced by the previous way of teaching children with disabilities, where specially trained teachers taught them. One of the interviewees responded that:

I think professional development for teachers is very important because some of us are still in the traditional way of teaching. I mean our old ways of teaching children. We know that children with disabilities were not included in our school; if this will change then we need training. (Interview)

Another interviewee mentioned that teachers previously trained were not introduced to inclusive education and children with disabilities, so they need proper training before teaching children with disabilities. When he was asked why he mentioned that, he responded that:

The teachers who graduated before the introduction of inclusive do not have any knowledge about inclusive education and children with difficulties. (Interview)

The teachers in the focus group also supported the assertion that professional development was important for teachers before teaching children with disabilities and suggested:

Funded training opportunities should be made available for existing teachers because some teachers do not like to take up training since they cannot fund it. (Focus group)

The focus group members also pointed out that through professional development training, teachers' attitudes are shaped. They mentioned: 
Our previous ways of thinking about inclusive education and children with disabilities have changed after going through several training sessions (Focus group).

The data from the document analysis also revealed that professional development for teachers was considered important in the school. It indicated that selected teachers attend workshops and in-service training in the main town. However, the criterion used to select the teachers was not stated clearly.

Table 15: Q14: The government should train more specialist teachers to assist teachers in the implementation of the inclusive education programmes.

\begin{tabular}{|l|c|l|l|l|l|l|l|c|c|}
\hline $\begin{array}{l}\text { Strongly } \\
\text { Disagree }\end{array}$ & $\%$ & Disagree & $\%$ & Neutral & $\%$ & Agree & \% & $\begin{array}{c}\text { Strongly } \\
\text { Agree }\end{array}$ & $\%$ \\
\hline & & & & & & & & 20 & 100 \\
\hline
\end{tabular}

All the teachers (100\%) strongly felt that the government should train more specialist teachers to support other teachers to implement inclusive programmes. The responses to the open-ended items on the questionnaire also supported the statement. Twenty five percent of the teachers mentioned that the government should train more specialists to work along with the teachers in implementing inclusive programmes in schools. The data from the interviews also indicates that all the interviewees supported that statement. They all agreed that some of the teachers did not know enough about disability types, so working together with some kind of specialist would be good.

One of the interviewees stated:

The government should have some trained specialist such as Braille translators who can go around the schools and assist the teachers. (Interview)

Another interviewee thought that having one specialist going around all schools could not work well. He wanted every school to have trained personnel each and said: 
The government should train at least one teacher from every school who can oversee the implementation of inclusive education programmes. (Interview)

The focus group data also supported the statement. They mentioned that the government should train specialists in all areas of disability. They stated: "If we are really going to implement the inclusive education policy, we need specialists teachers in all areas of disabilities". When they were further asked to explain what they meant by 'specialists in all areas of disabilities', one teacher stated:

We mean people who can teach us the different techniques used to assess and identify disabilities which are not noticeable like minor hearing problems and also how to use Braille and sign language. (Focus group)

They all agreed that some of the teachers do not know about some type of disability so it could be better for them to work together with specialists. This shows that these teachers really wanted to up-skill themselves in inclusive education.

The data from the document analysis revealed that teachers required specialist teachers to assist them. This can be for in-servicing them on some of the things that require special skills. For example, one of the documents reviewed had indicated that the teacher was using another child in the class to explain what was taught because he did not know how to use sign language.

Table 16: Q15: The National Government and the local level Government have to provide sufficient funds to the school for improving the school facilities (e.g., disability toilets, walkways) so that inclusive education policy can be successfully implemented.

\begin{tabular}{|c|c|c|c|c|c|c|c|c|c|}
\hline $\begin{array}{c}\text { Strongly } \\
\text { Disagree }\end{array}$ & $\%$ & Disagree & $\%$ & Neutral & $\%$ & Agree & $\%$ & $\begin{array}{c}\text { Strongly } \\
\text { Agree }\end{array}$ & $\%$ \\
\hline & & & & & & & & 20 & 100 \\
\hline
\end{tabular}


Teachers were asked to consider how the National and Local level Government should fund the schools to implement inclusive education programmes. The questionnaire data showed that all $(100 \%)$ of the teachers strongly felt that the government should fully support the implementation of inclusive education programmes. The responses to the open-ended question also maintained this. For instance, one of the respondents stated:

If I were the Minister of Finance and had a substantial amount of money, I could provide sufficient funds to schools so that necessary facilities and resources needed for effective implementation of inclusive education programmes can be upgraded and built. (Questionnaire)

The interview data also shows that teachers wanted the government to provide sufficient funds to schools to implement the inclusive education programmes. They mentioned that the government subsidy given once a year does not support the school to run all programmes effectively. One of the senior officers stated:

The national and local government do give some money to the school, however that money is too small when comparing to the needs that we have in our school. We need money to keep our photocopy machine running, build disability access facilities and purchase new teaching and curriculum materials. (Interview)

When he was further asked to say how the school uses the money given, he stated: The money was spent on basic needs materials like stationeries for students and teachers. (Interview)

The focus group data indicated that teachers wanted the government to provide separate funds for inclusive education programmes. They argued that: 
Since the government wanted regular schools to implement inclusive education policy, its funding should be separate from the school subsidy money. (Focus group)

When they were further asked why they made the above comment, they mentioned that some of the needs of students with disabilities and their teachers were not considered in the school. For example, one of the teachers who had a child with disability in her class stated:

Last year I was teaching a moderate visually impaired child and the lighting in the classroom was not enough. I reported the matter to the school and they did nothing so I did nothing. I do not know how the student was reading the instructions on the board. (Focus group)

The data from the document analysis also had implications for financial assistance from the government. For example, one of the directive guidelines developed with the draft policy was for the government to allocated funds to build necessary facilities that with assist in the effective implementation of the inclusive education policy.

\section{Assessment strategies used}

The data from the interviews, focus group discussion and document analysis provided the information on the assessment used in the school. The data revealed that the type of assessment used in the school was based on the theory of outcome-based education. Teachers mentioned that they were challenged by the new way of assessing students. Most of them were used to the traditional way of assessing students using standardised test and exams. For example, one of the interviewees stated: 
The type of assessment used now is different from the previous way of assessing students through fixed test and exams. Now were keep records of everything that the students do. We observe them during different context like in the agriculture gardens, on the sports field as well as in the classroom. We keep records of everything that we see as important to be used for assessment. (Interview)

Another interviewee stated:

Previously, I just gave test, mark the papers and awarded grades according to their marks, now I am required to keep records of so many things. I do not like this. (Interview)

The data from the focus group also revealed that the new assessment used in the school has an outcome-based orientation. They mentioned that they assess all aspect of the child's development, not just academic skill and abilities. This meant they were required to assess the attitudes and behaviours, special skills and interests that they have as well as their successes and strengths.

The data from the document analysis also revealed that assessment of students were continuous. For example, the teaching programme books reviewed had sections where teachers were required to write what would be assessed in every lesson, and how it would be assessed. The data revealed that this was done for all planned and programmed lessons that were taught.

\section{Summary}

The main objective in this chapter was to present the results of this study. The focus of the study was to investigate the teachers' perceptions towards the implementation of inclusive education policy in the regular school. The results from the data were put into three major themes. The first theme was 'teachers' attitudes, knowledge and 
understanding of inclusive education policy and practice.' The data from the results revealed that teachers had diverse attitudes towards inclusion. The trained teachers were more positive towards inclusion then the untrained teachers. The second theme was, 'the teachers' experiences and views on the strategies involved when implementing inclusive education policy'. The data also shows that teachers' experiences and views also differed. The final theme was on some of the important issues pertaining to effective inclusion. The data showed that not all the teachers in the school under study had similar needs and insights. Discussion on how these issues might be addressed is the focus of the next chapter. 


\section{Chapter Five: Discussion}

\section{Chapter overview}

This chapter discusses the findings of the data collected from the questionnaire, interviews and document review in reference to literature reviewed for this study. Much of the data focused on teachers' reports gathered through interviews and questionnaire, rather than actual observation. The purpose of this study was to identify the primary school teachers' perceptions on the implementation of inclusive education policy in a regular school. In relation to the research purpose, three major themes emerged from the data analysis. Firstly, the teachers' attitudes, knowledge and understanding of inclusive education are presented. Secondly, the teachers' views and experiences of the implementation inclusive education policy are discussed. The final section of this chapter discusses the teachers' understanding of some important issues pertaining to inclusive education. Each of the themes is discussed below together with the findings derived from the literature.

\section{Teachers' attitudes, knowledge and understanding of the inclusive education concept and policy}

\section{Inclusive education}

According to Mitchell (2005), inclusive education is a complex and problematic notion that lacks a common understanding of what constitutes inclusion. Some authors (Mastropeire \& Scruggs, 2004) limit its definition to the education of children with disabilities in regular schools while others (Ainscow, 2007; Stainback \& Stainback, 1996) take a broader 'educational for all' perspective, arguing that it is education provided to all students, which includes those who are talented as well as those with disabilities and those vulnerable to exclusion in regular schools. The results from this study revealed that teachers had diverse understandings of inclusive education concepts. 
Their understanding of what constitutes inclusive education concepts and disabilities depended on the training that they received in inclusive education. It was revealed that teachers who had received training in inclusive education either through further studies, professional development or teachers colleges were able to define what constituted inclusive education while those who had no training were confused between inclusive education and special education and were unable to tell the difference.

\section{Trained teachers' perception}

The results of this study revealed that teachers who had received some form of training in inclusive education viewed inclusion in terms of an 'education for all' approach, where all students are brought together in the same classroom to be taught by a regular teacher. They mentioned that children with and without disabilities were supposed to be taught together in regular schools. These views were in line with the World Declaration for Education for All of 1990, which stressed education as a fundamental human right and pushed countries to strengthen their efforts to improve education in order to ensure the basic learning needs for all individuals were met (UNESCO, 1994). The results also revealed that, the trained teachers were also aware of the term 'children with disabilities'. The majority of these teachers believed that children with disabilities include those who are talented as well as those with disabilities and those that are vulnerable to exclusion. These views were consistent with Stainback and Stainback's (1996) definition. The teachers mentioned that they were prepared to teach students with disabilities. This means that training and professional development in inclusive education had equipped these regular teachers with the necessary skills and knowledge in inclusive education and increased their confidence in their ability to teach children of all abilities as Jimenez \& Graf (2008) recommended. This finding is consistent with a 
study undertaken by Dickens-Smith (1995), which found that teachers' knowledge and understanding of inclusive education was increased through training.

It was also found that the trained teachers considered education as a right for all children. They mentioned that all children have the right to formal education in regular schools, regardless of their disabilities and needs. This means that the teachers believed that children with disabilities and others that are categorised as having special needs should have the same rights as their non-disabled peers and have equal access to formal education. Their views were in line with the views of Florian (2007); Mitchell (2005) and Ryba (1995), which considered inclusive education as the right for all learners to be accepted and taught together in the regular classroom.

While the teachers believed that education was a right for all children, the results also revealed that the enrolment of students with disabilities at the school under study was low. Teachers blamed the parents and children with disabilities for not recognising education as a right.

\section{Untrained teachers' perceptions}

The teachers who have not received any training in inclusive education had little or no knowledge about the concepts of inclusive education. In the current study, the results revealed that most of the untrained teachers defined the concept based on the individual beliefs and insights that they have towards people with disabilities. Some viewed ‘inclusive education' as a synonym for 'special education'. They mentioned that inclusive education was about providing educational services to children with severe disabilities by specially trained teachers in special education centres which was seems consistent with charity and lay discourses (Neilson, 2005). This finding is in-line with 
O’Neill et al. (2009) view, where special education ideology was still very dominant in the thinking, policy and practice of many educators.

Others believed that it was about the inclusion of children with obvious disabilities at regular schools. The results revealed that teachers' understandings were consistent with the earlier definition of inclusive education where the definition was limited to the education of children with disabilities in regular schools (Mastropiere \& Scruggs, 2004). They do not consider the children with special needs who are already part of the class/school community. These include the talented students, students with unnoticed impairments, slow learners and other disadvantaged students who are vulnerable to exclusion. Therefore, this study suggests that students without obvious impairments who require inclusive education programmes are marginalised or ignored by the untrained teachers at the school under study

\section{Teachers' attitudes}

Attitudes are any belief or opinion that includes a positive or negative evaluation of something that influences us to act in a certain way towards that particular thing. According to Frost (2002), teachers' attitudes play an important role in the matter of whether inclusive education can be fully implemented in a regular school or not. In the current study, the results show that teachers' attitudes towards inclusive education and children with disabilities varied. Firstly, it was noticed that teacher training in inclusive education had a positive influence on their attitudes towards inclusive education approaches. The teachers who had received training in inclusive education were more positive to inclusion and were willing to accept children with disabilities into their class/school. For example, one of the teachers mentioned that his negative thoughts about disabilities and children with special educational needs had changed from the time when he attended training to be the mentor for other head teachers in the district. 
He now allows children with disabilities to be enrolled in the school. His attitudes were shaped during the training as Forlin (2008) stated. This means that training in inclusive education can change teachers' negative thoughts and attitudes towards inclusive education and children with disabilities. This finding is consistent with the findings of another study undertaken in PNG (Mapea, 2006), where teachers who received training in inclusive education were more positive towards inclusive education approaches.

Secondly, teachers' prior association with a person with disability also had some impact on their attitudes. According to a study (Parasuram, 2006) undertaken in India, it was seen that teachers who had prior association with a person with a disability were more positive towards inclusive education. This finding is similar to the current study. The current study found that some teachers who had interactions with a person with a disability were more positive towards inclusion. It was noticed that interacting with a family member or someone very close had greater positive influence than other types of interactions. That is, the results from the current study also revealed that some teachers who had previous experiences of associating with a student with disability were more negative towards inclusive education. For example, a teacher who had previously taught a student with a moderate visual impairment mentioned that he would no longer teach children with such disabilities because it was more problematic having that child in his class. This notion is an example of the deficit model or medical discourse (Neilson, 2005) where disability was seen as a problem within the child.

Therefore, the current study suggests the following findings on attitudes of teachers toward inclusive education and children with disabilities; (i) training in inclusive education helps teachers develop positive attitudes towards inclusion, (ii) prior association with someone with disabilities had some effect on the teachers' attitudes. Teachers who had prior association with family members with disabilities were more 
positive towards inclusion. Teachers who had associated with a person with a disability in the classroom were more negative towards inclusion.

\section{Teachers' views and experiences on the implementation of inclusive education policy}

The implementation of inclusive education policy requires a lot of commitment, preparation and planning because students with diverse needs are educated together in one classroom/school setting (Mapea, 2006). This means inclusive schools have to recognise and respond to the diverse needs of their students, accommodate both different styles and rates of learning and ensure quality education to all through appropriate curricula, organisational arrangements, teaching strategies, resources use and partnerships with communities (UNESCO, 1994). For effective implementation of the inclusive education policy, teachers are seen as the key agents of success (Mitchell, et al., 1999). Thus, the teachers' views and experiences of the implementation of the inclusive education policy are presented in this section.

\section{Teachers' experiences and views on workload and time allocation}

The results from teachers' experiences and views on workload and time allocation are related so they are discussed together. The results revealed that teachers experienced increases in their workload when implementing inclusive education policy. It was perceived that planning and preparing additional work to meet the diverse needs of the students meant more work for them. Teachers mentioned that they were doing extra work apart from their daily teaching responsibilities and extracurricular duties. This finding is in line with Forlin's (2008) views, where the inclusion of students with special needs at a regular school meant additional work added to the existing workload of the teacher. Secondly, the data shows that teachers' required additional time when implementing inclusive education policy because they were teaching students with 
diverse abilities. Some students required one-on-one assistance while others required modification to the curriculum or special equipments. This means teachers need extra time to recognise and respond to the diverse needs of their students, accommodate both different approaches and rates of learning and ensure quality education to all through appropriate curricular, organisational arrangements, teaching strategies and resources use (UNESCO, 1994). Most of the teachers admitted that explaining and showing examples to students with special needs took up extra time. It was noticed that if teachers spend more time on one lesson to explain it thoroughly and show examples, the other lessons/units remain behind schedule. For example, one female teacher mentioned that sometimes she uses other lesson's allocated time to explain and show examples; this slows the pace of the other lessons. The other male teacher mentioned that he moves on to other lessons whether they understand the concept or not. Some others mentioned that they were using their own free time for planning and preparation. The results revealed that effective implementation of inclusive education requires additional time for teachers to effectively assist the students to achieve their potential goals.

On the other hand, the results revealed that some teachers viewed the burden of increased workload and requirement of extra time as manageable. They mentioned that it could be minimised by sharing responsibilities with others. This meant, teachers should collaborate with other colleagues to share responsibilities, involve parents (Gartledge, Gardner \& Ford, 2009; Putman, 1998; Schmidt \& Harriman, 1998) that can provide support in some way, and use teaching and learning strategies that will involve all other stakeholders ( teachers, parents, peers, other supportive community members.

\section{Teachers' experience and views on the issue of separate curricula}

In terms of having separate curricula for children with disabilities, the results revealed that most of the teachers disliked the idea of using a separate curriculum. This view was 
influenced by the curriculum statements formulated by the National Department of Education in Port Moresby, which directed teachers to only use official national curriculum (Department of Education, 2002). Teachers mentioned that teaching instructions and activities were varied according to the understanding level of the students in their classes. For instance, a teacher mentioned:

It's the same curriculum but I prepare simpler work and explain in simpler terms for those children who don't understand the concepts. This helps my slow learners to understand the concepts and they enjoy learning. (Interview)

This means teachers were creative and inventive to appropriately differentiate their teaching instructions and strategies to help all learners to have meaningful and enriched learning opportunities (Pearce, 2008). Differentiating the curriculum, teaching strategies and planning can ensure equal opportunities for all learners (Santangelo, Knots, Clemmer \& Mitchell, 2008). Within the ecological paradigm, the teachers are to adapt and improve educational organisations and environments to meet the needs of all students (Mitchell et al., 1999). The data from the interviews, questionnaire and focus group indicated that necessary adaptations and modifications were made to the curriculum when teaching students with disabilities.

\section{Teachers' experiences and views on teaching strategies used}

The teaching strategies employed by the teachers played an important role in implementation of the inclusive education policy. The results indicated that teachers who received training in inclusive education appeared to be comfortable with some of the inclusive teaching strategies. One of the causes for this positive attitude towards the implementation was because they had learnt how to use some of these strategies during their training in inclusive education. This group of teachers seemed to use various teaching strategies such as peer teaching, cooperative learning and collaboration with 
colleagues. This supports the findings of Forlin (2008), where teachers who received

training in inclusive education were found to be more supportive and confident in implementing inclusion. They mentioned that the use of such teaching strategies had helped to minimise the burden of workload and time limitations.

However, the results revealed that teachers who had not received any form of training in inclusive education were not comfortable with some of the inclusive teaching strategies. For example, one of the interviewees mentioned:

I do not like other teachers to interfere with my teaching because they think that they know more than me" (Interview)

This means that this particular person does not like to collaborate with other teachers or any support person around even though he lacks the content knowledge of some subjects or topics that a colleague could assist him in. The study suggested that teachers' lack of training in inclusive education hindered the effective implementation of some of the useful inclusive teaching strategies.

While the reactions of teachers towards some of the inclusive teaching strategies differed, the study indicated that all teachers at the school under study were comfortable with parent and community involvement in the teaching and learning process. One of the reasons for this must have been because parents and community members came to the school every Monday to help in school development projects like building new toilets and classrooms and keeping school gardens clean. This is supported by findings from Macfarlane (2005), who indicated that utilising parents' skills and knowledge to support school activities promoted inclusion. The results revealed that parents were 
often invited to discuss issues that concerned their children's learning. This established a 'sense of community' in the school where teachers accepted parents and parents and students developed positive attitudes and felt belonged and valued (Macfarlane, 2005). Though most of the effective inclusive teaching strategies were not used by all the teachers at the school under study, parent and teacher cooperation was one of the factors that did increase the opportunities for success (Tilton, 1996).

\section{Other attributes for effective implementation of inclusive education policy}

This section discusses some of the important elements that are seen as being important for the effective implementation of inclusive education policy.

\section{Funding}

In terms of funding, the results revealed that the majority of the teachers felt financial support for the implementation of inclusive education policy was an important aspect. According to Fraser, et al. (2005), the goals of inclusive education can be achieved if there is adequate funding from the government. In the current study, it was found that the National and Provincial level Government did fund the implementation of inclusive education policy. However, these funds could not meet all the costs because implementation of inclusive education policy in a regular school setting is more financially demanding. Teachers who had experiences of teaching children with disabilities strongly stated that the school needed money for building proper facilities like disability access toilets, walkways and for purchasing new teaching and learning materials and special equipment. According to Mitchell (1999), schools should have facilities that are appropriate for children with disabilities. To establish a learning environment that is easily accessible to children with disabilities, funding is required. This is because regular school settings are different from special schools/classrooms. 
Therefore, this study suggests that there has to be continuous support and funding for effective implementation of the inclusive education policy in a regular school setting. This finding supports the views of O'Brien and Ryba (2005), where funding and resourcing of inclusive education has to be unconditional and ongoing.

\section{School leadership}

Inclusive schools require school head teachers who can work together and side by side with their other teachers (Sharma \& Desai, 2008) because the journey of inclusion needs to be taken by the entire school community and not the head teacher alone ( Sharma, 2001). This encourages teachers to develop positive attitudes and demonstrate a motivation to develop beyond expectation (Armstrong, 2006). This means all that the head teachers' do to support inclusive education can make a difference in the teachers' performances. For example, in the current study it was identified that the head teacher of the school was willing to work together with his staff and facilitate initiative to include students with disabilities in the school. Hence, teachers agreed to change and implement inclusive practices after being involved in the study. Therefore, this study suggested that head teachers have to work in collaboration with other school teachers, parents and community members to see effective implementation of inclusive education.

\section{Assessment}

Assessment is part of the teaching and learning process and consequently appropriate assessment should be made to focus on the achievements of the students (Mentis et al., 2005). The results in the current study indicated that assessment used at the school was based on the outcome-based education model. This shows that there was a change in the way assessment was done. The teachers have moved from the traditional standardised testing methods to measure learning (Peterson, LeRoy, Field \& Wood, 1992) to a more ecological-oriented assessment model where emphasis is placed on the students' 
interaction with their surrounding environment (Moore et al., $1999 \&$ Smith et al., 2005). The data revealed that teachers were using information from multiple sources to assess the students. For example, one teacher mentioned that the assessment is continuous, with students being observed in everything they do and records of this being kept. These records are then put together to make a final report for the child. This shows that the teachers at the school under study were using information gathered from multiple sources to assess the children's ability. This finding was in line with Shmidt and Harriman's (1998) view, where teachers were required to gather a variety of information from multiple sources to create comprehensive reports for students because this gives a clear picture of the student.

\section{Inclusive education policy}

The existence of inclusive education policy at the national level was on the whole well known by majority of the teachers; however the level of this knowledge varied. The results in the current study revealed that teachers who received training in inclusive education were more aware of the existence of inclusive education policy then those who had not. The National Inclusive Education policy for PNG which was formulated in 1993 with its directive guidelines, which included introducing inclusive education courses to the teachers' college courses, and directing schools to accept children with disabilities (Department of Education, 1993). It was noticed that most teachers at the school under study were aware of the national inclusive education policy. According to Fraser et al. (2005), inclusive education policies are put in place at the government and school level to guide the implementation of inclusion. The results indicate that there was a draft inclusive policy developed to support the children with disabilities at the school. However, results revealed that not all the teachers were aware of the policy. Therefore, this study suggests that the teachers' lack of knowledge towards the 
existence of the inclusive policy at the school had some impact on their perceptions of inclusion.

\section{Summary}

The discussion on the findings of this study revealed important issues that need consideration in order to see effective implementation of the inclusive education policy at the school under study. These issues range from having positive attitudes towards inclusion and children with disabilities and the importance of teacher training in inclusive education, to using effective teaching and learning strategies to achieve the goals of inclusion. Other issues include adequate funding, good school leadership, and having school inclusive policies to support children with disabilities. 


\section{Chapter Six: Limitations, Implication for Practice and Implication for Further Research}

\section{Chapter overview}

This chapter looks at the limitations of this study, discusses the implications for practice and provides recommendations for further research in this field.

\section{Limitations of the research}

Several limitations identified in this study are presented below.

1. The study was undertaken in only one school and in one province of the country and therefore findings may vary across other schools in the province and other provinces in the country too. The study was conducted in a Primary School in the Southern Highlands Province of Papua New Guinea. The analyses made were based on the views of teachers in this particular primary school and the results of this study may differ from the views and experiences of teachers in other schools in both this province and other provinces in the country.

2. Participants were not keeping up with the research schedule. Some participants returned the completed questionnaire forms late and some did not return them at all. Since the sample size was small, it could have been better if all participants returned the completed questionnaires. The results gathered from the questionnaire data were not the views of all participants so the results may not be the views of all the teachers at the school under study.

3. Translating and transcribing the PNG 'Tok Pisin' version of the interview data in English meant losing some of the meaning of the participants' views. It may have been preferable if all the responses were made in English. 
4. The dates scheduled for issuing the questionnaire forms were affected by a community event. The participating school was closed for the first few days of the study's schedule because teachers were attending a funeral in a nearby community. This made it difficult for the researcher to deliver the questionnaires as scheduled. However, the researcher managed to deliver the questionnaires but it is believed that the teachers may have rushed to complete the questionnaires. Some of their inner thoughts and experiences may not have been expressed fully.

5. The researcher had insufficient time to do the fieldwork. All the data collection and other procedures involved in the data collection were done in four weeks. This means the researcher was rushing to get things done on time and as a consequence some information may be missed.

\section{Implication for practice}

This study has looked at the teachers' perceptions of the implementation of the inclusive education policy in a regular school in SHP of PNG. Due to the nature of this case study, the implications from the research may be confined to the school under study. However, one of the characteristics of this study predicted was that the results may be related to what was happening in other schools in the Southern Highlands Provinces and PNG at large. The details of the implications are presented below in view of the three themes that emerged from the data.

\section{Knowledge, understanding and attitudes}

Teachers' attitudes, knowledge and understanding of inclusive education practices and policy differed. The teachers at the school who received some form of training in inclusive education were aware of the policy and were more positive towards inclusion and children with disabilities. The teachers who received no training generally had 
limited or no knowledge about inclusive education. This finding implied that there was a marked difference in implementing the inclusive policy in the school. The teaching and learning that occurred in trained teachers' classrooms was much more inclusive then that of the others.

It was also noticed that attitude played an important role in the progress of inclusive education. Positive attitudes promoted inclusion and negative attitudes hindered progress. Therefore, these situations signal the need for more awareness programmes on inclusive education to be made available to all teachers through appropriate professional development practices.

\section{Teachers' experiences}

The study suggested that teachers had experienced increased workload and needed extra time when implementing inclusive education policy. Teachers mentioned that teaching children with disabilities meant a lot to them. They need to prepare additional work, do additional explanations, and at the same time attend to the general teaching obligations like maintaining continuous student assessment. They admitted that they could not do much in the little time that they have because all lessons and activities follow fixed schedules/timetables. It was identified that most of the students were not provided the necessary assistance required because teachers had no time. Therefore, this situation calls for the school to develop inclusive programmes such as co-teaching and collaboration to be used in the school. When they have established programmes that assist the teachers, work is shared, and students will benefit. 


\section{School leadership}

The study suggested that the school leader who is the head teacher should initiate professional development programmes for his teachers. The data revealed that most teachers in the school did not receive any training in inclusive education. They were confused between inclusive and special education, though their head teacher facilitated an initiative to include children with disabilities in the school. Some teachers were not aware of the school's draft inclusive policy. The influence of a single leader on the teachers is limited. Therefore, these situations call for the school leader to initiate professional development programmes at their school so that the teachers can be equipped with the necessary skills and knowledge in inclusion.

\section{Funding}

The National Government has committed itself to providing education for all children. Funding was provided to each school to purchase basic materials for teachers and children to use in schools. The curriculum materials were developed by the Department of Education and distributed to individual schools in the province. However, there should be money budgeted for children with special needs which should be given to each school to meet the specific needs of those children. For instance, if the school has a student with a visual impairment, the Board of Management should be able to buy a Braille machine for the school, which such a student could use. The funding should also be continuous and ongoing.

\section{Specialist teachers}

Training of specialists in different areas of disability is very essential to promoting collaborative and effective implementation of the inclusive Education Policy. The Department of Education has to select potential officers to be trained as school 
counsellors, speech and language therapists, occupational therapists, and physiotherapists or behaviour specialists. There is also a need for the National Department of Education to consider planning a teacher aide training programme so that teachers and teacher aides can collaboratively provide educational support for children with special needs in regular classrooms. This would lessen some of the concerns that teachers have, such as increased workloads, and additional planning and preparation for children with special needs.

\section{Implications for further research}

This research is first of its kind in the province and aimed at discovering teachers' perceptions of the implementation of inclusive education. Since the Department of Education has incorporated the Inclusive Education Policy and developed a special education policy, it has encouraged teachers to implement the policy. This study has focused on one province yet highlighted some possible areas for further research

1. It is recommended that there should be further research that is similar but involving many schools and teachers who have experience implementing the Inclusive Education Policy.

2. The National Department of Education has developed the Special Education Policy and has created a special education unit to coordinate special education programmes around the country. However, further research is needed to assess the outcome of the implementation of the policy across the entire country. 
3. The areas of disability are broad and yet there are no accurate statistics on the number of children with special needs in each school in the provinces, what those special needs are, or how teachers are providing assistance to these children either academically or socially. More work is required here to give an understanding of disability specific issues.

\section{Conclusion}

This study was conducted with the aim of determining how primary school teachers viewed and experienced teaching children with disabilities alongside their non-disabled peers in regular classrooms. The study was conducted in one of the biggest primary schools in the SHP of PNG. The school was made up of twenty-five teachers and an estimated of 350 students. It was a qualitative study using case study approaches. The data was gathered through questionnaires, individual interviews, a focus group interview, and document analysis. All the teachers in the school were invited to participate in the study but five teachers withdrew from the study. Therefore, twenty teachers responded to the research questionnaire. From this twenty, one head teacher, one deputy head teacher and two senior subject heads (four teachers altogether) participated in the individual interview, and six other classroom teachers who had an experience in inclusive education or children with disabilities participated in the focus group discussion.

From the findings several important issues emerged which need to be addressed. Firstly, many teachers in this study were not aware of the concept of inclusion and the inclusive education policy. Thus, it is important for the Department of Education to develop and provide awareness through professional development programmes. 
It was also found that not all students with disabilities were enrolled in the school. This was due to teachers' limited knowledge in inclusive education, there being no specialist teacher to assist the regular teachers, and inadequate resources to support children with disability.

Secondly, attitudes of teachers towards inclusion were a big concern. In this study teachers indicated that attitude had a huge impact on educating children with special needs in regular classrooms and needed to be changed. Teachers also pointed out that attitudes of peers and parents were also important for the progress of an inclusive education programme. Hence, positive attitudes are needed to teach and support children with special needs in regular schools.

Thirdly, teachers in this study have raised concerns that in order for the Inclusive Education Policy to be implemented effectively in regular school, teachers need more training in the field of inclusive education and children with disabilities. Ongoing training in all areas of disabilities would provide the teachers with adequate knowledge and skills to cater for children with disabilities. There needs to be training for specialists in different areas of disability support because currently there are no specialists available to provide assistance. Financial assistance was considered very important to effectively implement the inclusive policy. Funding is needed to purchase teaching and learning materials and also for upgrading school facilities.

It was important that the National Government and the National Department of Education develop strategies on how the highlighted issues can best be addressed so that Inclusive Education Policy is effectively implemented in primary schools not only in the participating school, but throughout the whole province and country as well. 


\section{References}

Ahai, N. (1993). Evaluation of the Western Highlands Association for the disabled program. Division of Educational research report No. 72. Port Moresby: National Research Institute.

Ainscow, M. (2007). From special education to effective schools for all: A review of progress so far. In L. Florian (Ed.), The SAGE handbook of special education. London: Sage.

Ainscow, M. (1999). Understanding the development of inclusive schools. London: Falmer Press.

Al-Zyoudi, M. (2006). Teachers' attitudes towards inclusive education in Jordonian schools. International Journal of Special Education, 21(2), 55-62.

Anderson, G. (1990). Fundamentals of educational research. London: Falmer.

Anderson, G., \& Arsenualt, N. (1998). Fundamentals of educational research. London: Routledge Falmer.

Andrews, J., \& Lupart, J. (1993). Inclusive classroom; educating exceptional children. Scarborough: Nelson Canada.

Armstrong, J. (2006). How principals lead to promote inclusive practices. A descriptive study. Unpublished doctoral dissertation, School of Education, Duquesne, University, USA.

Artiles, A., \& Dyson, A. (2005). Inclusive education in the globalization age: The promise of comparative cultural-historical analysis. In D. Mitchell (Ed.), Contextualizing inclusive education: Evaluation old and new international perspectives (pp. 37-62). London: Routledge. 
Baker, J., \& Zigmond, N. (1990). Are regular education classes equipped to accommodate students with learning disabilities? Exceptional Children, 56, $515-526$.

Ballard, K. (1999). International voices: An introduction. USA: Falmer Press.

Best, J., \& Kahn, T. (1998). Research in education ( $8^{\text {th }}$ ed). Boston: Allyn and Bacon.

Bailey, D., \& Winton, J. (1987). Stability and change in parents' expectations about mainstreaming. Topics in Early Childhood Special Education, 7, 73-88.

Boer, A., Pijl, S., \& Minnaert, A. (2010). Attitudes of parents towards inclusive education: A review of the literature. European Journal of Special Needs Education, 25(2), 165-181.

Bogdan, C., \& Biklen, K. (2007). Qualitative research for education. An introduction to theories and methods. USA: Pearson Education Inc.

Booth, T., Ainscow, M., Black-Hawkins, K., Vaughan, M., \& Shaw, L. (2000). The index for inclusion. Developing learning and participation in schools. Bristol: Centre for Studies in Inclusive Education.

Bosi, W. (2004). A pilot implementation of inclusive education in Malaysia. A review. Unpublished doctoral dissertation, Massey University, New Zealand.

Bouma, D. G. (1996). The research process (3rd ed.). Melbourne: Oxford University.

Brown, R. (2005). Inclusive education in Middle Eastern cultures. In D. Mitchell (Ed.), Contextualizing inclusive education: evaluating old and new international perspectives (pp. 253-278). London: Routledge. 
Center, Y. (1989). Integration-historical perspectives. In J. Ward, S. Bochner, Y. Center, L. Outhred \& M. Pieterse (Eds.), Educating children with special needs in regular classrooms: An Australia perspective (pp. 11-18). Australia: Special Education Centre.

Choate, J. (1997). Successful inclusive teaching proven ways to direct and correct special needs. USA: Allyn and Bacon.

Cheminais, R. (2001). Developing inclusive school practice. A practical guide. London: David Fulton.

Corbett, J. (2001). Supporting inclusive education. A connective pedagogy. London: Routledge Falmer.

Creswell, J. W. (2003). Research design: Qualitative, quantitative and mixed research methods approach (2nd ed.). London: Sage Publication.

Cross, J. (2002). Special educational needs in the primary school. A practical guide. Buckingham: Open University Press.

Department of Education. (2002). National education plan on the provision of inclusive education. Port Moresby: Author.

Department of Education. (1993). Papua New Guinea country study. The state of inclusive education: the way forward. Port Moresby: Author.

Davies, T., \& Pragnell, A. (1999). Special Education 2000: A National Framework. Research Conference Keynote Address. New Zealand: Ministry of Education.

Dickens-Smith, M. (1995). The effect of inclusion training on teacher attitude towards inclusion, ERIC Document No. ED 332802. 
Farrell, M. (2008). Educating special children. An introduction to provision for pupils with disabilities and disorders. London: David Fulton.

Farrell, M. (2005). Key issues in special education, raising standard of pupils' attainment and achievement. USA: Routledge.

Farrell, M. (2000). Special education hand book. London: David Fulton.

Florian, L. (2007). The SAGE hand book of special education. USA: Sage.

Florian, L. (1998). Inclusive practice; what, why and how? In C. Tilstone, L. Florian \& R. Rose (Eds.), Promoting inclusive practice (pp. 13-26). London: Routledge.

Forlin, C., \& Sin, K. (2010). Developing support for inclusion: A professional learning approach for teachers in Hong Kong. International Journal of Whole Schooling, $6(1), 7-26$.

Forlin, C., \& Lian, J. (2008). Reform, inclusion and teacher education. Towards a new era of special education in the Asia-Pacific region.USA: Routledge.

Forlin, C. (1995). Educators' belief about inclusive education practices in Western Australia. Journal of Special Education, 22, 179-185.

Fox, N., \& Yesseldyke, J. E. (1997). Implementing inclusion in the middle school level: Lessons from a negative example. International Journal of Disability, Development and Education, 51(3), 271-285.

Fraenkel, R., \& Wallen, E. (2006). How to design and evaluate research in education (6th ed.). New York: McGraw-Hill. 
Fraser, D. (2005). Collaborating with parents/caregivers and whanau. In D. Fraser, R. Moltzen \& K. Ryba (Eds.), Learners with special needs in Aotearoa New Zealand (pp. 128-154, 3rd ed.). Australia: Dunmore Press.

Frost, M. (2002). Introduction of special education: Lecturers' support. Waigani. Department of Education.

Gartledge, G., Gardner , R., \& Ford, D. (2009). Diverse learners with exceptionalities: Culturally responsive teaching in the inclusive classroom. USA: Pearson Inc.

Government of Papua New Guinea. (2002). National curriculum statement of Papua New Guinea. Papua New Guinea, Department of Education.

Haider, S.I. (2006). Pakistani teachers' attitudes towards inclusion of students with Special Educational Needs. Pakistan Journal of Medical Science, 24(4), 632-6.

Heiman, T. (2002). Inclusive schooling: Middle school teachers' perceptions. School Psychology International, 23(1), 174-186.

Hodkinson, A. (2005). Conceptions and misconceptions of inclusive education. A critical examination of final-year teacher trainees' knowledge and understanding of inclusion. Research in Education, 73, 15-28.

Hoskins, B. (1996). Developing inclusive schools. A guide. USA: Bloomington.

Jimenez, T., \& Graf, V. (2008). Education for all. Critical issues in the education of children and youth with disabilities.USA: John Wiley and Sons.

Johnson, B., \& Christensen, L. (2008). Educational research: Quantitative, qualitative and mixed approaches (3rd ed.). USA: Sage.

Johnson, W. E., Johnson, R., \& Holubec, J. (1994). Cooperative learning in the classroom. Alexandria: Association for Supervision and Curriculum Development. 
Kale, J., \& Marimyas, J. (2003). Implementing multilingual education in a country with 860 languages: Challenges for the National Department of Education in Papua New Guinea. Papua New Guinea: PNG Department of Education.

Kauffman, M., \& Hallahan, P. (1995). The illusion of full inclusion. A comprehensive critique of a current special education bandwagon. USA: Pro-ed Inc.

Kitchen, S. (2007). Perception of students with disabilities. An assessment of attitudes held by pre-service teachers. USA: West Virginia University.

Krefting, L. (1991). Rigor in qualitative research: The assessment of trustworthiness. The American Journal of Occupational Therapy, 45(3), 214-222.

Laure, P. (2003). Analyzing national and international policy. Michigan: Lexington.

Leyser, T., \& Kirk, R. (2004). Evaluating inclusion: An examination of parents views and factors influencing their perspectives. International Journal of Disability, Development and Education, 51(3), 271-285.

Lipsky, D., \& Gartner, A. (1997). Inclusion and school reform. Transforming America's classrooms. USA: Paul H. Brookes.

Macfarlane, A. (2005). Inclusion in Maori Ecologies: An educultural approach. In D. Fraser, R. Moltzen \& K. Ryba (Eds.), Learners with special needs in Aotearoa New Zealand (pp. 99-116, 3rd ed.). Australia: Dunmore Press.

Maha, A. (2009). A reflection on the reform and implementation of the primary curriculum in Papua New Guinea. In K. Sanga \& K. H. Thaman (Eds.), Rethinking education curricula in the Pacific: Challenges and prospects (pp. 29-42). New Zealand: Victoria University. 
Mapea, J. (2006). Teachers views on providing for children with special needs in inclusive classrooms. A Papua New Guinea case stud. Unpublished master's thesis. Waikato University, New Zealand.

Mastropiere, M., \& Scruggs, T. (2004). The inclusive classroom: Strategies for effective instruction (2nd ed.). Ohio: Pearson, Merrill Prentice.

Matane, P. (1986). A philosophy of education for Papua New Guinea. A ministerial report. Port Moresby: Department of Education.

McLaughlin, M. J., \& Verstegen, D. A. (1998). Increasing regulatory flexibility of special education programs: Problems and promising strategies. Exceptional Children, 64, 371-384.

Mentis, M., Quinn, S., \& Ryba, K. (2005). Linking inclusive policies with effective teaching practices. In D. Fraser, R. Moltzen, \& K. Ryba (Eds.), Learners with special needs in Aotearoa New Zealand (pp. 74-98, 3rd ed.). Australia: Dunmore Press.

Ministry of Education. (2008). Papua New Guinea country report. Inclusive education the way forward. Port Moresby: Department of Education.

Ministry of Education. (2008). Meeting special education needs at school: Information for board of trustees. Wellington, NZ: Author.

Mitchell, D. (2005). Contextualizing inclusive education: Evaluating old and new international perspectives. London: Routledge

Mitchell, D. (1999). Special education in New Zealand; A decade of change. New Zealand Journal of Education Studies, 349(10), 199-210.

Mitchell, D. (1989). Creating inclusive schools. Hamilton: University of Waikato. 
Morton, M., \& Gordon, L. (2006). Inclusive education in Aotearoa, what are you doing in initial teacher educational professional learning and development. Final report to NZCCS. Christchurch, New Zealand, Canterbury University.

Moore, D., Anderson, A., Timperley, H., Glynn, T., Macfarlane, A., Brown, D., \& Thomson, C. (1999). Caught between stories: Special education in New Zealand. New Zealand: NZCER.

Naicker, S. (2005). Inclusive education in South Africa: an emerging pedagogy of possibility (pp. 230-252). In D. Mitchell (Ed.), Contextualising inclusive education. Evaluating of old and new international perspectives. New York: Routledge.

Naidu, A. (2008). Collaboration in the era of inclusion. In C. Forlin \& M. Lian (Eds.), Reform, inclusion and teacher education. Towards a new era of special education in the Asia-Pacific region (pp. 30-41). London: Routledge.

Neilson, W. (2007). Disability, attitude, history and discourses. In D. Fraser, R. Moltzen \& K. Ryba (Eds.), Learners with special needs in Aotearoa New Zealand (pp. 9-21, 3rd ed.). Australia: Dunmore Press

O’Brien, P., \& Ryba, K. (2005). Policy and system in special education. In D. Fraser, R. Moltzen \& K. Ryba (Eds.), Learners with special needs in Aotearoa New Zealand (pp. 22-48, 3rd ed.). Australia: Dunmore Press.

O’Neil, J., Bourke, R., \& Kearney, A. (2009). Discourses of inclusion in initial teacher education: Unravelling a New Zealand number eight knot. Teaching and teacher education. An International Journal of Research and Studies, 25, 588-593. 
Parasuram, K. (2006). Variables that affect teachers' attitudes towards disability and inclusive education in Mumbai, India. Disability and Society, 21(3), 231-242.

Pearce, M. (2008). The inclusive secondary school teacher. In C. Forlin \& M. Lian(Ed.), Reform, inclusion and teacher education. Towards a new era of special education in the Asia-Pacific region (pp. 142-152). London: Routledge.

Peters, S. (2007). Inclusion as a strategy for achieving education for all. In L. Florian (Ed.), The Sage handbook of special education (pp. 117-141). London: Sage.

Peterson, M., LeRoy, B., Field, S., \& Wood, P. (1992). Community referenced learning in inclusive schools: Effective curriculum for all students. In S. Stainback \& W. Stainback (Eds.), Curriculum considerations in inclusive classrooms: Facilitating learning for all students (pp. 207-227). Baltimore: Paul H. Brooks; Publishing Company.

Prochnow, J. E., Kearney, A.C., \& Caroll-Lind, J. (2000). Successful inclusion: What do teachers say they need? New Zealand Journal of Educational Studies, 35(2), $157-178$

Putman, J. (1998). Celebrating diversity in the classroom. Cooperative learning and strategies for inclusion (2nd ed.). London: Paul H. Publishing Co.

Rombo, J. L. (2007). School cultural features and practices that influence inclusive education in Papua New Guinea. A case study of schools in Southern highlands provinces. Unpublished master's thesis, Waikato University, New Zealand.

Rombo, J. L. (2006). Inclusive education: Policies, teachers' attitudes and perspectives. Contemporary PNG Studies: Divine Word University Research Journal, 5, $29-44$. 
Rose, R. (2008). Promoting inclusion in the primary classroom. In C. Forlin \& J. Lian (Eds.), Reform inclusion and teacher education. Towards a new era of special education in the Asia-Pacific region (pp. 129-141). London: Routledge.

Ryan, J. (2006). Inclusive leadership and social justice for schools. Leadership and Policy in Schools, 5(1), 3-17.

Ryba, K. (1995). Inclusive education policy and practice in the school environment. In D. Fraser, R. Molten \& K. Ryba (Eds.), Learners with special needs in Aotearoa New Zealands (2nd ed.). New Zealand, Dunmore Press.

Ryba, K., \& Annan, J. (2000). Students with intellectual disabilities. In D. Fraser, R. Molten \& K. Ryba (Eds.), Learners with special needs in Aotearoa New Zealands. (pp. 265-288, 2nd ed.). New Zealand, Dunmore Press.

Santangelo, T., Knotts, G., Clemmer, K., \& Mitchell, M. (2008). Differentiated instruction. Legislative support and classroom practices. In T. Jemenez \& V. Graf (Eds.), Education for all. Critical issues in the education of children and youth with disabilities (pp. 195-240). USA: John Wiley \& Sons.

Schmidt, M., \& Harriman, N. (1998). Teaching strategies for inclusive classrooms, schools, students, strategies and success. USA: Harcourt Brace.

Scruggs, T. E., \& Mastropieri, M. A. (1996). Teacher perceptions of mainstreaming inclusion, 1958-1995: A research synthesis. Exceptional Children, 63, 59-74.

Semi, J. (2008). Teacher educators' and pre-service teachers' attitudes, knowledge and understanding on special education and inclusive education in the Solomon Islands, Unpublished thesis. Waikato University, New Zealand. 
Sergiovanni, T. (2001). Leadership: What's in it for leadership? London: Routledge Falmers.

Sharma, U. (2001). The attitudes and concerns for school principals and teachers regarding the integration schools in India, Unpublished doctoral dissertation. University of Melbourne, Australia.

Sharma, U., \& Desai, I. (2008). The changing roles and responsibilities of school principals relative to inclusive education. In C. Forlin \& J. Lian (Eds.), Reform inclusion and teacher education. Towards a new era of special education in the Asia-Pacific region for all students (pp. 153-168). USA: Wadworth Publication.

Sileo, N., \& Prater, M. (2001). Working with families of children with special needs. Family and professional partnership and roles. USA: Pearson.

Smith, T., Polloway, E., Patton, J., \& Dowdy, C. (2005). Teaching students with special needs in inclusive settings (4th ed.). Boston: Pearson Education.

Stainback, S., \& Stainback, W. (1996). Inclusion: A guide for educators. Baltimore: Paul H. Brooks Publication.

Stewart, W., \& Shamdasani, N. (1990). Focus group: Theory and practice. USA: Sage Publication.

Sutherland, G. (1981). The origin of special education. In W. Swann (Ed.), The practice of special education. USA: Open University Press.

Tilton, L. (1996). Inclusion a fresh look: Practical strategies to help all students succeed. USA: Covington Cove.

Udvari-Solnar, A. (1995). Designing effective adaptation for inclusive classroom. Network, 4(3), 31-35. 
UNESCO. (2001). Understanding the responsibility for children's needs in inclusive classroom. A guide for teachers. Paris: Author.

UNESCO. (1994). The Salamanca Statement and framework on special educational needs of education. Paris: Author.

Vaughan, G. M., \& Hogg, M. A. (2002). Introduction to social psychology. French Forest: Pearson Education.

Villa, R. A., \& Thousand, J. S. (2005). Creating an inclusive school (2 ed.). USA: Association for Supervisor and Curriculum Development (ASCD).

Vlachou, A. (1997). Struggles for inclusive education. An ethnographic study. Buckingham: Open University Press.

Waiko, J. D. (1997). A history of Papua New Guinea. Melbourne: Oxford University Press.

Wang, H. (2008). Preparing teachers to work with young children with disabilities. In C. Forlin \& M. Lian (Eds.), Reform, inclusion and teacher education. Towards a new era of special education in the Asia-Pacific region (pp.74-82). London: Routledge.

Ware, L. (1999). My kids and kids kinda like him. In K. Ballard (Ed.), Inclusive education: International voices on disability (pp. 43-65). London: Falmer.

Working Forum on Inclusive Schools. (1994). Creating schools for all our students: What 12 schools have to say: A product of the Working Forum on Inclusive Schools. USA: The Council for Exceptional Children.

Yin, R. K. (2003). Case study research: Design and methods. Thousand Oaks: Sage Publications. 
Zionts, P. (1997). Inclusion: Chasing the impossible dream? Maybe. In P. Zionts (Ed.), Inclusion strategies for students with learning and behaviour problems (pp. 3-11). Austin, TX: Pro-Ed. 
Appendices

Appendix A: Table 1: Demographic information for the study

\begin{tabular}{|c|c|c|c|c|c|}
\hline Teachers & Gender & Qualification & $\begin{array}{c}\text { Yrs } \\
\text { teaching }\end{array}$ & Grade Teaching & $\begin{array}{c}\text { Training } \\
\text { in } \\
\text { Inclusion }\end{array}$ \\
\hline H/T & M & T/Certificate & 28 & $4 \mathrm{~A}(9$ yrs olds $)$ & yes \\
\hline D/HT & M & T/Certificate & 32 & $5 \mathrm{~A}(10 \mathrm{yrs}$ old $)$ & no \\
\hline S/ST-1 & F & T/Certificate & 28 & $3 \mathrm{~A}(8 \mathrm{yrs}$ old $)$ & no \\
\hline S/ST-2 & M & T/Diploma & 26 & $6 \mathrm{C}(11 \mathrm{yrs}$ old $)$ & yes \\
\hline S/T-1 & M & BE/Degree & 22 & $8 \mathrm{~A}(13 \mathrm{yrs}$ old $)$ & yes \\
\hline S/T-2 & F & T/Certificate & 19 & $7 \mathrm{D}(12 \mathrm{yrs}$ olds & no \\
\hline S/T-3 & M & T/Certificate & 26 & $7 \mathrm{~A}(12$ yr old $)$ & no \\
\hline S/T-4 & M & T/Certificate & 22 & $3 \mathrm{C}(8 \mathrm{yrs}$ old $)$ & no \\
\hline S/T-5 & M & T/Certificate & 18 & $5 \mathrm{D}(10 \mathrm{yrs}$ old $)$ & yes \\
\hline T-1 & M & T/Diploma & 10 & $7 \mathrm{C}(12 \mathrm{yrs}$ old $)$ & no \\
\hline T-2 & F & T/Certificate & 18 & $8 \mathrm{~B}(13 \mathrm{yrs}$ old $)$ & no \\
\hline T-3 & M & T/Certificate & 29 & $6 \mathrm{~B}(11 \mathrm{yrs}$ old $)$ & no \\
\hline T-4 & M & T/Diploma & 4 & $8 \mathrm{D}(13 \mathrm{yrs}$ old $)$ & yes \\
\hline T-5 & F & T/Certificate & 31 & $5 \mathrm{~B}(10 \mathrm{yrs}$ old $)$ & no \\
\hline T-6 & F & T/Certificate & 29 & $4 \mathrm{D}(9 \mathrm{yrs}$ old $)$ & no \\
\hline T-7 & M & T/Certificate & 23 & $4 \mathrm{C}(9$ yrs old $)$ & no \\
\hline T-8 & F & T/Diploma & 3 & $7 \mathrm{~B}(12 \mathrm{yrs}$ old $)$ & yes \\
\hline T-9 & M & T/Certificate & 20 & $5 \mathrm{C}(10 \mathrm{yrs}$ old $)$ & no \\
\hline T-10 & F & T/Certificate & 26 & $4 \mathrm{~B}(9$ yrs old $)$ & no \\
\hline T-11 & M & T/Certificate & 17 & $6 \mathrm{D}(11 \mathrm{yrs}$ old $)$ & no \\
\hline & & & & & \\
\hline
\end{tabular}


Appendix B: Summary of research questionnaire results

\begin{tabular}{|l|l|l|l|l|l|l|l|l|l|l|}
\hline $\begin{array}{l}\text { Q. } \\
\text { no }\end{array}$ & $\begin{array}{l}\text { Strongly } \\
\text { Disagree }\end{array}$ & $\%$ & Disagree & $\%$ & Neutral & \% & Agree & $\%$ & $\begin{array}{l}\text { Strongly } \\
\text { Agree }\end{array}$ & $\%$ \\
\hline 1 & & & 5 & 25 & & & & & 15 & 75 \\
\hline 2 & & & 6 & 30 & 2 & 10 & 10 & 50 & 2 & 10 \\
\hline 3 & 15 & 75 & 3 & 15 & & & 2 & 10 & & \\
\hline 4 & 15 & 75 & 5 & 25 & & & & & & \\
\hline 5 & & & & & & & & & 20 & 100 \\
\hline 6 & & & & & 2 & 10 & 10 & 50 & 8 & 40 \\
\hline 7 & & & & & & & 15 & 75 & 5 & 25 \\
\hline 8 & & & & & & & 2 & 10 & 18 & 90 \\
\hline 9 & & & & & & & 14 & 70 & 6 & 30 \\
\hline 10 & 4 & 20 & 12 & 60 & & & 4 & 20 & & \\
\hline 11 & & & 8 & 40 & 2 & 10 & 10 & 50 & & \\
\hline 12 & & & & & & & & & 20 & 100 \\
\hline 13 & & & & & & & & & 20 & 100 \\
\hline 14 & & & & & & & & & 20 & 100 \\
\hline 15 & & & & & & & & & 20 & 100 \\
\hline
\end{tabular}




\section{Appendix C: Questionnaires questions}

This questionnaire invites you to share your views and experiences concerning the implementation of inclusive education in your school.

\section{Section 1: Personal details}

Name

Gender

Grade teaching

1. What is your highest qualification?

2. How many year teaching?

3. Did your whole training include any course relating to inclusive education?

4. If yes, please explain one or two things about it?

5. Have you completed any other training in inclusive education since graduating from teachers college?

6. If yes, please explain the nature of the course? Indicate the topics covered.

8. Explain how you understand the term "children with disabilities".

9. Do you have/did you have any child with disability in your class?

10. If yes, explain the nature of the disability. 


\section{Section 2: Inclusive education practices in regular school.}

Respond to the items below using the following scale where;

1 Strongly disagree (SD) 2 Disagree (D)
3 Neutral (N)
4 Agree (A)
5 Strongly agree (SA)

Pleases place a tick $(\sqrt{ })$ in the appropriate box below

\begin{tabular}{|c|c|c|c|c|c|c|}
\hline & The points are... & $\begin{array}{l}\text { SD } \\
1\end{array}$ & $\begin{array}{l}\mathrm{D} \\
2\end{array}$ & $\begin{array}{l}\mathrm{N} \\
3\end{array}$ & $\begin{array}{l}\text { A } \\
4\end{array}$ & $\begin{array}{l}\text { SA } \\
5\end{array}$ \\
\hline 1 & $\begin{array}{l}\text { Inclusive education meaning all children learning together in } \\
\text { one classroom/school. }\end{array}$ & & & & & \\
\hline 2 & $\begin{array}{l}\text { Every child regardless of disability has the right to a formal } \\
\text { education at a regular school. }\end{array}$ & & & & & \\
\hline 3 & All regular schools enrol children with disabilities in PNG. & & & & & \\
\hline 4 & $\begin{array}{l}\text { All regular teachers are fully trained to teach children with } \\
\text { disabilities. }\end{array}$ & & & & & \\
\hline 5 & $\begin{array}{l}\text { All regular schools should have polices that support children } \\
\text { with disabilities. }\end{array}$ & & & & & \\
\hline 6 & $\begin{array}{l}\text { Children with disabilities require extra time from the regular } \\
\text { teacher. }\end{array}$ & & & & & \\
\hline 7 & $\begin{array}{l}\text { The inclusion of children with disabilities in regular schools is } \\
\text { moving at a very slow pace. }\end{array}$ & & & & & \\
\hline 8 & $\begin{array}{l}\text { Regular schools need to be fully equipped before enrolling } \\
\text { children with disabilities. }\end{array}$ & & & & & \\
\hline 9 & Children with disabilities disrupt other students learning. & & & & & \\
\hline 10 & $\begin{array}{l}\text { Teachers have to use a separate curriculum to cater for children } \\
\text { with disabilities. }\end{array}$ & & & & & \\
\hline 11 & $\begin{array}{l}\text { Children with disabilities enjoy learning in a regular school if } \\
\text { their individual needs are fully met. }\end{array}$ & & & & & \\
\hline 12 & Teachers work load is increased in an inclusive classroom. & & & & & \\
\hline 13 & $\begin{array}{l}\text { Professional development is important for regular teachers } \\
\text { before teaching children with disabilities. }\end{array}$ & & & & & \\
\hline 14 & $\begin{array}{l}\text { The government should train more specialist teachers to assist } \\
\text { teachers in the implementation of the inclusive education } \\
\text { programmes. }\end{array}$ & & & & & \\
\hline 15 & $\begin{array}{l}\text { The National Government and the local level Government } \\
\text { have to provide sufficient funds to the school for improving the } \\
\text { school facilities (e.g. disability toilets, walkways) so that } \\
\text { inclusive education policy can be successfully implemented. }\end{array}$ & & & & & \\
\hline
\end{tabular}




\section{Section 3: Open-Ended Questions}

Express your views by responding to these questions.

1. What practices, ideas and strategies could you recommend other teachers to use to assist children with disabilities?

2. If you were the Minister of Education and had some finance, how could you improve inclusive education?

3. Do you have any other comments?

\section{Appendix D: Interview questions for Head teacher, deputy and senior teachers}

Teacher's Name Gender

Title

Date

Starting Time Finishing Time

\section{Conceptualisation inclusive education}

1. What is inclusive education and can you tell me what you know about inclusive education.

2. Tell me about the inclusive education policy in PNG and explain what we mean by children with disabilities?

\section{Strategies of inclusive education}

\section{(a) Policy}

1. Tell me about any policy or procedure you have in your school that promotes inclusive education? How effective is it?

2. How did the inclusive education policy affected some of your policy?

\section{(b) Administrative practices}

1. What administrative practices, strategies ideas, (etc) that you use in your school promote inclusive education, or include every student to learn actively as much as possible? How did you learn about them?

2. How confident are you in enrolling children with disabilities in your school?

3. How did the introduction of inclusive education policy changed some of your planning and administrative strategies (class allocation, supervisory structure, teacher recruitment, enrolment)? 


\section{(c) Teacher professionalism}

1. Tell me about any training that equipped you with some knowledge about inclusive education? Do you tell others?

2. Do you observe your teachers using any teaching strategies to teach children with disabilities?

3. Are there any changes in in-services, workshops or further training as a result of the introduction of inclusive education policy?

\section{(d) Attitudes}

1. What is your attitude towards inclusive education? That is, what beliefs and ideas do you have about inclusive education?

2. How is the introduction of inclusive education affecting your attitudes towards teaching?

\section{(e) Curriculum}

1. What strategies used in your school promote inclusive education?

2. How is inclusive education policy affecting the curriculum? Is there any special curriculum for it?

\section{(f) Assessment}

1. What assessment criteria does your school use to assess children with disabilities? What are some things that you consider when assessing them?

2. What are some of the impact of inclusive education policy on your school assessment?

\section{General}

1. From your experiences, what are some other challenges you or your school as a whole encounter when children with barriers to learning and participation are part of the school communities?

2. Do you have other comments? 


\section{Appendix E: Focus group interview questions for teachers}

School

No of teachers

1. Conceptualisation of inclusive education

2. Strategies of inclusive education

3. Import issues involved in effective implementation of inclusion

\section{1: Conceptualisation inclusive education}

1. What is inclusive education and tell me some of the things you know about inclusive education policy in PNG?

\section{2: Strategies of inclusive education}

(a) Teaching practices

1. Tell me about some strategies used in your school that promotes inclusive education? (More follow-up questions will be asked about specific strategies that they mention. For example. A number of teachers mentioned "peer tutor". Can you say more on that?)

(b) Attitudes

1. Some people believe that all children with disabilities cannot learn effectively together with their non-disabled peers. Lets discus more on that.

(c) Curriculum

1. Tell me about how you organise the curriculum and teaching resources?

(d) Assessment

1. How do you do your assessment?

\section{3: General}

1. Can you make some recommendations about how to effectively accommodate or teach child with disabilities in the school?

2. Do you have any other comments? 


\section{Appendix F: Document review guide}

The following documents will be reviewed to see evidence of inclusive education practices. The researcher will have a set of guiding questions when reviewing the documents?

\begin{tabular}{|c|c|c|}
\hline Document type & Reviewing guide & $\begin{array}{l}\text { Researchers' } \\
\text { comments }\end{array}$ \\
\hline $\begin{array}{l}\text { Overall inclusive } \\
\text { 1. School policies from head teacher } \\
\text { 2. Assessment reports and criteria from } \\
\text { head teacher }\end{array}$ & $\begin{array}{l}\text { 1. Does it incorporate some of } \\
\text { the IEPs into the school } \\
\text { policy? } \\
\text { 2. How are the reports made } \\
\text { and kept? Does it have } \\
\text { some inclusive strategies? }\end{array}$ & \\
\hline $\begin{array}{l}\text { Curriculum documents sample } \\
\text { 1. Math text books yr8 (1) \& yr3 (1). } \\
\text { 2. Personal development text books yr8 } \\
\text { (1) \& yr3 (1). }\end{array}$ & $\begin{array}{l}\text { How are the lessons } \\
\text { organised? Do they suggest } \\
\text { any IE strategies for the } \\
\text { teachers to use? }\end{array}$ & \\
\hline $\begin{array}{l}\text { Programme books } \\
\text { 1. Math day books yr8(1), yr3(1) } \\
\text { 2. Personal development day books yr8 } \\
\text { (1), yr3 (1). }\end{array}$ & $\begin{array}{l}\text { 1. Did the teacher planned } \\
\text { lessons that benefited all } \\
\text { students in the class? } \\
\text { 2. Were the objectives clearly } \\
\text { written and were they } \\
\text { achieved. } \\
\text { 3. Were there any inclusive } \\
\text { teaching strategies } \\
\text { planned? }\end{array}$ & \\
\hline
\end{tabular}


Appendix G: Ethics approval letter - Victoria University Ethics Committee

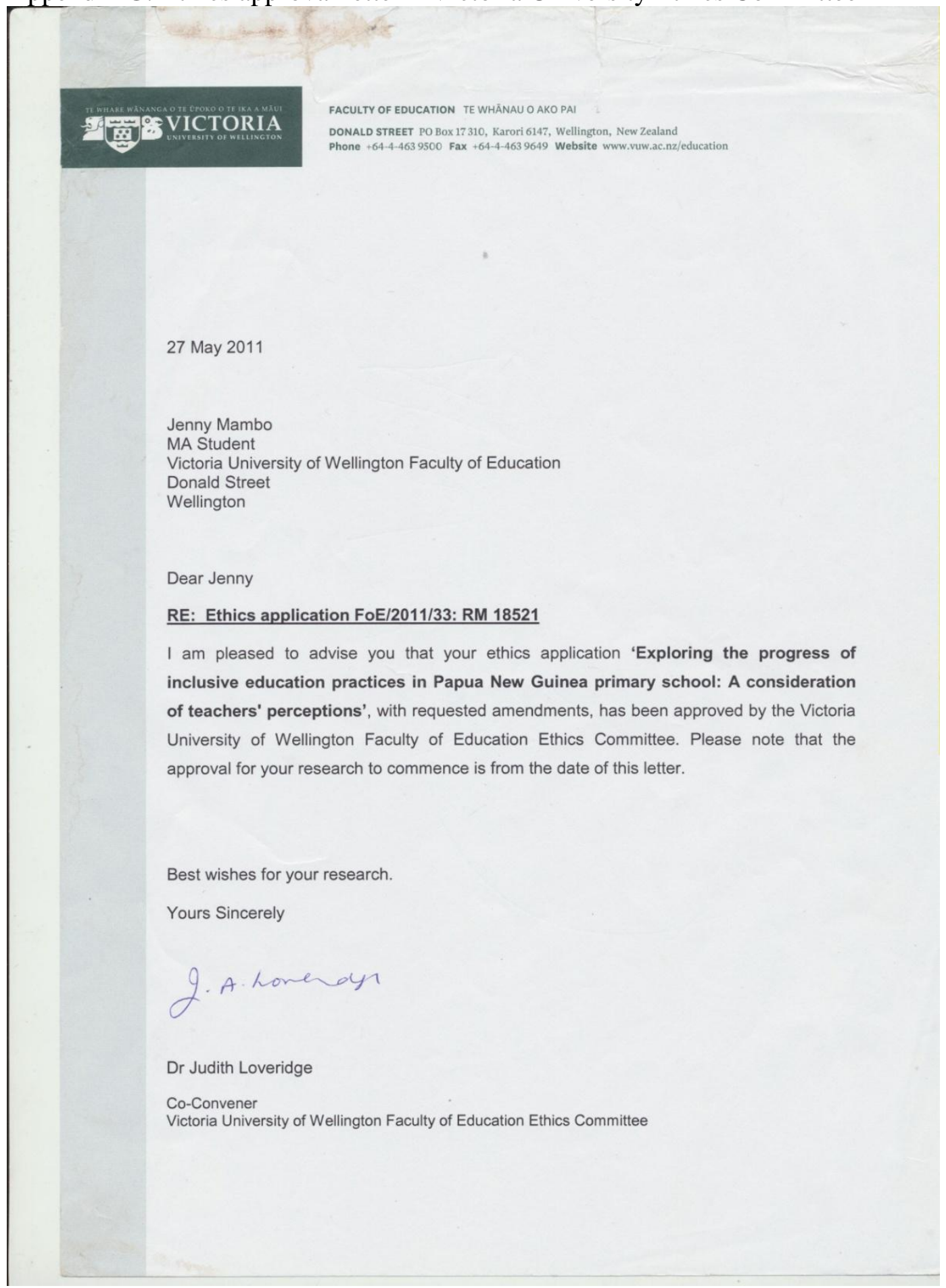




\section{Appendix H: Ethics approval letter - PNG National Research Committee}

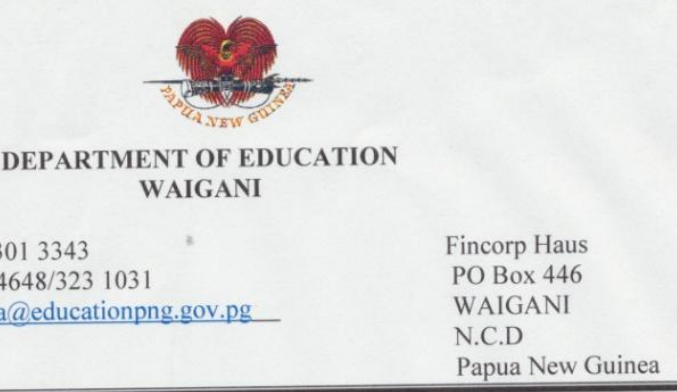

Date: 5th July 2011-07-05

File: PPR 1-1-2

Mrs. Mambo Jenny

Masters of Education Candidate

School of Education

Victoria University of Wellington

38 Mt Pleasant Road

Wellington 6011

New Zealand

Dear Mrs. Mambo

SUBJECT: APPROVAL OF RESEARCH PROPOSAL

Your research proposal titled: "Exploring the practices of inclusive education in a regular primary school in Papua New Guinea: A consideration of teachers perception" has been approved in principle prior to Monitoring Evaluation and Research Steering Committee (MERSC) next meeting.

The approval in principle is given due to the urgency of your data collection and presentation of final report for the award of your nominated degree program. Use this letter as an approval for your data collection in your appointed institutions and provinces in Papua New Guinea.

While your research is approved in principle to collect data in educational institutions/s, it is also subject to approval by Provincial Research Committee (where applicable) and /or the Provincial Education Advisor or the principles or head teachers of your nominated institutions. It is your responsibility to ensure such is obtained prior to the field work.

In serious case of breach of ethical issues and DOE research guidelines the Department of Education reserves the right to inform your home institution or sponsors directly and take necessary actions as deem necessary.

Failure to observe the above conditions may lead to the withdrawal of research approval. 


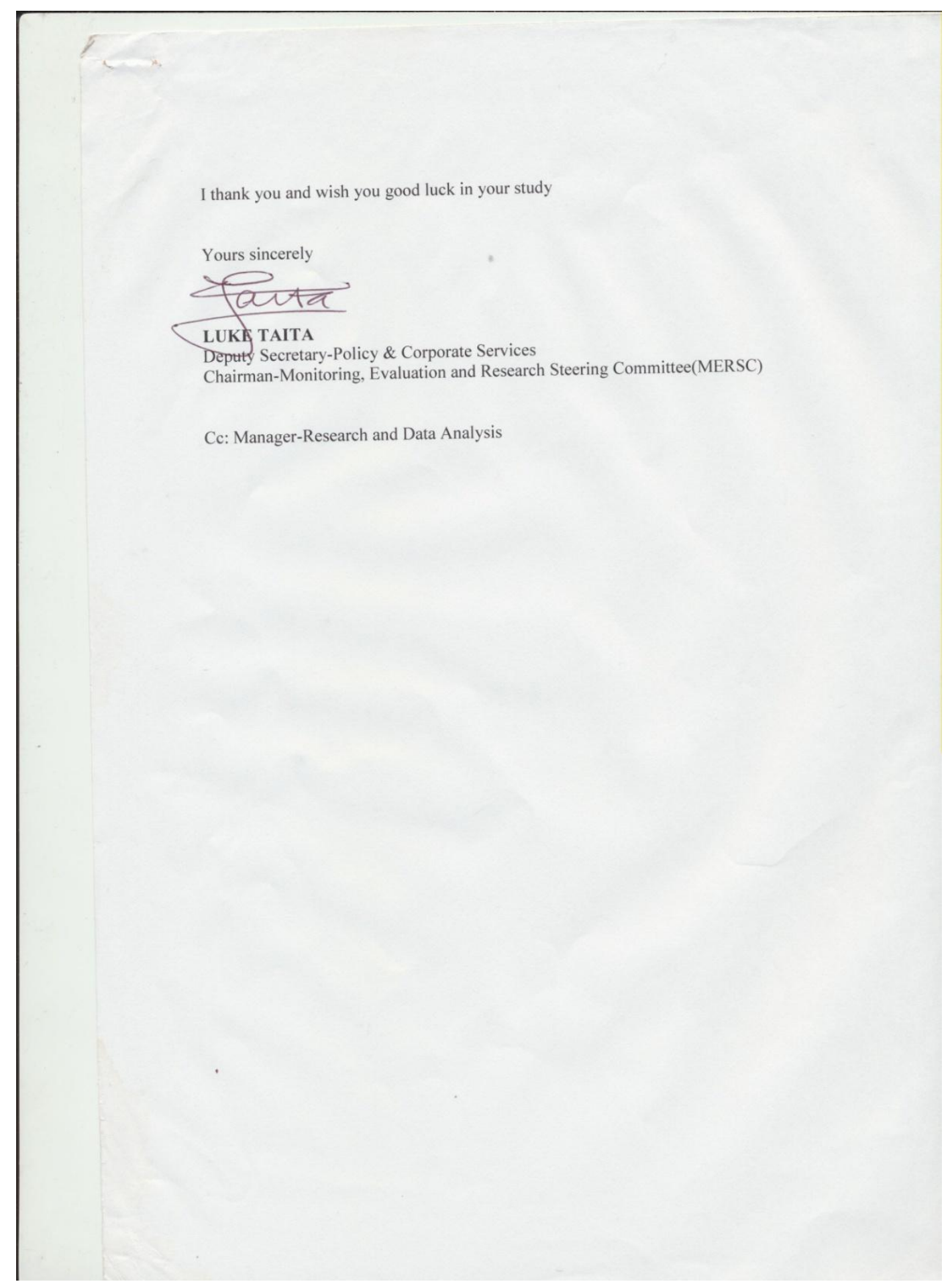




\section{Appendix I: Ethics approval letter - PEB Southern Highlands Province}

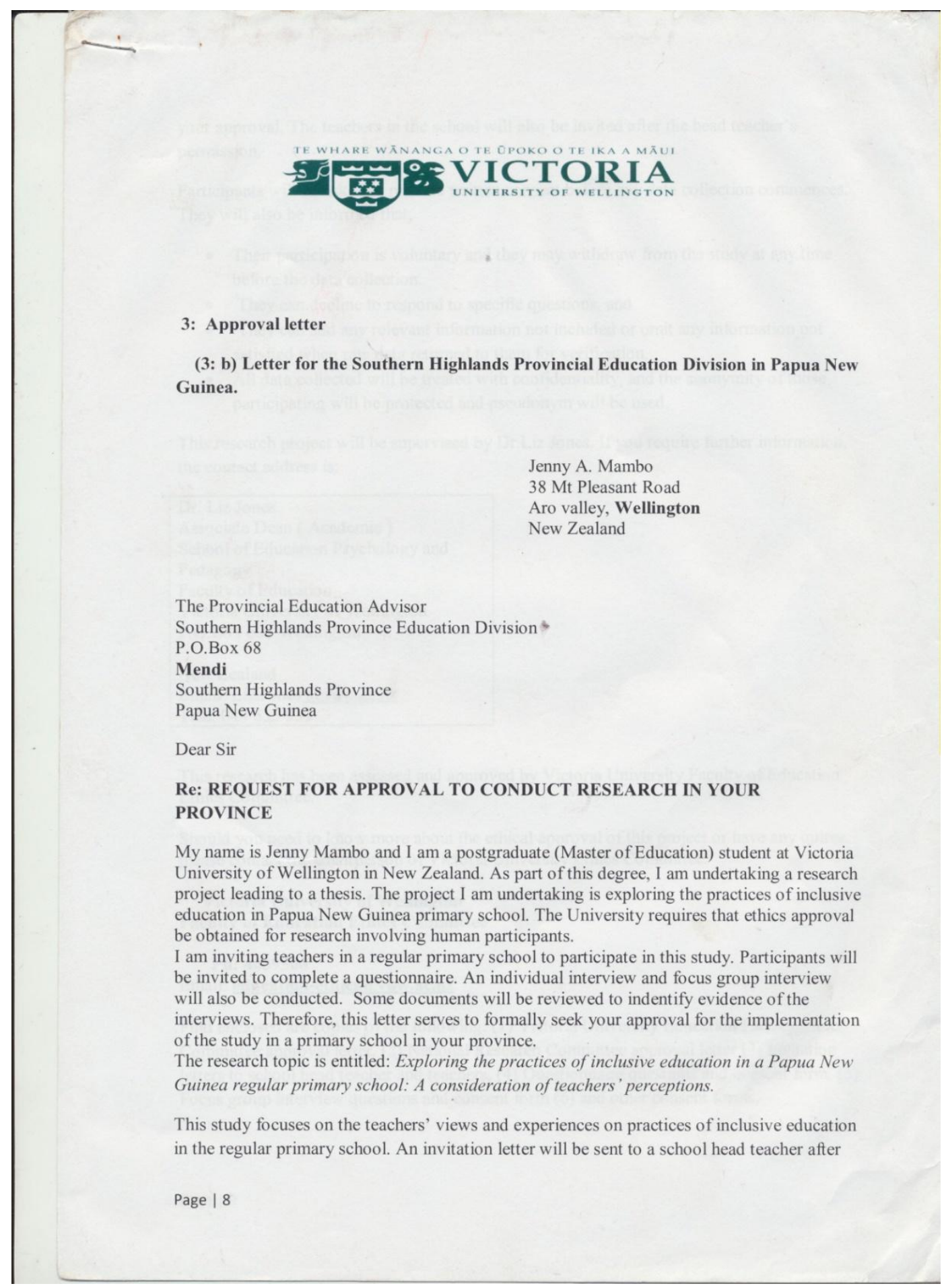


your approval. The teachers in the school will also be invited after the head teacher's permission.

Participants will be asked to provide written consent before any data collection commences. They will also be informed that;

- Their participation is voluntary and they may withdraw from the study at any time before the data collection.

- They can decline to respond to specific questions, and

- They can add any relevant information not included or omit any information not satisfied when raw data returned to them for verification.

- All data collected will be treated with confidentiality, and the anonymity of those participating will be protected and pseudonym will be used.

This research project will be supervised by Dr.Liz Jones. If you require further information, the contact address is:

\section{Dr. Liz Jones}

Associate Dean ( Academic )

School of Education Psychology and

Pedagogy

Faculty of Education

Victoria University of Wellington

P.O.Box 600 Wellington

New Zealand

Email: Liz.Jones@vuw.ac.nz

Tele: 044635939

This research has been assessed and approved by Victoria University Faculty of Education Ethics Committee.

Should you need to know more about the ethical approval of this project or have any quires, please contact the Chairperson of Victoria University Ethics Committee.

Victoria University of Wellington

Faculty of Education Ethics Committee

Ph: 4639500

Email: education-ethics@vuw.ac.nz

Find enclosed are copies of the following: (1) Victoria University Education Faculty Ethics Committee approval letter, (2) National Research Committee approval letter (3) Invitation letters to school head teacher and teachers, (4) Questionnaire questions and consent form, (5) Focus group interview questions and consent form (6) and other consent forms. 
Yours Faithfully,

JENNY A. MAMBO (Mrs)

Master of Education student

Victoria University of Wellington

Mobile: 0212642509(nz),

Email: mambojenn@myvuw.ac.nz or mambojenny@hotmail.com

Please fill out this form to show that you have read and understood this letter and approve.

Name: Title: $\mathrm{Mr} / \mathrm{Mrs} /$ Miss.

Position in the Province:

Asproved to conduct reseaveh inte

MR. KA

OIPROVINCIAL EDUCATION ADVISOR

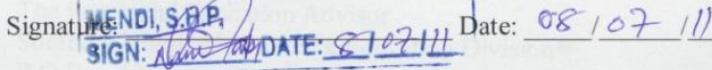

Page | 10 


\title{
Appendix J: Ethical approval letter - School Head Teacher
}

\author{
Appendix 5c: Invitation letter \\ Letter for Primary School Head Teacher
}

\author{
Jenny A. Mambo \\ 38 Mt Pleasant Road \\ Aro Valley \\ Wellington \\ New Zealand
}

The Head teacher

PO Box............

Primary School

\section{Mendi}

Southern Highlands Province

Papua New Guinea

\section{Dear Sir/Madam}

\section{Re: SEEKING PERMISSION TO CONDUCT RESEARCH IN YOUR SCHOOL}

My name is Jenny Mambo and I am a postgraduate (Master of Education) student at Victoria University of Wellington in New Zealand. As part of this degree, I am undertaking a research project leading to a thesis. The project I am undertaking is exploring the practices of inclusive education in Papua New Guinea primary school. The University requires that ethics approval be obtained for research involving human participants.

I am inviting teachers in a regular primary school to participate in this study. Participants will be invited to complete a questionnaire. An individual interview and focus group interview will also be conducted. Some documents will be reviewed to identify evidence of the interviews. Thus, I am seeking your permission to allow me to involve your school and teachers in the study. I will invite your teachers after your approval.

The research topic is entitled: Exploring the practices of inclusive education in a Papua New Guinea regular primary school: A consideration of teachers' perceptions.

This study focuses on the teachers' views and experiences on the practices of inclusive education in the regular primary schools. Participants will be asked to provide written consent before any data collection commences. They will also be informed that:

- Their participation is voluntary and they may withdraw from the study at any time before the data collection.

- They can decline to respond to specific questions, and

- They can add any relevant information not included or omit any information not satisfied when transcripts are returned to them for verification.

- All data collected will be treated with confidentiality, and the anonymity of those participating will be protected and pseudonym will be used. 
This research project will be supervised by Dr Liz Jones. If you require further information, the contact address is:

\author{
Dr Liz Jones \\ Associate Dean (Academic) \\ School of Education Psychology and \\ Pedagogy \\ Faculty of Education \\ Victoria University of Wellington \\ PO Box 600 \\ Wellington \\ New Zealand \\ Email: Liz.Jones@vuw.ac.nz \\ Tele: 044635939
}

This research has been assessed and approved by Victoria University Faculty of Education Ethics Committee.

Should you need to know more about the ethical approval of this project or have any quires, please contact the Chairperson of Victoria University Ethics Committee.

Victoria University of Wellington

Faculty of Education Ethics Committee

Ph: 4639500

Email: education-ethics@vuw.ac.nz

Find enclosed are copies of the following: (1) Victoria University Education Faculty Ethics Committee approval letter, (2) National Research Committee approval letter (3) Approval letter from Chairperson of Southern Highlands Provincial Education Board, (4) Invitation letter to teachers, (4) Questionnaire questions and consent form, (5) Focus group interview questions and consent form, (6) and other consent forms.

Yours Faithfully,

JENNY A. MAMBO (Mrs)

Master of Education student

Victoria University of Wellington

Mobile: 0212642509(nz)

Email: mambojenn@myvuw.ac.nz or mambojenny@hotmail.com 
Please fill out this form to show that you have read and understood this letter and grant permission.

Name

Title: Mr./Mrs./Miss.

Position in school

Signature:

Date:

1 


\section{Appendix K: Participants' letter}

Invitation letter Participants (teachers)

Jenny A. Mambo

38 Mt Pleasant Road

Aro Valley

Wellington

New Zealand

$\mathrm{Mr} / \mathrm{Mrs} / \mathrm{Miss}$

Primary School

PO Box

Mendi

Southern Highlands Province

Papua New Guinea

Dear Sir/Madam

\section{RE: INVITATION TO PARTICIPATE IN A RESEARCH}

My name is Jenny Mambo and I am a postgraduate (Master of Education) student at Victoria University of Wellington in New Zealand. As part of this degree, I am undertaking a research project leading to a thesis. The project I am undertaking is exploring the practices of inclusive education in Papua New Guinea primary school. The University requires that ethics approval be obtained for research involving human participants.

I am inviting teachers in a regular primary school to participate in this study.

Participants will be invited to complete a questionnaire. An individual interview and focus group interview will also be conducted. Some documents will be reviewed to identify evidence of the interviews. Thus, I am inviting you to participate in the study. The research topic is entitled: Exploring the practices of inclusive education in a Papua New Guinea regular primary school: A consideration of teachers' perceptions.

This study focuses on the teachers' views and experiences on the practices of inclusive education in the regular primary schools.

You will be asked to provide written consent before any data collection commences. In this research:

- Your participation is voluntary, that you may withdraw from the study at any time before the third week of data collection.

- You can decline to respond to specific questions if you do not feel comfortable.

- You can add any relevant information not included or omit any information not satisfied when transcripts are returned to you for verification.

- All data collected will be treated with confidentiality, and the anonymity of those participating will be protected and pseudonym will be used. 
This research project will be supervised by Dr Liz Jones. If you require further information, the contact address is:

\title{
Dr Liz Jones
}

Associate Dean (Academic)

School of Education Psychology and

Pedagogy

Faculty of Education

Victoria University of Wellington

PO Box 600

Wellington

New Zealand

Email: Liz.Jones@vuw.ac.nz

Tele: 044635939

This research has been assessed and approved by Victoria University Faculty of Education Ethics Committee.

Should you need to know more about the ethical approval of this project or have any quires, please contact the Chairperson of Victoria University Ethics Committee.

\author{
Victoria University of Wellington \\ Faculty of Education Ethics Committee \\ $\mathrm{Ph}: 4639500$ \\ Email: education-ethics@vuw.ac.nz
}

Find enclosed are copies of the following: (1) Victoria University Education Faculty Ethics Committee approval letter, (2) National Research Committee approval letter (3) Approval letter from Chairperson of Southern Highlands Provincial Education Board, (4) Acceptance letter from school head teacher, (5) Questionnaire questions and consent form, (6) Focus group interview questions and consent form, (7) and other consent forms.

Yours Faithfully,

JENNY A. MAMBO (Mrs)

Master of Education student

Victoria University of Wellington

Mobile: 0212642509(nz),

Email: mambojenny@hotmail.com 


\section{Appendix L: Consent Form}

\section{CONSENT TO PARTICIPATE IN RESEARCH (all Teachers)}

Title of project: Exploring the practices of inclusive education in Papua New Guinea regular primary school: A consideration of teachers' perceptions.

Please read the following and place a tick in the box if you agree, and sign below to indicate your agreement to participate in the research.

I have been given and have understood an explanation of the purpose of this research project.

I understand that I will complete a questionnaire.

I understand that I may be asked to participate in a focus group/individual interview or release official documents.

$\square$ I understand that my participation to this study is voluntary and I may withdraw before the third week of data collection without giving any reasons or without penalty of any sort.

$\square \quad$ I understand that any information I provide will be kept confidential to the researcher and the supervisors.

$\square \quad$ I understand that the published results will not use my name, and that no opinions will be attributed to me in any way that will identify me.

understand that I may choose not to respond to any questions if I don't feel comfortable.

$\square \quad$ I understand that I can be sent a summary of the findings if I request.

I agree to take part in this research.

Name: Gender: Male/Female/Others (circle 1)

Your signature: Date:

I could like a summary of the findings: Yes / No. (Please circle 1) 


\section{Appendix M: Questionnaire Consent Form (all teachers)}

Title of project: Exploring the practices of inclusive education in Papua New Guinea regular primary school: A consideration of teachers' perceptions.

Purpose of the Research is to identify:

1. Teachers' perceptions of inclusive education

2. Strategies of inclusive education

3. Important elements of effective inclusion

Purpose of this questionnaire is twofold, section 1 will be used to select the focus group members and section 2 and 3 will be used as data for analysing.

The researcher (Jenny Mambo) has explained the topic and purpose of the research questionnaire to me. I understand that:

I may choose not to answer any question I consider inappropriate.

My comments will be treated as confidential within the research process and I will have a pseudonym.

My remarks will be transcribed by the researcher and a transcript will be provided to me to check for accuracy and feedback.

Data I provide will be kept in a locked filling cabinet and in a password protected computer and destroyed one year after completion of this project.

I may withdraw before the third week of data collection without giving any reasons or without penalty of any sort.

Signed: Dated:

(Participant) 


\section{Appendix N: Focus Group Interview Consent Form (Selected teachers)}

Ground rules and purpose of the focus group interview.

What is a focus group?

A focus group is a relaxed, non-threatening discussion with a number of people, the purpose being to obtain perceptions on a defined topic. The group comprises a neutral moderator (interviewer/facilitator, which is me) who interacts with the participants asks questions, encourages sharing of ideas between the participants. Group members can add to and respond to others.

Purpose of the focus group interview

1. Gather collective ideas of teachers' experiences.

2. Identify teachers' perceptions about inclusive education.

Planning of the session

1. The interview will be audio recorded by the moderator (researcher/ me) and the tape will be transcribed at a later date.

2. It is important that all participants can readily communicate with each other so being seating in a circle or letter $U$ shape is most useful arrangement.

3. A light summary of all points discussed under each question will be emphasised to participants.

4. It is important that participants agree to a number of ground rules for the meeting which are suggested below.

Suggested ground rules

1. Keep focused on the questions that are being asked.

2. Try to keep the meeting moving by being concise, but do give all relevant information.

3. It is important that all your co-participants contribute to the discussion. Do assist others to contribute if you feel this is appropriate.

4. All participants need to agree that, discussion points are confidential to the participants. No names or identification of individual is to occur in any subsequent discussions.

5. All participants will keep all discussed points confidential.

6. You may withdraw from the focus group if you wish before the third week of data collection. 
The researcher (Jenny Mambo) has explained the topic and purpose of the focus group interview. I understand that:

$\square \quad$ The focus group interview will be audio recorded and transcribed by the researcher.

The comments made and points raised will be treated as confidential.

No member of the focus group will disclose any information to anyone.

My/our comments will be treated as confidential within the research process and pseudonym be used.

$\square \quad$ I may withdraw from the focus group interview before the third week of data collection.

Signed: Dated:

(The Interviewee) 


\section{Appendix O: Individual Interview Consent Form}

(Head, Deputy and Senior Teachers)

Title of project: Exploring the practices of inclusive education in Papua New Guinea regular primary school: A consideration of teachers' perceptions.

Purpose of the interview is to find out;

1. Your knowledge about inclusive education and inclusive education policies, practices, ideas and strategies.

2. Any administrative or supervisory issues concerned with inclusive education/schooling.

The researcher (Jenny Mambo) has explained the topic and purpose of the research interview to me. I understand that:

I may choose not to answer any questions I consider inappropriate.

My comments will be treated as confidential within the research process and I will have a pseudonym.

I will be provided with a transcript of the interview to check for accuracy and provide comments.

The interview will be audio recorded, transcribed and destroyed after completion of this study.

$\square \quad$ I may withdraw before the third week of data collection without giving any reasons or without penalty of any sort.

Signed: Position Dated:

(The Interviewee) 


\section{Appendix P: Document Analysis Consent Form}

(Head teacher, Deputy Head teacher, senior subject master-curriculum)

\section{Documents to review}

1. Sample of policies (assessment, school).

2. Sample of curriculum documents (mathematics \& personal development).

3. Teaching programme books.

\section{Purpose for reviewing}

1. To indentify or gather evidence of inclusive education strategies used.

2. To identify how topics, lessons and activities are organised and distributed.

\section{Note:}

1. The data from these documents will only be used to confirm and supplement evidence from the interviews.

2. All data will be kept confidential and pseudonyms will be used for document owners.

3. Transcripts will be given to document owners to check for accuracy.

The researcher (Jenny Mambo) has explained the purpose for viewing the official documents. I understand that;

The data will be kept confidential and use pseudonyms.

The data will be used to confirm and supplement evidence from the interviews.

The transcript will be given to me to check for accuracy.

I may withdraw from the study before the third week of data collection.

Sign-

Date

Document name 